Papers and Proceedings of the Royal Society of Tasmania, Volume 114, 1980.

(ms. received 24.10.1979)

\title{
OBSERVATIONS ON SOME TASMANIAN FISHES: PART XXVI.
}

by E.O.G. Scott

Launceston

(with seven tables and two text figures and two plates)

SCOTT, E.O.G., $1980(31 \mathrm{v})$ : Observations on some Tasmanian fishes: Part XXVI.

Pap. Proe. R. Soc. Txem., 114: 85-144 (incl. two plates). ISSN 0080-4703.82

Penquite Road, Launceston, Tasmania, Australia.

One new species is described one species is added to the local list and observations are presented on eight other species most of which are rarely met with in Tasmanian waters.

SCYLIORHINIDAE - Galeus boardmani (second Tasmanian record, general description, possible sexual dimorphism). TRIAKIDAE - Furgaleus ventralis (first Tasmanian record, adult female and 3 full-term embryos, morphometric data, allometric growth, key to Tasmanian Triakidae). XENoCONGRIDAE - Muraenichthys (M.) Zengomena, sp. nov. (type 2 paratypes, described and figured). OPHICHTHYIDAE - Ophisurus serpens (third Tasmanian record, general description). SYNGNATHIDAE - Histiogamphelus briggsii (first local specimen reported since oriqjnal description exhibits some features of H.b. briggsiz and some of H.b. orae - suggested subspecies be abandoned). KYPHOSIDAE - GireZza tricuspidata (xanthic individual). SOLEIDAE - Zebrias fasciatus (confirmatory local record). ODACIDAE - Neoodax attenuatus (descriptions of 3 specimens; species hitherto known from 4 examples only). URANOSCOPIDAE - Kathetostoma giganteum (general account of second and third reported local examples); Gnathagnus innotabizis (morphometric and other features of 8 specimens, 4 being Tasmanian; no published local record of species at date of completion of MS). TETRAODONTIDAE - Boesemanichthys firmamentum (general account of second and third local specimens).

In the case of several species one or more of three sets of dimensions has been found to be significantly collinear in a loglog plot with as abscissae natural numbers: the relation involves length of head, length to vent, standard length; lengths to insertions and terminations of certain fins; lengths of spines and rays. polynomial equations for head in plan have been calculated for several species; in one instance parameters have been found to show significant correlation with standard length.

\section{INTRODUCTION}

This paper follows the general plan of others in the series. Linear measurements are given throughout unless otherwise specified in millimetres, the name of the unit commonly being omitted. The symbols Ls, Lt, TLs, TLt denote standard length, total length, thousandths (permillages) of standard length, thousandths of total length, respectively. Registration numbers denoted by Q.V.M. are those of the Queen Victoria Museum and Art Gallery, Launceston. Certain other conventions are noted in earlier contributions.

\section{ERRATA IN PART XXV}

Two unfortunate errors crept into Part XXV (1979). The paper on Chauliodidae ascribed (p.100) to R.C. Baird was written by J.E. Morrow (confusion occasioned by an incomplete photocopy). In an inexplicable blunder on the writer's part a specimen of Diretmus argenteus Johnston, 1863 was recorded (p.108) under Embiotocidae instead of Diretmidae, it being incorrectly stated Greenwood et al. 1966 subsumed the latter in 


\section{Tasmanian Fishes}

the former, the fact being that Diretmidae is listed by these authors as a valid family.

\section{Family Scyliorhinidae}

Six Australian species are listed in the Handbook (Munro 1956): to these McKay (1966) has added Atezomyetems mamonatus (Bennett, 1830) and HaZaezums burgeri (Muller \& Hen1e, 1841) both based on Western Australian records. The four Tasmanian species (a) Galeus boardmani (Whitley, 1928) (b) Halaelums analis (Ogilby, 1885) (c) H. vincenti (Zeitz, 1908) (d) Cephaloscyztizm isabelia Zaticeps (Duméril, 1853) have been keyed in Part XI (1963), which includes also observations on eight local specimens (one, a foetus, figured) of (d). Species (a) (c), not included i.n any local 1 ist and not accredited to Tasmania in the Check-List (McCulloch 1929), were first reported from this state by 01sen (1958), each being represented by a single example.

\section{Genus GALEUS Rafinesque, 1810}

Galeus Rafinesque, 1810, CARATT. NUOV. GEN. SP. SICIL., p.13. Type-species (by selection, Fowler 1908), Galeus melastomus Rafinesque, 1800.

Pristiurus Bonaparte, 1831, Giom. Arcad., 52, p.187. Type-species, Pristiurus meZanostomum Bonaparte = Galeus melastomus Rafinesque, 1800

Figaro Whitley, 1928, Rec. Aust. Mus., 16(4), p.238, as subgenus; given generic status 1929, Aust. Zooz., 5(4), p.354. Type-species, Pristiums (Figaro) boardmani Whitley, 1928.

GaZeus boardmoni (Whitley, 1928)

Pristiurus sp. Whitley, 1926, Mid-Pac. Mag., 31(6), p.578.

Pristiurus (Figaro) boardmani Whitley, 1928, Ree. Aust. Mus., 16(4), p.238, p.18, fig.3. Type locality: off Montague Island, New South Wales.

Figaro boardmani. Whit1ey, 1929 Aust. Zool., 5(4), p.354; 1934, Mem. Q2d Mus., 10(4), p.198; 1939, Aust. Zool., 9(3), p.230; 1940, FISH AUST., 1, p.90, figs 78, 83; 1964, Proc. Linn. Soc. N.S.W., $89(1)$, p.33.

Galeus boardmani: Fow1er, 1941, Bull. U.S. Nat. Mus., 100(13): Munro 1956, HANDBK AUST.

FISH., 1, p.6, fig.34: Olsen, 1958, Pap. Proc. R. Soc. Tasm., 92 p.156: Scott,

1962, MAR. FRESH WAT. FISH. S. AUST., p.24, unnumbered fig., p.24: Stead, 1963

SHARKS RAYS AUST.,pp.22, 199 , fig.6.

Remarks

Our knowledge of this interesting species is virtually confined to the information given in three notices of it by its author (Whitley 1928, 1929b, 1940) and a note in this journal by 01sen (1958) of the only Tasmanian specimen till now recorded. Apart from the length of the type ( $L t 540$ ), the maximum length of 'many specimens' in the Endeavour collections ('up to 16 inches') and a dozen dimensions of his specimen recorded by 0lsen no morphometric data have hitherto been published; no information is available on dentition denticles or cephalic pores - apart from an observation by Whitley that these are fewer than in the extralimita1 Pristiurus mezanostomus (Rafinesque, 1800) - possible sex differences have not been considered. An attempt is here made to fill these and some other lacunae.

The type locality of the species is incorrectly given by Stead (1962, p.22) as the Great Australian Bight, this being the provenance not of the type-specimen of 1926 but that of the 1913 Endeavour material subsequently noticed by Whit1ey (1939). In the paper (Whitley 1928, p.238) cited by McKay (1966, p.65) as the source of the genus Figaro the present species is referred to the genus Pristiurus with Figaro as a new subgenus (based on the presence of specialized denticles not only on the upper but also 


\section{E.O.G.Scott}

on the lower surface of the caudal peduncle), Figaro being given generic status in the following year (Whitley 1929b, p.354; McCulloch, 1929, p.8, or, since Whitley prepared the Check-List for publication after McCulloch's death in 1925, effectively Whitley in McCulloch).

\section{Material}

A specimen, 378 in length to origin of upper caudal 1obe, 488 in total length collected by Mr Shane Down on the continental shelf off Binalong Bay, east coast, 28 April 1979 (Q.V.M. Reg. No. 1979/5/40); second record for Tasmania, first by Olsen (1958), Lt 503, female, taken off Maria Island in $300 \mathrm{fm}$ (550 m) on $2 \mathrm{July} 1952$.

\section{Dimensions}

The set of standard elasmobranch measurements formulated by whit1ey (1943b, p.114) is set out in table 1, entries being given as thousandths of 'standard length', i.e., length from tip of snout to origin of anterior (here upper) caudal lobe (in this species the cephalad lapse of this lobe is extremely gradual, the precise point of origin being difficult to determine; in the specimen it is taken to be located at 378 mm, 2 in advance of lower lobe origin).

Some additional dimensions, all as TLs, follow. Distal border of first dorsal 48 second dorsal 53 anal 108 ventral 108 pectoral 127; vertical height of first dorsal second dorsal anal 485048 ; width of ventral 50, inner border of pectoral 69 . In caudal posterior border 75 lower border behind notch 50 notch to lowest point of fin 167; maximum width 93 width at notch 36 greatest width behind notch 66 . Interpectoral at front of bases 130 at back 56 .

Comparative dimensions

01sen reported for his female specimen total length (503) and 10 other linear dimensions in mm. As his data do not include standard length as such (though length to origin of lower caudal lobe is noted), both these and the data for our female are here presented as TLt, together with approximate values for the male type as read off from the definitive figure (Whitley 1928, pl.18, fig. 3). Snout to anterior edge of eye 6061 (O1sen) 66 (Whitley) to posterior edge of eye 9995105 to spiracle 109107 112 (entry in 01sen reads by typographical error 'Snout tip to spiracle edge of eye') to 1 st gill slit 150130148 to 5 th gill slit 182173183 to base of pectoral 174169 188 to vent 416398410 . 'Base of 1st dorsal' (interpreted as length to fin origin) 451567437 of 2nd dorsal 652652638 lower caudal lobe 779775764 .

It will be seen the agreement is in general very close. The one marked divergence, that of length to first dorsal origin as given by 01sen may possibly be attributable to a typographical error. A consideration of proportions relative to other relevant landmarks suggests the entry of 285 could we11 be an error for 225 , which would give TLt length to fin origin a plausible 446 .

Dentition

The dentition has not hitherto been described. It conforms to the general scyliorhinid type of a large moderately slender acute mesial cusp flanked on a broad base by two small subequal lateral cusps.

External to the normal large teeth the upper jaw presents a narrow mesial strip of several rows of minute tubercles (individual feature?). Normal teeth in $3-4$ rows mesially mainly 2 rows laterally, elongate acute, two sma11 subequal cusps arising from the angles of the broad base, about 20 in a row on each side, viewed from in front members of the rows either wholly or partly occluding each other or clearly alternate, some lateral teeth with two internal cusps and one external. Teeth in lower jaw similar to those in upper but somewhat less massive, medially in non-alternate rows, 
with single cusp, rapidly decreasing in size at the sides where some develop 2 or 3 secondary basal cusps.

\section{Denticles}

(a) Unspecialized. On midflank basal plates subrectangular or lozenge-shaped, closely set but not in contact superficially, in crisscross rows, about 30 per $10 \mathrm{~mm}$, each with a low backwardly and upwardly directed ridge terminating posteriorly in a free acute spine. On tail keel increasingly assumes form of a triangle, approximately equiangular free apex directed forward. On dorsum of snout, beginning shortly in advance of orbit and extending two-thirds of the way to snout tip a smooth somewhat depressed mesial band, on either side of this a subtriangular area (broad hind border strongly outer lateral border moderately convex, inner border virtually straight) with some three score irregularly circular clusters of about half a dozen denticles with obsolescent spines, many clusters with a central perforation. On tip of snout spines obsolete.

(b) Specialized. On upper surface of caudal peduncle the enlarged specialized denticles, characteristic of the genus Galeus, originate obscurely as a narrow, flush almost smooth band about halfway between second dorsal termination and level of lower caudal lobe origin, developing shortly into a ridge about $2 \mathrm{~mm}$ wide extending back to some two-thirds of distance between end of dorsal base and tip of caudal and comprising modally 2 rows of broad acute lanceolate blade-like processes modally about $1.8 \mathrm{~mm}$ in length directed outward backward and slightly upward, three score or more in each row; between the blades 3-4 irregular rows of minute mamilloid protuberances.

Specialized denticles on lower surface of caudal peduncle, reported only in the present species, extend in a band of processes and protuberances similar to that on upper surface but with only about half as many blades, extending from just behind elongated pennon-like tip of anal at level of end of dorsal base to origin of lower caudal lobe, a mesial specialized region continuing beyond this as a low flat narrow pavement devoid of spines at least halfway up margin of lower caudal lobe. In the European species of Galeus the lower surface of the caudal peduncle, while devoid of specialized denticles, bears a narrow mesial band of naked skin.

\section{Coloration}

General colour light grey, about a score of brownish somewhat purplish saddles not reaching ventral profile mostly terminating above it by about one-third of height of side, saddles of two shades darker and lighter alternating usually rather clearly separated by subvertical arc of ground color. Saddles in order caudad: dark interorbital, light bordered behind by forwardly convex arc of ground color from near middle of gill slits, thereafter to end of first dorsal base 3 dark 3 light last dark under dorsal and extending briefly beyond it, interdorsal with 2 light 2 dark second dark beginning just anterior to and extending full length of second dorsal base, to level of notch of caudal 3 light 3 dark last 2 dark subcontinuous along dorsal profile. One conspicuous separate dark marking, subrectangular on left side pyriform on right, immediately behind adpressed pectoral in lower half of flank beneath second dark saddle behind head. Saddles in advance of first dorsal of more or less uniform color on both dorsum and flank, later ones tending to break up on side into 3-5 deeper alternating with less intense subvertical bars. Ventral surface in advance of gill slits chiefly off-white, snout a little darker than rest, an obscure forwardly pointed chevron immediately before pectoral, behind gill slits tolerably uniform pale greyish. Roof of mouth dusky. Upper surface of tongue mainly pale bluish anteriorly, tending to become whitish posteriorly, lower surface bluish except tip which is off-white.

Proximal portion of both dorsals somewhat darker than distal one-third, the areas separated by a broad dark stripe sloping down and back (angle much less acute than in figure of type). Anal dark greyish darker in middle of upper half. Upper surface 
E.O.G. Scott

of pectoral about concolorous with lighter body saddles, lower surface paler more greyish. Upper surface of ventral dark greyish darker mesially, lower proximally whitish or dark greyish (darker than any part of dorsal surface) in distal half or more. Upper caudal lobe greyish in places close to white, with saddles as noted above, lower lobe much like anal but with relatively greater dark area, including an ovoid patch in upper half of anterior border, a long pennon from lowest point of fin to caudal notch bordered externally by pale grey, an obscure broad darkish arc crossing posterior half of portion of fin behind notch.

While the color pattern in the present specimen is of the same general character as that in the figure of the type it presents some marked differences. Some of these such as the presence of the large detached marking of the trunk and the detailed disposition of dark markings on caudal peduncle and on upper caudal lobe above vertebral column and anterior to notch inay well represent merely individual variation. However, other markings in particular the interorbital bar (noted by 01sen as occurring in his female but not evident in the figure of the type, which does however exhibit some mesial darkening here) and the markings unrepresented in the figure, on ventral anal and caudal behind notch may possibly point to some variation in color pattern between the sexes.

Commenting on some Endeavour examples Whitley (1939, p.230) observed 'The colourbands of the [Great Australian] Bight specimens (subspecies socius nov.) are fainter than those of the holotype'. No useful light is cast by the present example on the status of the proposed subspecies, which though mentioned in the Handbook (Munro 1956, p.6) as a 'paler variety' and maintained by its author as a formal subspecies in his name-list (Whitley 1964, p.33, entry No.36) appears to have received no more precise specification.

Possible sexual dimorphism

The type is a male. Subsequent to its description Whitley (1939, p.230) noted "Many specimens referable to this species are in the "Endeavour" collections" trawled in Bass Strait in 1912 and in the Great Australian Bight in 1913, observing 'Curiously, all are males'. Later $(1940$, p.91) he wrote 'Whilst the trawlers have caught numbers of this shark, all the known specimens are males, suggesting a segregation of the sexes, perhaps for migrating purposes'. The Tasmanian example reported by 01sen (1958) was the first, the present specimen is the second female noted in the literature. In quoting Whitley's statement just cited and following it immediately by 'However, females have been caught off Tasmania' Stead (1963, p.22) would appear to imply more than olsen's single record justifies.

Some possible differences in coloration between the sexes have been noted above. In the absence of detailed morphometric specifications of the male no firm conclusion can be drawn on the presence or absence of any significant variation in general body form: a comparison of available dimensions in the section on Proportions would indicate that in respect at least of the major morphological landmarks there considered there is good agreement between the sexes. However, our female exhibits some noticeable differences in fin shape and size from the holotype male as figured, the most marked departure being found in the anal. In the female the distal border of this fin is notably longer its tip reaching to about nine-tenths ( $c f$. barely half) of length of second dorsal base, its length being about one and one-fifth of (subequal to) that of the anterior border and being contained about two and one-fifth (about two and four-fifths) in the interval between ventral and anal origins: with the fin normally posed the general sense of the distal border is noticeably closer to horizontal than in the male. Other, mostly minor, differences in the fins include: inferior border of caudal between lowest point and notch evenly sigmoid (depicted as biconcave), upper angle of terminal caudal lobe less rounded its hind border biconcave (evenly convex), pectoral relatively larger its 
anterior border one and a half times (twice) in length to its origin.

Some aspects of form

(a) Dorsal projize of head. In his original account whitley remarked, 'In Garman's key to the species of Pxistiums in his monograph of the Plagiostoma [1913] the new species comes closest to P. eastmani Jordan \& Snyder [1904] but differs in having a more arched back....' however, after examination of the Endeavour materjal he reported 'the humped back is characteristic of the largest specimens'. The present example shows no sign of the marked convexity above the gill slits, the curve to this region being a virtually even sweep. Ten measurements of the height of the dorsal profile above the anteroposterior axis of the fish taken at equal intervals along the axis back to the level of the 5 th gill slit are $8.011 .514 .115 .717 .318 .819 .5 \quad 20.0$ $20.420 .6 \mathrm{~mm}$. The curve is well fitted ( $R 0.9753)$ by a second-degree polynomial, significantly better ( $F 9.355^{*}$ ) by a third-degree ( $R 0.9764$ ), non-significantly better by a fourth-degree $(R 0.9766)$. In the subjoined equations $H=$ height of curve, mm, $N=$ serial decile number of measurement proceeding caudad:

$H=6.20+2.8843 N-0.1420 N^{2}$. Predicted heights 8.811 .413 .615 .517 .018 .4 $19.420 .2 \quad 20.7 \quad 20.8$.

$H=5.11+3.8434 \mathrm{~N}-0.3500 \mathrm{~N}^{2}+0.01260 \mathrm{~N}^{3}$. Predicted heights 8.611 .513 .8

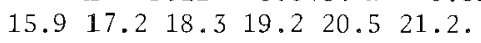

(b) Under surface of head. A small figure has been provided for the type (Whitley 1940, fig.78): with this our example is in general agreement. As millesimals of length to 5th gill slit we find preoral length 337, length to leve1 of rictus 551 , width of mouth 382, anteroposterior length of nostril 112 oblique length 129, internarial minimum 146 maximum 337.

(c) Girth of head. Ten measurements of girth at equal intervals back to 1 evel of 5 th gill slit are in mm $58 \quad 79 \quad 95 \quad 105 \quad 113 \quad 128 \quad 136 \quad 144 \quad 154 \quad 142$. It will be seen they increase up to the last but one. On a $\log \log$ grid the ascendant 9 are significantly linear ( $t 128.909^{* * *}$ ) on 1-9. The extremely high $t$ value can be regarded as fortuitous. $\log G=0.4367 \log N+1.7680$. Predicted girths 597595107118128137145153.

(d) Head, Zength to vent, standard Zength. On a loglog grid these 3 lengths are significantly linear ( $t$ 155.143**) on 123 .

$\log L=1.3153 \log N+1.9486$. Measured (predicted) 1engths $89(89) 220(222) 378(377)$.

(e) Disposition of fin origins and terminations. On a loglog grid length to ventral origin, to first dorsal origin, to first dorsal termination, to anal origin, to second clorsal origin, to anal termination, to caudal origin (at commencement of anterior, here lower, caudal lobe) are significantly linear ( $t 4.622^{* *}$ ) on 234578910 . Measured (predicted) lengths as TLS 497(493) $587(586) 651(663) \quad 735(727) \quad 841(841) 883$ (890) 923(926) $1000(991)$. The agreement is striking, predicted values differing from measured by $0-7$ mean $3.2 \mathrm{~mm}$, or $0-2$ mean $1.1 \%$.

Parts XXIII (1977) and XXIV (1978) record equations specifying some of the above relations as found in some other sharks, Carcharhinus greyi greyi (Owen, 1853), Sphyma aygaena (Linné, 1758), Isurus oxyminchus Rafinesque, 1810.

\section{Family Triakidae}

The members of this world-wide group of some seven genera are distinguished from those of all other families represented in Australian waters by the following combination of characters: shape of head norma1 (i.e., not hammer-shaped, Sphyrnidae), shape of caudal normal (i.e., not with upper lobe greatly produced, Alopiidae), two dorsal fins, neither with a spine, the first wholly in advance of ventrals, an anal fin, caudal 


\section{E.O.G. Scott}

peduncle without keels, teeth sma11, those in the side of the lower jaw flattened. Their closest relatives are the Carcharhinidae, from which they differ in 1 acking a true nictitating membrane and caudal pits and in the character of the teeth, in which last feature they approach the otherwise widely dissimilar orectolobidae and Scyliorhinidae.

The Handbook (Munro 1956) recognizes five Australian species, of which two are noted as occurring in Tasmanian waters, Mustezus antaretiaus Güther, 1870 (a11 States), M. Zentioularis Phillipps, 1952 (Tasmania only). An additional species, M. mangeanus (Whitley, 1939) from Bass Strait, which appears to be inadequately differentiated, has not received general recognition, though maintained by its author in his Australian name-1ist (1964) in which (with Phillipps' species dropped and M. ganeam (Whitley, 1945) added) Emissola Jarocki, 1882 is preferred to Mustelus Linck, 1970

Furgateus ventratis (Whitley, 1943) hitherto known only from western Australia and South Australia is here reported from this state.

\section{KEY TO TRIAKIDAE RECORDED FROM TASMANIA}

1. Teeth not forming a pavement; in upper jaw triangular with a central oblique cusp and 4 blunt serrations on outer side, in lower jaw more flattened. A median interdorsal ridge. Without white spots in adult. . . . . . . . . . . . . . . . . .

Teeth in both jaws forming a pavement. No median

Furgaleus ventrazis interdorsal ridge. With some white spots... . 2

2. First dorsal originating above free end of upper pectoral border. Uniform grey with minute

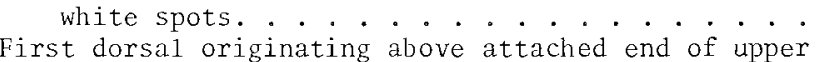
pectoral border. Grey with conspicuous larger white spots . . . . . . . . . . . . .

Mustelus antareticus

Mustelus Zenticuzaris

Genus EURGALEUS Whitiey, 1951

Fur Whitley, 1943, Aust. Zool., 10(2), p.167. Type-species, Fur macki Whitley. Furgaleus Whitley, 1951, Proc.'R. 2002. Soc. N.S.W., 1949/1951, p.67; substitute for Fur Whitley, 1943, preoccupied by Fur Jones, 1940 (Diptera).

Triakis: Stead, 1963, SHARKS RAYS AUST. SEAS, p.109; non Triakis Muller \& Henle, 1838.

Furgazeus ventralis (Whitley, 1943)

(Fig. 1; Plate 1)

Fur ventralis whitley, 1943, Rec. S. Aust. Mus., 7(4), p.397. Type 1ocality: Off Bunbury, Western Australia.

Fur ventralis Whitley, 1944, Aust. Zool., 10(3), p.259, fig.5; 1948, Aust. Zool., $11(4)$, p. 259 , figs 1,2 .

Furgaleus ventratis Whitley, 1964, Proc. Linn. Soc. N.S.W., 89(1), p.33 and 1967, Aust. Zool. , 14(2), p.173: Munro, 1956, HANDBK AUST. FISH., 1, p.7, fig.40: Scott, 1962 , MAR. FRESH WAT. FISH. S. AUST., p.29, unnumbered fig., p.29: Whitley, 1967, Aust. Zool., 14(2), p.173: Scott, Glover \& Southcott, 1974, MAR. FRESHW. FISH. S. AUST., p.33, unnumbered fig., p.33.

Note on synonymy

Mr Ian S.R. Munro, who has been good enough to provide some references not available here, has called my attention to the fact that the entry for Whitley's genus Fur, 1943 in the Nomenclator Zoologicus (Neave 1940, 5, p.100) cites Rec. S. Aust. Mus., 7 , p.167, in error for Aust. 20ol., 10(2), p.167; Neave's reference relates not to the 
Dimensions in accordance with morphometric schema of Whitley (1943b) of a female, total length $488 \mathrm{~mm}$, standard length (to origin of upper caudal lobe) $378 \mathrm{~mm}$, from off Binalong Bay, east coast, Tasmania (Mr S. Down): cimensions in mm and in millesimals of standard length, Thes

No. $\quad$ Dimension

H1 Length of head to first gill slit

H2 Length of head to last gill slit

H3 Tip of snout to anterior margin of eye

H4 Breadth of snout immediately before eyes

H5 Snout tip to origin of pectorals

H6 Snout tip to origin of ventrals

H7 Eye, horizontal diameter

H8 Eye, vertical diameter (outsice nictitating membrane)

H9 Interorbital

H10 Eye to spiracle

H11 Length of nostril [oblique]

H1 2 Internarial between posterior angles

H13 Preoral length

H14 Width of mouth (distance between angles)

H15 Labial fold, upper

Hil6 Labial fold, lower

H17 Height of first gill slit

H18 Height of last gill slit

B1 Length, tip of snout to origin of anterior [here upper] caudal lobe

B2 Length, tip of snout to middle of vent

B3 Predorsal length

B4 Depth at origin of first dorsal

B5 Breadth below origin of first dorsal

B6 Depth of caudal peduncle (immediately before origin of upper caudal lobe)

B7 Breadth of caudal peduncle (immediately before origin of upper caudal lobe)

B8 Claspers, outer margin to membrane

B9 Claspers, inner margin at base to membrane

F1 First dorsal, anterior margin

F2 First dorsa1, base

F3 First dorsal, last ray

F4 Interdorsal space

F5 Second dorsal, anterior margin

F6 Second dorsa1, base

F7 Second dorsal, last ray

F8 Second dorsal to origin of upper caudal lobe

F9 Anal fin, anterior margin

F10 Ana1 fin, base

F11 Anal fin, last ray

F12 Anal base to origin of lower caudal lobe

F13 Relative positions of second dorsal and anal (sketch)

F14 Pectora1, length

F15 Pectoral, base [antêroposterior extension]

F16 Origin of pectoral to origin of ventral

F17 Ventral, anterior margin

F18 Ventra1, base [anteroposterior extension]

$\begin{array}{rr}\mathrm{mm} & T L S \\ 73 & 193 \\ 89 & 235 \\ 29 & 77 \\ 35 & 93 \\ 85 & 225 \\ 188 & 497 \\ 19.5 & 52 \\ 12 & 32 \\ 18 & 48 \\ 4.5 & 12 \\ 12 & 32 \\ 13 & 34 \\ 30 & 79 \\ 34 & 90 \\ 7.7 & 20 \\ 7.0 & 19 \\ 9.5 & 25 \\ 8.5 & 22 \\ \end{array}$

$T L S$

193 


\section{$E \cdot O \cdot G . S \cot t$}

No.

Dimension

F19 Ventral, last ray (measured externally, i.e., superiorly) [from inembrane]

F20 Ventral origin to anal origin

holotype, $F$. macki, but to the present (second) species of the genus, described later the same year. In his 1951 paper cited above, in which he notes 'further study' of the Nomenclator has indicated the necessity for changing some generic names (including Fur) owing to their being preoccupied, Whitley strangely did not pick up this error.

Material

(a) A mutilated female (head, part of caudal fin removed; gutted), present total length from insertion of pectoral to origin of lower caudal lobe 783 , off Wynyard, northwest coast, January 1979, Mr D. Batcheler (Q.V.M. Reg. No. 1979/5/1); 3 foetaI specimens, about at full term, taken from (a), comprising (b) female Ls (1ength to origin of anterior, here lower, caudal lobe) 191 Lt 241 , (c) male 191, 249, (d) male $187.5,245$.

\section{Dimensions}

The 'set of standard measurements for comparative and biometric studies of Australian sharks' proposed by Whitley (1943b) and employed by him in a number of his papers is here adopted. The full suite of dimensions is exhibited in table 2 for the 3 foetal specimens and for the type of $F$. ventrazis, Ls 2021 (Whitley 1943c) together with the 29 items reported for F. macki (Whitley 1943a) - the last-named described prior to the promulgation of the scheme: all these entries are given as millesimals of standard length (defined as in preceding paragraph; Whitley's original measurements in mu). In recording the dimensions of the type of $F$. ventralis Whitley added two items to his standard schedule (end of upper caudal lobe, upper edge of subcaudal notch); these were not noted earlier for $F$. macki, clearly being added in view of the comment that these two species exhibit 'minor differences in ... and outline of caudal': they are here included in the table.

Our large female $F$. ventralis being imperfect it is not possibie to give those measurements that can be made as millesimals of standard length; they are, however recorded in table 2 , being entered, unlike all other entries there, in m.

It may be observed that entry F16 in Whitley's schedule 'Origin of pectoral to that of ventral' is superfluous, the measurement being directly derivable from H5 'Snout [tip] to origin of pectorals' and 16 'Snout [tip] to origin of ventrals'. Some minor alterations in wording and punctuation of the original schedule are here made.

The considerable length of the schema no doubt influenced its proposer to restrict fin measurements to lengths of anterior border base and last ray. Other dimensions of fins sometimes reported are here noted, those for the embryos being given in TLs units those for the (imperfect) adult in mm. First dorsal distal border 897996128 height 897983 115. Second dorsal distal border 737180102 height 73636987 . Anal distal border 47525352 height 45424860 . Pectoral distal border 102105123140 width 58505398 inner border 84688050 . Ventral distal border 68686980.

Additional dimensions of the caudal fin, of taxonomic interest in the present context, include: subterminal notch to angle at junction of lower lobe and lower border of upper lobe 999480 , angle to tip of lower lobe 212124 , depth at notch 526051 , depth at junction of lower lobe and lower border of upper lobe 868691 , maximum width of fin at tip of lower lobe 102115127 . 
Embryos

The original account of $F$. ventralis (Whitley 1943c) was shortly followed (1944) by a brief note on some variations in the dental formula, accompanied by the first figure of the spocies prepared too late for inclusion in the initial notice. A third paper (1948) provided (in addition to observations on the commercial significance of the two species and two tables of selected dimensions) the first information on the reproductive cycle and the nature of the embryo. Later $(1967, \mathrm{p} .173)$ he noted of this species 'breeds at just over 4 feet' $(1.2 \mathrm{~m})$. The largest embryos noted, 11 $30-45 \mathrm{~mm}$ long from a female about 1200 long, possessed cxternal gills and were attached to yolk sacs $76-95$ by 33-40 mm. It was remarked it was not feasible to continue the studies on embryonic growth, 'and the size of the full-term embryo is unknown'. Our specimens with a length some six times that of the largest examined by Whitley are at full-term. The yolk sac has been completely absorbed, the site of its attachment being marked by the small shallow umbilical slit ( $4 \mathrm{~mm}$ long in female, 5 in males) about at level at front of pectoral, or at 29.3 (female) 28.529 .3 (males) percent of standard length.

Comparison of embryonic and adult specimens

A comparison of our foetal examples with the adult type reveals some interesting evidence of differences in relative growth and a marked dissimilarity in coloration.

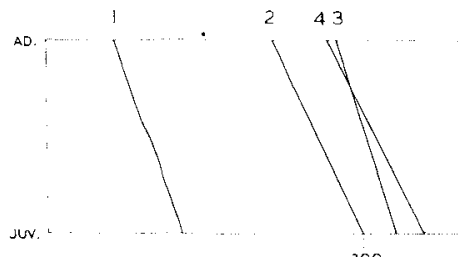

200

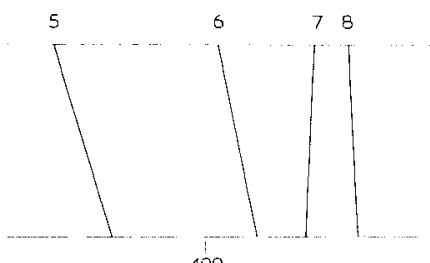

MILLESIMALS OF TOTAL LENGTH

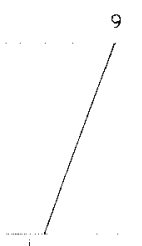

600

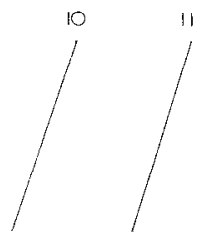

800

FIG.1.- Furgaleus ventralis (Whitley, 1943). Relative growth: increase with age in relative length of posterior part of body. Lengths to numbered points as millesimals of total length: upper line, holotype female, total length $1250 \mathrm{~mm}$, off Bunbury, Western Australia; lower line, arithmetic means for three ful1-term embryos, one female two males, total lengths $241,245,249$, off Wynyard, northwest coast, Tasmania, January 1979. Points noted: 1 mouth, 2 first gill slit, 3 pectoral origin, 4 fifth gill slit, 5 first dorsal origin, 6 first dorsal termination, 7 ventral origin, 8 vent, 9 second dorsal origin, 10 second dorsal termination, upper caudal lobe origin ('standard length').

(a) ReLative growth. An overall growth gradient along the whole length of the shark clearly obtains. As is evident from fig. 1, which shows the millesimals of total length at which certain important morphological landmarks are sited in the small individuals (mean values) and in the large individual, such landmarks from the mouth back to (and somewhat beyond) first dorsal origin are relatively more anteriorly located in the adult than in the embryos, while backward from the region of the origin of the ventral they lie relatively further caudad in the adult. Two minor anomalies are apparent. Whereas we find the length to the fifth gill slit greater than the length to pectoral origin, Whitley's measurements place the fin behind the slit (ef., however, the original description of the species (Whitley $1943 \mathrm{c}, \mathrm{p}$. 397) in which it is noted the slit 'opens over the pectoral', and the later illustration (Whitley 1944, fig.5) in which the pectoral insertion appears the anterior point). Again, with the recorded measurements, while the insertion of the ventral fin is siightly more caudad 


\section{E.O.G. Scott}

in the adult, the location of the middle of the vent is marginally more anterior. For the following set of landmarks, lengths to mouth first gill slit pectoral origin fifth gill slit first dorsal origin first dorsal termination ventral origin vent second dorsal origin second dorsal termination origin of upper caudal lobe the dimensions of the adult as percentages of the means of the embryos are $61.783 .5 \quad 74.0 \quad 89.893 .8101 .5$ 99.2108 .1106 .5105 .4 .

In both the anterior set of 7 dimensions in which (apart from the anomalous length to pectoral origin) the TLs values exceed those of the adult and in the posterior set of 3 dimensions in which the reverse is the case the relation is an exponential one, growth being allometric. The rectified equations are given below $(A=$ adult length $E=$ embryonic length)

$\log A=1.2919 \log E-0.7930$. For the full set of 7 items $t$ is $94.171^{* * *}$; with length to vent omitted $32.305^{* * *}$ with length to ventral origin onitted $90.936^{* * *}$, with in all cases $r \quad 0.998$.

$\log A=0.8971 \log E+0.3204$. The linear fit is (fortuitously) a virtually perfect one, with $r^{2} 0.9999999$ or $t 14144.27$.

In an extensive contribution to the biology of the species (including abundance, osteology, sex ratio, sex, weight, reproductive cycle) Whitley (1948, table 2) gave some means of total length head interdorsal space and length to origin of upper caudal lobe. Mean measurements of our embryos as TLt show these dimensions to be in them 1.350 .70 0.95 those in the holotype adult.

(b) Coloration. In a key (Whitley 1943c, p.398) to the two species of Furgaleus the entry for $F$. ventralis is 'Coloration uniform', the couplet for $F$. macki reading 'Coloration transversely barred and with light spots.' However, while our adult specimen, with a general color of slate above white below and without noticeable markings, agrees well with the fairly detailed account in the description of the holotype, the embryos differ trenchantly, exhibiting a very conspicuous and well defined color pattern (plate 1).

Dorsal surface with a number of broad dark slate cross bars separated by narrow cream or whitish lines and large rounded or subrectangular markings of the same color margined with lighter; in all specimens a whitish subcircular or longitudinally elliptical median spot just in front of eyes. Lateral surface with extensions on to its upper one-fifth to one-third of most of dark markings of dorsum; below or between these numerous dark spots and patches of varying shapes and sizes partly or wholly separated by lighter patches of lines (latter tending, particularly behind first dorsal, to form a partly interrupted narrow longitudina1 band), some dark spots more or less annulated with lighter. Ventral surfaces whitish or creamy, immaculate. Both dorsals with most of distal half occupied by a large ovoid dark spot narrowly bordered externally with whitish, smaller dark spot on proximal part of anterior border and dark or darkish triangle on lower hind tip. Anal and ventral dusky in distal two-thirds with more or less distinct dark spot in front part of this area; lower surface of ventral more or less dusky in distal half. Pectoral with large dark patch in distal two-thirds bordered with lighter, one dark spot a.t front of base another at end of base the latter continuous with, but noticeably darker than, the large marking; lower surface dusky in distal half. Upper border of caudal with four dark rounded or ovoid spots followed behind by a light-margined dark marking occupying most of fin behind notch, three or four dark spots or smudges along lower border. Iris dark bluish, pupil white or pale bluish; orbit narrowly bordered with whitish in front above and behind, dusky below.

Though some individual variation is evident the overall pattern shows a high degree of consistency. No consistent difference between the female and two males is apparent. 


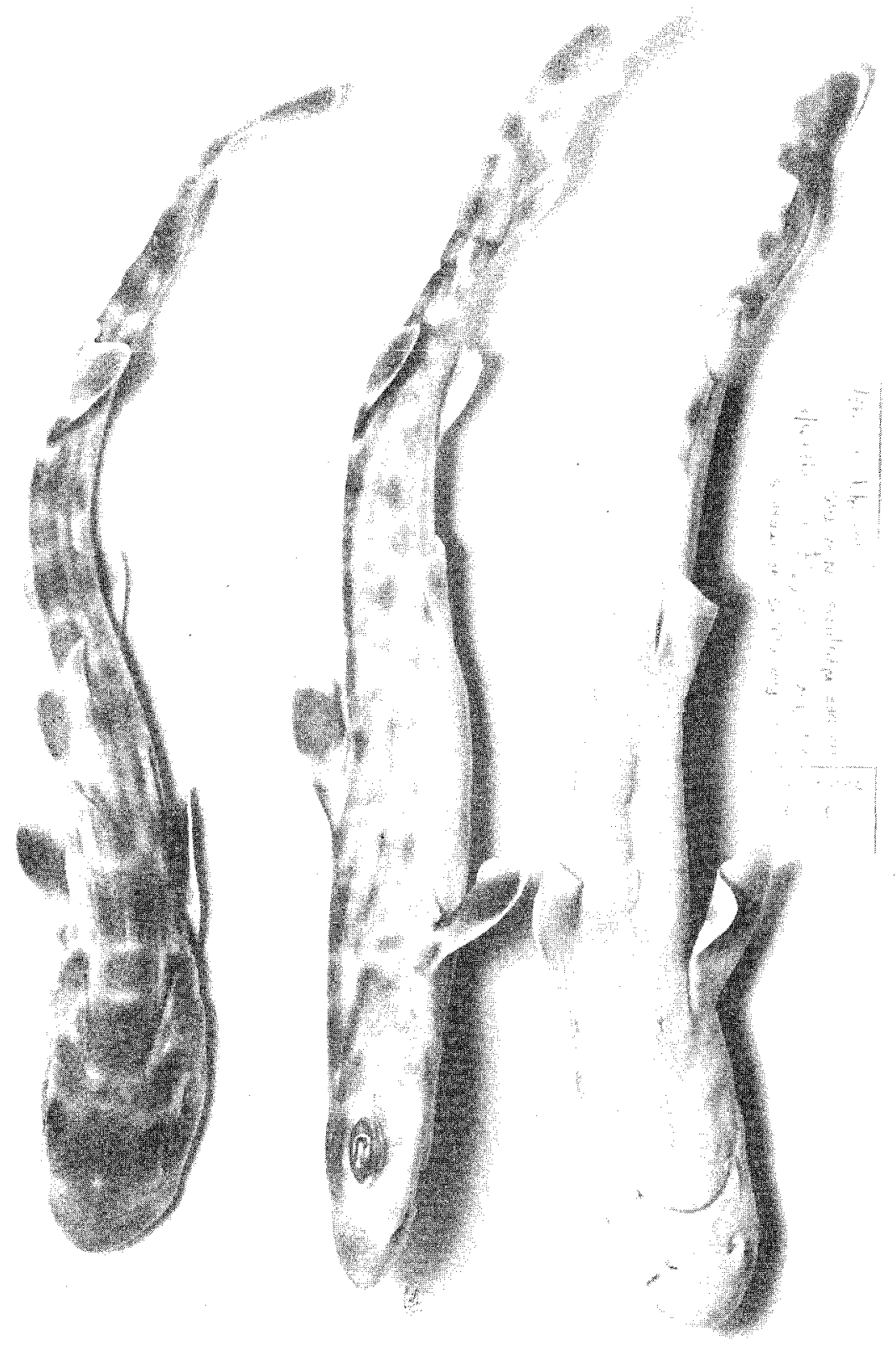

PLATE 1.- Furgaleus ventralis (Whitley, 1943). Three full-term embryos (parent taken off Wynyard, northwest coast, Tasmania, January 1979), total 1ength 241-249 mm, top and middle specimens males bottom specimen female - showing colour pattern (not present in adult) and general features. Photograph R.H. Green). 
E.O.G. Scott

Comparison with $r$. macki

The key provided (Whitley 1943c, p.398) in the description of $F$. ventralis to separate it from the earlier-described F. macki involves four characters as follows (F. macki here cited first): (a) ventral origin below posterior lobe of first dorsal fin, behind level of fin (b) a marked (no) gibbosity predorsally (c) no (an) interdorsal ridge (d) transversely barred and with light spots, coloration uniform. It is of interest to note that in these characters other than (b) the embryos of $F_{\text {. }} v e n t r a z i s$ are closer to the adult $F$. macki than to the adult $F$. ventralis. Thus (a) ventral originates below tip of posterior lobe of first dorsal, being behind it in adult by a distance exceeding half length of dorsal base (Whitley 1944, fig.5) (c) no interdorsal ridge developed, though its presumed site is detectable on examination with a lens, being indicated by a fant line somewhat. Iighter than the ground color (d) with distinctive color pattern. Further, the adult head viewed in plan as represented in Whitley's illustrations is decidedly more pointed in $F^{\prime}$. ventralis (1944, fig.5; 1948, figs 12 ) than in $F$. macki (1943a, fig.1) that of our embryos more closely resembling the latter (see below).

In the available material the same trans-species resemblance extends to certain ratios defining general body form. In the following examples the Ths figures are the mean for the embryos and the values for the holotypes of $F$. macki and $F$. ventralis in that order : snout 978170 ; preoral length 1098864 ; length to fifth gill slit 306 257 215; predorsal length 437388 372; interdorsal 225245223 ; width of mouth 91 7666 , length of upper caudal lobe 277245223 . As shown above in $F$. ventralis proportional lengths to points along the anteroposterior axis of the shark are a function of overall length. As the holotype of $F$. ventrazis, a female $1250 \mathrm{~mm}$ in total length, is longer than the holotype of $F$. macki, an immature male $500 \mathrm{~mm}$ in total length, differences in the first five dimensions noted above may be, at least in part, size related.

Some aspects of form

(a) Head, length to vent, standard length. As has been found to be the case in some other sharks (and in some teleosts) the lengths of head (to fifth gill slit), head plus trunk, head plus trunk plus tail (to origin of caudal) are such that in a loglog plot they occur on integral abscissal values, most commonly, as here, on 123 . Statistics for our three foetal examples of $F$. ventralis and for the adult type of that species, together with some estimated results for the holotype of $F$. macki, are set out in that sequence below, all dimensions being millesimals of standard Iength.

$\log L=1.0800 \log N+2.4791 ; t 46.415 *$; measured (predicted) Iengths $304(301)$

$623(637) 1000(987)$

$\log L=1.0793 \log N+2.4832 ; t 104.586^{* *} ; 305(304) 639(643) 1000(996)$.

$\log L=1.0673 \log N+2.4899 ; t 206.831^{* *} ; 309(309) 645(647) 1000(998)$.

$\log L=1.4020 \log N+3.3367 ; t 43.239^{*} ; 242(244) 614(600) 1000(1015)$. The greater slope in the type is indicative of the more rapid rate of growth in the posterior part of the shark noticed above in the comparison of the embryos with the adult; a similar increase is evident in the next set of equations (the concomitant greater magnitude of the independent term is of course attributable to the greater length of the adult).

While length of head and length to caudal origin ('standard length') are recorded for the type of $F$. macki the table of measurements provided does not include length to vent or the subequal length to ventral origin. By interpolation the equation in the next section for the disposition along the general anteroposterior axis of those fin origins for which length-to measurements are available (Whitley 1943a, p.169) gives length to ventral $247 \mathrm{~mm}$ or, by proportional adjustment based on data for $F$. ventralis, length to vent 258. If this datum is accepted the resultant calculation for $F$. macki is as follows. 
$\log L=1.2959 \log N+2.3881 ; t 35.112^{*} ; 242(244) 614(600) 1000(1015)$.

(b) Location of fin origins. Lengths from tip of snout to the origins of all six fins are such that in a $\log \log$ context they fall when taken in sequence caudad on abscissal integral values of 1246710 to yield a linear function. Dimensions below as TLs.

$\log L=0.5436 \log N+2.4565 ; t 49.709 * * *$; measured (predicted) lengths $283(286)$ $429(427) 592(608) 764(758) \quad 825(824) 1000(1000)$.

$\log L=0.5498 \log N+2.4563 ; t 38.094^{* * *} ; 280(286) 435(419) 597(613) 780(766)$ $838(834) 1000(1014)$.

$\log L=0.5327 \log N+2.4719 ; t 26.304^{* * * *} ; 291(296) 448(429) 592(620) 800(770)$ $832(836) 1000(1011)$

$\log L=0.6542 \log N+2.3644 ; t 27.675^{* * *} ; 225(231) 372(364) 572(573) 801(747)$ $810(826) 1000(1044)$.

For F. macki only the lengths to origins of first dorsal second dorsal anal and caudal are available; with these data.

$\log L=0.5935 \log N+2.4124 ; t 51.787^{* * *}$ (d.f.2);-164(163)-313(317) $345(348) 426(420) \ldots$.

(c) Head in plan. It has been noted above that on the basis of illustrations the snout viewed in plan is more pointed in $F$. ventralis than in $F$. macki. Using 10 measurements taken at equal intervals between tip of snout and level of front of mouth polynomials have been calculated for a male and a female embryo of the former species and are noted below - to permit of direct comparison between these and individuals of different size widths are expressed as percentages of length to level of front of mouth. $N$ is serial number of measurement counting back from snout tip.

Ma1e. $W=39.38+20.175 \mathrm{~N}-1.0360 \mathrm{~N}^{2} ; R 0.9919$; measured (predicted) widths $56.0(58.5) \quad 76.5(75.6) \quad 91.5(90.6) \quad 104.5(103.5) \quad 115.0(114.4) \quad 122.5(123.1) \quad 131.0(129.8)$ 134.5(134.5) 135.5(137.0) 137.5(137.5). A slightly better fit, $R 0.9922$, is obtained by the addition of a term, $W=36.6+22.843 \mathrm{~N}-1.6236 \mathrm{~N}^{2}+0.03506 \mathrm{~N}^{3}$, yielding predicted values $57.6 \quad 72.891 .2 \quad 104.0 \quad 114.4 \quad 122.6 \quad 128.7 \quad 133.1 \quad 136.0 \quad 137.5$.

Female. $\quad W=49.62+19.325 N-1.0626 N^{2} ; 0.9965 ; 65.0(67.9) 85.5(84.0)$ $100.5(98.0) \quad 110.5(109.9) \quad 121.0(119.7) \quad 126.5(127.3) \quad 130.5(132.8) \quad 135.0(135.5) \quad 137.0(137.5)$ 138.5(136.6). The addition of the $N^{3}$ term improves $R$ to $0.9997 ; W=39.60+28.212 \mathrm{~N}$ $-2.9895 \mathrm{~N}^{2}+0.11678 \mathrm{~m}^{3}$, yíelding predicted values 64.983 .0100 .5112 .1120 .5130 .7 133.7139 .6139 .6 .

Comparable equations derived from figures of the female holotype of $F$. ventralis (Whitley 1944, fig.1) and the male holotype of $F$. macki (Whit1ey 1943a, fig.1) are provided for comparison with the Tasmanian embryos of the first species. While a high degree of accuracy cannot be looked for in such data a tolerably clear picture of the out1ine of the snout in plan emerges from it.

$F$. ventralis. $W=13.72+5.445 \mathrm{~N}^{2}(R 0.9981)$ or $W=11.46+7.448 \mathrm{~N}-0.66517$ $N^{2}+0.26321 n^{3}(R 0.9994)$.

F. macki. $W=39.30+16.998 N-0.91667 N^{2}(R 0.9873)$ or $W=25.31+29.407 N$ $-3.6071 N^{2}+0.16306 N^{3}(R 0.9976)$.

By differentiation of the second-degree equations the tangents to the outline of the head in plan are found to be for $F$. ventralis in male embryo female embryo adult female (estimated from figure) 2.072 .130 .43 , for $F$. mack $i$ in male adult (estimated from figure) 1.83. Thus the present data suggest that in F. ventralis the head becomes more obtuse with age, and indicates the degree of pointedness in the embryos of $F$. ventralis is (1ike certain other characters noted above) closer to that in $F$. macki than to that in the adult of their own species. 


\section{E.O.G. Scott}

\section{TABLE 2}

FURCALEUS VENTRALIS (Whitley, 1943)

binensions of (a) an imperfect female from near Stanley, northwest coast, Tasmania, (b) female (c) male (d) male, three embryos, standard lengths 191191187.5 mm, taken from (a); together with (e) female holotype of $F$. ventralig standard Iength $1021 \mathrm{~mm}$, and (f) male holotype of $F$. macki (Whitley, 1943), standard length $420 \mathrm{~mm}$. Dimensions of (a) given in milimetres, of all other specimens as thousandths of standard length (7Ts).

H1 Length of head to first gill sil F. vertrazis

H2 Length of head to fifth gill slit

\begin{tabular}{|c|c|c|c|c|c|c|}
\hline & \multicolumn{4}{|c|}{ F. ventralis } & \multicolumn{2}{|c|}{ F. macki } \\
\hline & (a) & (b) & (c) & (d) & (e) & (f) \\
\hline & $\mathrm{mm}$ & TLS & ThS & TLS & $T L S$ & TLS \\
\hline $\mathrm{H} 1$ & Length of head to first gill slit & 259 & 251 & 259 & 175 & 202 \\
\hline $\mathrm{H} 2$ & Length of head to fifth gill slit & 304 & 306 & 309 & 215 & 257 \\
\hline H3 & Tip of snout to anterior margin of eye & 94 & 94 & 101 & 70 & 81 \\
\hline $\mathrm{H} 4$ & Breadth of snout immediately before eyes & 136 & 147 & 139 & 88 & \\
\hline H5 & Snout tip to origin of pectora 1 & 283 & 280 & 291 & 225 & \\
\hline $\mathrm{H} 6$ & Snout tip to origin of ventral & 592 & 597 & 592 & 572 & \\
\hline $\mathrm{H7}$ & Eye, horizonta1 diameter & 57 & 62 & 60 & 26 & 38 \\
\hline H8 & Eye, vertical diameter (outside & & & & & \\
\hline & nictitating membrane) & 36 & 37 & 35 & 11 & 17 \\
\hline H9 & Interorbita 1 & 113 & 115 & 115 & 68 & 79 \\
\hline H10 & Eye to spiracle & 16 & 17 & 19 & 13 & \\
\hline H11 & Length of nostril, anteroposterior & & & & & \\
\hline & oblique & 21,38 & 21 , & 24,37 & 21 & \\
\hline H12 & Internarial, between posterior angles & 60 & 65 & 59 & 31 & 38 \\
\hline H1 3 & Preoral length & 105 & 110 & 112 & 64 & 88 \\
\hline H14 & Width of mouth (distance between angles) & 93 & 90 & 92 & 66 & 76 \\
\hline H15 & Upper labial fold & 42 & 39 & 37 & 25 & \\
\hline H16 & Lower labial fold & 21 & 21 & 20 & 15 & \\
\hline $\mathrm{H} 17$ & Height of first gill slit & 26 & 24 & 26 & 22 & \\
\hline H18 & Height of fifth gill slit & 17 & 13 & 13 & 19 & \\
\hline B1 & Length from snout tip to anterior & & & & & \\
\hline & [lower] caudal root & 1000 & 1000 & 1000 & 1000 & 1000 \\
\hline B2 & Length from snout tip to middle of vent & 623 & 639 & 645 & 598 & \\
\hline B3 & Predorsal length & 429 & 435 & 448 & 372 & 388 \\
\hline B4 & Depth at origin of first dorsal & 141 & 147 & 149 & 168 & 171 \\
\hline B5 & Breadth below origin of first dorsal & 141 & 136 & 117 & 144 & \\
\hline B6 & Depth of caudal peduncle before & & & & & \\
\hline & caudal origin & 47 & 52 & 51 & 38 & \\
\hline B7 & Breadth of caudal peduncle before & & & & & \\
\hline & cauda1 origin & 37 & 36 & 37 & 29 & \\
\hline B8 & Claspers, outer margin & & 25 & 29 & & \\
\hline B9 & C1aspers, inner margin to membrane at base & & 26 & 29 & & \\
\hline F1 & First dorsa1, anterior margin $\quad 170$ & 157 & 168 & 152 & 126 & 140 \\
\hline $\mathrm{F} 2$ & First dorsal, base & 110 & 120 & 128 & 123 & 110 \\
\hline F3 & First dorsa 1 , last ray & 47 & 52 & 59 & 51 & 60 \\
\hline F4 & Interdorsal space & 225 & 225 & 224 & 306 & 245 \\
\hline F5 & Second dorsal, anterior margin & 147 & 147 & 137 & 137 & 138 \\
\hline F6 & Second dorsa1, base & 120 & 126 & 120 & 112 & 105 \\
\hline F7 & Second dorsal, last ray & 37 & 42 & 45 & 40 & 45 \\
\hline F8 & Second dorsal to base of caudal & 115 & 115 & 120 & 117 & 140 \\
\hline F9 & Ana1, anterior margin & 115 & 115 & 109 & 103 & 105 \\
\hline F10 & Ana1, base & 83 & 89 & 93 & 88 & 74 \\
\hline $\mathrm{F} 11$ & Anal, last ray & 37 & 34 & 35 & 31 & 31 \\
\hline
\end{tabular}

F. macki 
F12 Anal base to base of caudal

F14 Pectoral, length

F15 Pectora1, base, anteroposterior oblique

F17 Ventral, anterior margin

F18 Ventral, base, in male to outer angle of clasper

F19 Ventral last ray, measured externa11y

F20 Ventra1 origin to anal origin 242

F21 Caudal, upper lobe

F22 Caudal, lower lobe

\begin{tabular}{|c|c|c|c|c|c|}
\hline \multicolumn{4}{|c|}{ I. ventralis } & \multicolumn{2}{|c|}{$\bar{F} \cdot \operatorname{macki}$} \\
\hline (a) & (b) & (c) & (d) & (e) & (f) \\
\hline $\mathrm{mm}$ & TLS & TLS & TLS & TLS & TLS \\
\hline 85 & 86 & 89 & 101 & 102 & 98 \\
\hline 175 & 157 & 165 & 171 & 163 & 152 \\
\hline 60,62 & 47,52 & 49 & 49,54 & 59 & 48 \\
\hline 100 & 99 & 94 & 107 & 78 & 83 \\
\hline 71 & 29 & 68 & 69 & 65 & 60 \\
\hline 62 & 58 & 52 & 56 & 45 & 48 \\
\hline 242 & 202 & 204 & 213 & 238 & \\
\hline & 267 & 280 & 285 & 223 & 245 \\
\hline 125 & 144 & 134 & 1.36 & 113 & 100 \\
\hline
\end{tabular}

Family XENOCONGRIDAE

By the generality of Australian authors - e.g., Lucas (1890) Ogilby (1916) McCu1loch $(1911,1929)$ Whitley $(1944,1958,1962)$ Munro (1957a, 1967) Scott (1962) Scott et al. (1974) - a tolerably compact regional assemblage of Worm Eels has been treated as the family Echelidae, a course hitherto followed in contributions in the present series, Part III (1936) VI (1953) VIII (1957) X (196I) XI (1963) XIX (1974a) XXI (1975) XXII (1976). In both of the early Tasmanian catalogues of Johnston (1883, 1891) the wide Guntherian Muraenidae is used, while among recent authors Marshal1 (1964) dealing with Queensland fishes adopts Myridae and in Allen et al. (1976, relevant section by Hoese) in a checklist of the fishes of Lord Howe Island the characteristic genus Mrcenichthys is listed in Ophichthidae. In their provisional outline classification of living teleosts Greenwood et al. (1966) abandon Echelidae, sharing it out between Xenocongridae (along with Chlopsidae, Myridae in part, Muraenichthyidae, Chilorhinidae) and Ophichthidae (Ophichthyidae, Myrophidae, Myridae in part): this usage is adopted here.

Two species only are credited to Tasmania in the Check-List (McCulloch 1929), Muraenichthys breviceps Günther, 1876 and $M$. tasmaniensis McCulloch, both with this State as type locality. M. australis Macleay, 1881 (type locality New South Wales) M. ogizby Fowler 1908 (type locality Victoria) and M. Zingowench Scott, 1975 (known only from Tasmania) were added to the local list in Parts III (1936) XIX (1974a) XIX (1975) respectively. A new species of Mraenichthys is here described.

\section{Genus MURAENICHTHYS Bleeker, 1853}

Muraenichthys Bleeker, 1853, Natuurk. Tijdschr. Ned-Ind., 4, p.505. Type-species, Muraenichthys gymnoptems Bleeker (designated 1864).

Muraenichthys: Schultz, 1953,U.S. Nat. Mis. BulZ., 202, p.70 (references and synonymy). Date of genus

The genus Muraenichthys is commonly attributed in Australian and New zealand texts, including the present studies, to Bleeker, 1864, Nat. Ti.jdschr. Dierk., 2, p.117 [date in Australian Check-List (McCulloch 1929) cited as 1865]. The reference given above is that listed in Neave (1940).

\section{Subgenus MURAENICHTHYS Schultz, 1953}

Muraenichthys Schu1tz, 1953,U.S. Nat. Mus. BuZ2., 202, p.71 (in key) subgenus of Mraenichthys Bleeker, 1853. 
E. . . G. Scott

Diagnos is

Attenuate, depth about 50 in length; dorsal originating behind head by less than head length; Schmidt's index 29-30; head 4-5 in trunk, 12-14 in total Jength; precaudal length $1.3-1.4$ in tail; eye 5-6 in snout; snout pointed, upper jaw the longer; maxillary and vomerine teeth uniserial; dorsal and anal fins low, caudal vestigial, pectoral and ventral lacking; trunk above lateral line greenish wi.th very numerous dark brown punctulations, yellowish below, the former color gradually extending downward on most of tail, the terminal portion lighter than the rest approaching white; no gross markings.

\section{Material}

Three specimens, (a) total length 232.5 mun (b) 153.5 (c) imperfect posteriorly $87+$, dredged in 25 fathoms $(46 \mathrm{~m})$ off Eddystone Point, east coast, Tasmania on 22 June 1975 by Mr Shane Down. Deposited at the Queen Victoria Museum and Art Gallery, Launceston, Tasmania (a) Holotype Q.V.M. Reg. No, 1979/5/68, Type No. 368. (b) Paratype Q.V.M. Reg. No. 1979/5/76, Type No. 369. (c) Paratype Q.V.M. Reg. No. 1979/5/77, Type No. 370 .

Principal dimensions

Dimensions in this paragraph are given as millesimals of total lengths (232.5 $153.5 \rightarrow$ with absolute measurements, mun, in parentheses. Length to dorsal origin $127(29.5) 137(21.0)-(15.9)$, to vent (middle) $422(98.0) 43.3(66.5)-(46.2)$, to anal origin $438(101.8) 44.5(68.3)-(47.4)$. Head $73(16.9) 85(13.0)-(9.0)$. Maximun depth of head 19 (4.3) 2.0 (3.1) - (specimen distorted), maximun depth of body $15(3.5) 19(2.9)-(1.9)$, depth at vent $13(3.1) 13(2.0)-(1.7)$.

Dimensions in this paragraph are lengths in length of head (absolute measurements, $\mathrm{mm}$, in parentheses). Eye $(0.50 .40 .2) \quad 333345$. Snout $\left(\begin{array}{ll}3.0 & 2.0 \\ 0 & 1.4\end{array}\right) 5.66 .56 .4$. Interorbital $(2.31 .71 .0) 7.47 .69 .2$. Mouth cleft from tip of lower $j$ aw to angle of

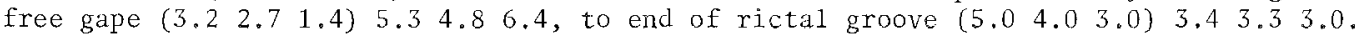

\section{Proportions}

Maximun depth 4.84 .54 .7 in head. Head 13.811 .8 - in total length, 4.8 4.14 .1 in trunk. Eye 6.05 .07 .0 in snout, 4.64 .35 .0 in interorbital. Total mouth cleft 5.34 .86 .4 in head.

To the above proportions commonly recorded in species descriptions may be added the following four ratios that have been found in these studies to be of diagnostic value and that are set out in a comparative schedule in Part XXI (1975, table 1). Head in dorsal-bearing trunk 4.05 3.50 3.37. Precaudal length in tail 1.371 .31 Predorsal trunk in total trunk 1.571 .641 .75 . Predorsal length in rest of length $6.886 .31-$.

\footnotetext{
Schmidt's index $\left(S=\frac{a-d}{t} \times 100\right.$, where $a=1$ ength to vent $d=1$ ength to dorsal origin $t=$ total 1ength) 29.529 .6 -
}

General features

Highly elongate, slender, depth 53-66 in length, subcylindrical throughout greater part of length becoming somewhat compressed posteriorly, Branchial basket well deve1oped, convex, projecting more ventrally than laterally, its length subequal to interval. between its origin and front of eye, the forwardly convex rays about 30, groove between branchiostegals traceable forward to level of eye. Gill opening small, dianeter less than that of eye, about midway between ventral profile and lateral line, the latter here about equidistant from dorsal and ventral profiles. Head small 4-5 in trunk, 12-14 in total length; mostly subcyclindrical, tapering from eye to fairly acute, more or less evenly rounded snout tip. Snout more rounded dorsally than ventrally, its 
102
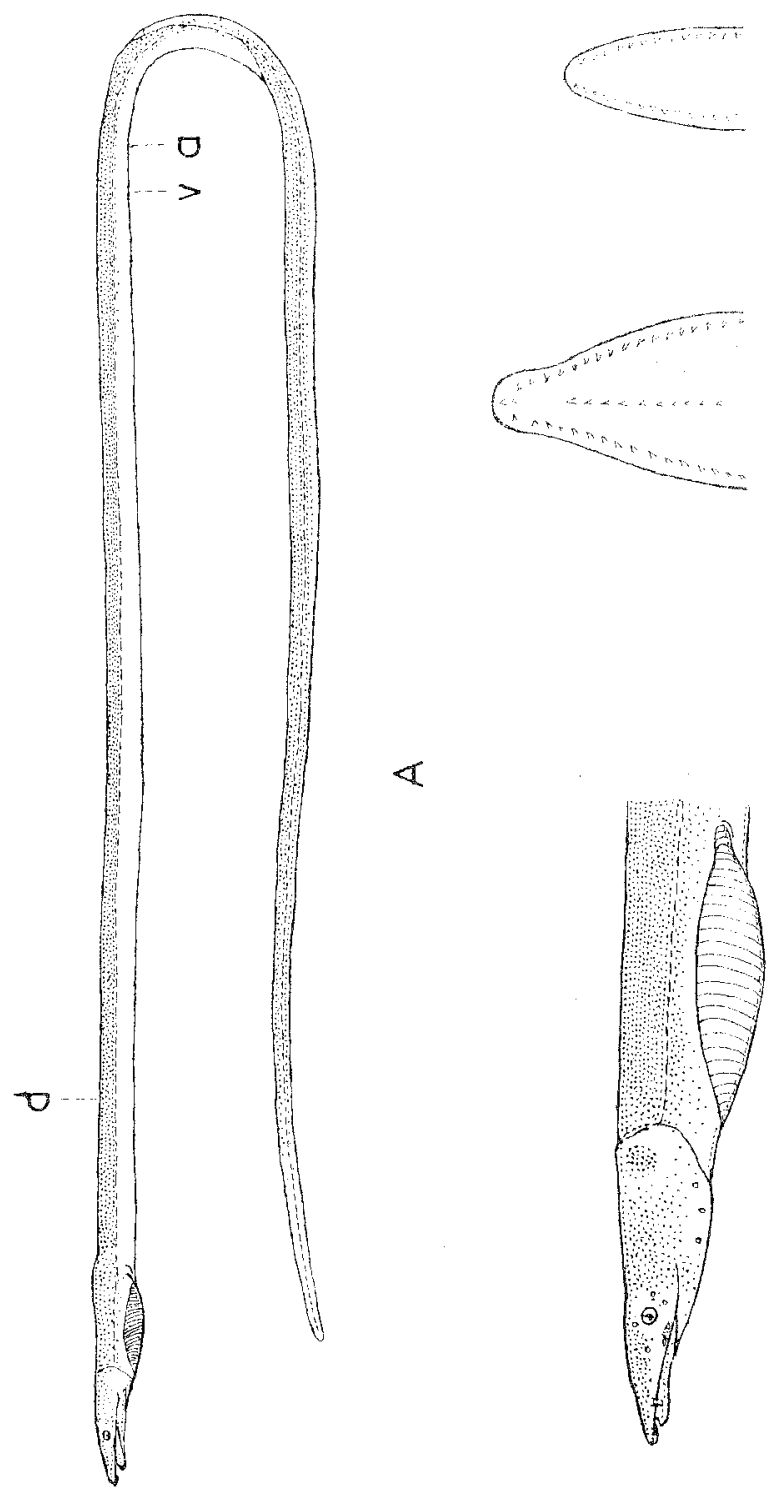

FIG. 2.- Muraenichthys (Muraenichthys) Zengomena sp. nov. Holotype, total length $232.5 \mathrm{~mm}$, dredged in 25 fathoms $(46 \mathrm{~m})$ off Eddystone Point, east coast, Tasmania, 22 June 1979 (Queen Victoria Museum Reg. No. 1979/5/68; Type No. 368). A, Lateral aspect, x 1 1/3: fins wholly lapsed; a, anal origin, d, corsal origin, $v$, vent (middle) B, Head, lateral aspect, $x$ 4, C, Dentition, upper jaw and vomer, semidiagrammatic, $x 7$. D, Dentition, lower jaw, semidiagrammatic, $\times 7$.

length $5-7$ cyo, $6-7$ in head. Upper jaw the longer and wider, its wilth anteriorly more than twice, poster

iorly about one and a quarter that of rower jaw; latter fitting against palate when mouth is closed behind a pad formed by the strongly convex ventral surface of the upper jaw. Anterior nostril in upper lip briefly tubuar, overhanging lower jaw barely behind its tip. Posterior nostril a slit in uppex lip just in advance of eye, overhung by a small downwardly directed flap. Eye small circular about equidistant from mouth cleft and dorsal profile, iris black pupil bluish, the pigmented organ encircled by a slightiy elevated annulus lighter than immediately adjacent area, its diameter 2-3 that of eye. Interorbital convex, strongly transversely moderately anteroposterioriy, 4-5 times eye. Free gape extending about to level of posterior border of eye, rictal groove continuing back as far again.

Several large teeth on the premaxilla. Maxillary and mandibular teeth uniserial, rather large well spaced tencing to decrease in size posteriorly. Teeth on vomer in a single series of about 10 , decreasing in size posteriorly, the anterior almost twice as large as the posterior.

Láteral line a low narrow continuous or subcontinuous ricge in places presenting short irregular contiguous extensions associated with local waviness; originating waving 


\section{F.0.6. $500^{+2}$}

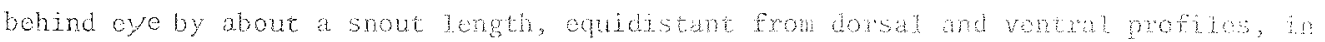
part of truk rising sonowhat, thotoutter continuing doont outuistant from profilos; the anterior ends of the two tines joined by a sightly forwal convox are acjoss occiput. Dorsal and ans fins amost wholly lipsed into groovos, ovidenty low confluent wh a minute and fin, somewhet more distinct in largor paratype.

\section{Cojoration}

(a) Thun. Laterial suriaco above jateral line somownt yollowish groon, the

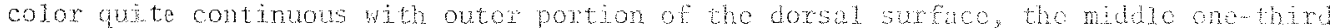
on slighty less of which is occuphed by a tolowaly shamply domareated band of dusky greenish; below lateral ine distincty mone yolowish the colou extenting with little variation on to whole of vontral surface in most of trink but very gradially be come somewhat lighter in the anterior portion. A vory naxrow band of brightor yel bow

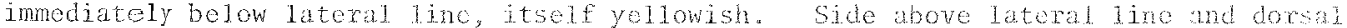
surface minutely and densely punctulated with bxownish, this punctuation serving to accentuate the differonce between uper and lower hat fian, the chromatophoros extond ing fuldy down to the lateral line, then ceasing abruptay save for abott a lread longth in advance of vent where a few well separated punctuiations, nover constituting mote than a single line, descend below the lateral line.

(b) Taiz. In generai sinilar to trunk, djffering from it as follows: whe extension of the brown chromatophores below the lateral 1 ine becones progressively moxe pronounced caudad, most of flank being involved by middle of tail; the median dusky dorsal band becomes 1 ess conspicuous almost to vanishing point; for morc than a head length in advance of its tip almost or wholly lacks the brown chromatophores, appearing overall much 1 ighter than rest of fish, approaching white.

(c) Head. Hojotype behind operculum similar to trunk; a brownish spot on upper front of operculum, region behind and below it without punctulation; whole of snout dark brownish, this color extending back on dorsum, somewhat decreasing in interk sity, to cover interorbital. Smaller paratype with dark brown spot on occiput, snout a trifle darker than rest of head. Larger paratype with whole head without discrete markings, a trifle lighter than trunk, tip of snout almost white.

\section{Affinities}

The seven species of Muraenichthys nccepted as valid in the Handbook (Munro 1957 a) - of which five are now recorded for Tasmania - together with the two endemic species described in Part XXI and here are divisible into two distinct groups on the basis of the location of the origin of the doxsal fin. A convenient quantitative specification of this location arrived at by subtracting length to dorsal origin from length to vent, dividing by overall length of fish and expressing the result as a percentage was first introduced by schmidt in his classical studies on eeis, being effectively used by him in the separation of the long-finned and short-finned eels of castern Australia (1928). Formally designated Schmidt's index and denoted by $S$ by the writer (1953) this formula has been found to be a useful tool in other groups, and is of prime importance in the taxonomy of the present family, the members of which exhibit in most somatic features a marked overall similarity.

Australian species with the dorsal fin originating behind the vent, the index thus having a negative value, are Mraenichthys australis Macleay, 1881, with S ranging (Part XXI, 1975, P.134) from - 1.10 to - 2.46, M. tasmaniensis McCulloch, 1911 fron - 2.6 to - 4.4 (in holotype of the Western Australian M. t. smithi (Whitley, 1944) ca -7.4 ) and $M_{0}$ iredalei Whitley, 1927 (no appropriate data available): the first two only have been reported from Tasmania. of the renaining six species two not found in this state are $M$. devisi Fowler, 1908 (Victoria) and $M$. godeffroyi Regan, 1909 (Queensland): in the absence of the relevant measurements it is not possible to 
calculate accurately values of $S$ for these two forms; however from proportional dimensions supplied it would appear these are round about 23 and round about 19 , respectively. Available values of $S$ for the three locally occurring echelids hitherto described with the index positive are: $M$. breviceps Güther 1876 19.1-21.9, M. ogizby Fowler, 1908 18.7-20.7, M. Zingowenah Scott, 19751.6 (unique holotype). (The two species with intersecting values of $S$ and with very similar morphometric characters in general are trenchantly separable by the dentition, Güther's species having teeth in the jaws in a single series and those on the vomer in three series, while Fowler's species has teeth triserial in the jaws (biserial laterally) and biserial on the vomer).

For the present species $S=29.5$ (holotype) 29.6. Though the species value of $S$ is subject to an excess of several units, the clear excess of these values over the highest figure for any other known Australian species satisfactorily serves to identify the present form. The magnitude of the index has been found to be positively correlated with length of fish; for 8 individuals of $M$. breviceps with Lt $234.8-583.0 x=$ $0.918(z=1.578)$ with $t=5.677^{* *}$ (Part XXI, 1975, p.132).

The following four body-ratios serve to distinguish the present species from one or more of the locally occurring species; values are given in succession for $M$.

Zingowenah (holotype) M. ogizby (range 21 specimens) M. brevioeps (range 8 specimens) $M$. Zengomena (holotype and 1 or 2 paratypes).

Head in dorsal-bearing trunk: $0.23,2.03-2.43,2.17-2.90,4.053 .503 .40$.

Precaudal length in tail: $1.24,1.47-1.75,1.63-1.80,1.371 .31-$.

Predorsal trunk in total trunk: 1.05, 2.27-2.87, 3.10-3.60, 1.57 1.65 1.75.

Predorsal length in total length: $1.32,4.62-4.94,4.59-5.20,6.88,6.31-$

In having the teeth uniserial both in the jaws and on the vomer (an arrangement conveniently denoted 1 1) $M$. Zengomena agrees with the three species, M. australis, $M$. tasmaniensis and $M$. iredalei that constitute the group otherwise trenchantly marked off by having $S$ negative. Among the remaining Australian species, of which the first three occur locally, the dental arrangements are as follows (figure in parentheses is number of rows in hinder part of jaw): $M$. breviceps $13, M$. ogilby 3 (2) $2, M$. lingowenah 1 (2) 2 , $M$. devisi 2 (1) $1, M$. godeffroyi 2.2 - hence the present species stands wholly apart in dentition from all other described species in which $S$ is positive.

In being largely bicolor with the darker component rather sharply bounded below by the lateral line back to or beyond the vent, thereafter gradually descending to the ventral profile $M$. Zengomena conforms to the modal pattern of the genus as represented in Australia ( $M$. godeffroyi is described as of uniform coloration); the presence in the darker region of abundant punctulation also is a general feature. However the presence of a noticeably lighter terminal segment in the tail has not elsewhere been reported and does not occur in any local material exanined by the writer.

The second binomen Zengomena is one of the two words for eel recorded in Milligan's vocabulary of the extinct Tasmanian Aborigines (Ling Roth 1899) — shown with an acute accent on the initial $e$ by Plomley (1976)-being used by tribes from Oyster Bay to Pittwater. A dialectal variant, Zingowenah, recorded for tribes about Mount Royal, Bruny Island, Recherche Bay and the south of the island has been adopted for an endenic species of this genus described in Part XXI (1975).

\section{Family OPHICHTHYIDAE}

The snake eels or serpent eels are at once distinguished from the worm eels (Echelidae) congers (Leptocephalidae) morays (Muraenidae) and typical eels (Anguilliclae) in having the dorsal and anal fins if present ending in front of the tail tip, which projects as a stiff point (said to serve as a burrowing organ). Of the 11 species 
E.O.G.S Scott

listed in the Handbook (Munro 1957a) only 2 are known to occur outside Queensland, Northern Territory and Western Australia, Matvoliophis pinguis (Güther, 1873), referred in the Check-List (McCulloch 1929) to Bascanichthys Jordan \& Davis, 1892, from southern Queenslind, Now South wales, and Ophisums serpens (Linné, 1758), from New South Wales, Western Australia and Tasmania. The species occurring locally differs trenchantly from other Australian forms by its longer nouth cleft $(2, a f \circ>3$, in head).

Genus OPHTSURUS Laćépède, 1800

Ophisurue Lacépede, 1800 , HIST. NAT. POISS., 2, p.195. Type--species,

Ophisurus serpens Lacépède $=$ Mraena serpens Linné

Ophisurus serpens (linné, 1758)

Muraena serpens Linné, 1758, SYST. NAT., ed. 10, p.244: based on Artedi, gen 24, syn.41 Type locality: southern European seas.

Occurrence in Tasmania

Ogilby (1897a) observed of a Tasmanian eel it belongs to the restricted genus Ophisums, but it is in such bad condition that the species cannot be determined. It may, however, be included in the Tasmanian catalogue as 0. serpens.' Later (1897b), p.159, footnote) he accepted fully the specific determination. Lord \& Scott (1924, p.37) remarked 'As regards the right of this species to appear upon the Tasmanian faunal list, we know of no further records of specimens beyond the reference [1897a] made by Ogilby.' A confirmatory record is given in Part XI (1963), in which some observations are made on a specinen, Lit 1 144, taken in a lagoon near the mouth of the George River, east coast, in August 1956. An additional example, Lt 601, hooked at Scamander, east coast, by Mr G. Viney on 12 May 1979 (Q.V.M. Reg. No. 1979/5/46) is here reported.

Dimensions as TLS

Head 68.2. Snout from tip of upper jaw 16.8, lower jaw 14.3. Eye 6.67. Interorbita1 6.49. Length of mouth cleft 34.8. Length to origin, termination of dorsal 104975 , of anal 356983 . Length to pectoral 71.5, length of fin 14.5 . Length to vent (middle) 344. Depth (width) at front of eye $9.7(7.0)$ back of eye $11.3(8.3)$ end of mouth cleft $16.5(14.6)$ gill slit $20.0(15.8)$ vent $15.1(16.3)$ anal termination $7.15(6.50)$; maximum head $21.6(15.8)$ body $16.6(16.6)$.

\section{Proportions}

Values for the 5 proportions given in the Handbook (Handbook values in parentheses) are as follows. Mouth cleft in head 2.0(2). Eye in snout, upper jaw 2.53 lower jaw 2.15(2.9). Head in trunk 4.05(3.6-5.2). Head in tail 9.61(7.1). Pectoral in head $4.71(6)$.

\section{Dentition}

The taxonomic importance of the dentition of Ophichthyids has been amply demonstrated by Schultz (1953). The pattern in the present specimen comprises clustered premaxillary, uniserial maxillary, dentary and vomerine sets. Premaxillary: lateral 3 pairs (second tooth missing on right sicle), large subconical recurved acute decreasing in size backward; medial 1 small, just behind level of hindmost premaxillary. Maxillary: in either jaw a single series of about 40, small subconical somewhat recurved rather bluntly pointed, largest near middle decreasing slightly anteriorly sonewhat more markedly posteriorly. Vomerine: an anterior line of 3 large acute strongly recurved, first just behind premaxillary median, followed after a short diastema by a series of about a dozen decreasing in size backward; unless the mouth is flattened by moderate pressure the hind part of the series is hidden where 2 palatal folds meet over a median groove. Dentary: on each side 2 large recurved acute well spaced followed by a uniserial set of about 40, all small the posterior only half the size of the anterior. 


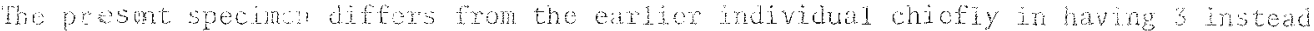

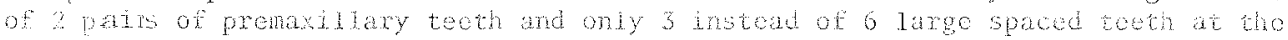
tron of the vomerine sexies.

a blade of a brom soaweed about 2 min wide projcctod for about 10 mm from tho mout and extended for about 60 m down the gullet.

Coloxition

Heal fom tr level of lower orbital rim, trunk on upper four-fiths, tall above Acoral line incensoly minutely punctulated wht brownish, overall olivacedus darkest dorsaly; bejow this lighter somewhat sivery. ventral surface of head and trunk lustrous silver, increasingly less brilliant more admixed with pale greenish behint vent. Terminal 2-3 mm of tail dusky. Dorsal and anal (wholly collapsed) narrow lines of dark greenish, doxsal bordered on ejther side by slemder pale greenish strip devoid of all punctulation. Pectoral brownish green barely darker than fiank.

Head, Iength to vent, total length

In this family the total absence of a caudal fin renders standard length (the diemsion conventionally used in the present context) and total length virtually the same. In a $\log \log$ plot length of head, length to vent and total length are significantly linear on 123 , both for the present specimen ( $t 31.22^{*}$ ) and for the larger individual noted in Part XI (t $36.507^{*}$ ). In the equations below (present fish first) dimensions are millesimals of total length.

$\log L=2.4325 \log N+1.8258$. Measured (predicted) 1engths 68(67) 344(361) $1000(969)$.

$\log L=2.3360 \log N+1.8743$. Lengths 76(75) 363(378) $1000(974)$.

Location of dorsal and anal origins

In a loglog plot the lengths to the origins of the dorsal and anal fins and the total. 1ength are significantly inear $\left(t \quad 31.191^{*}, 58.336^{*}\right.$ ) on 2510 .

$\log L=1.4030 \log N+1.5875$. Measured (predicted) lengths (TLS) 104(102) $356(370) 1000(978)$.

$\log L=1.2518 \log N+1.7433$. Lengths $133(132) 407(415) 1000(989)$.

The effective constancy of the fin origins may be noted. With their relative (exponential) lengths along the general axis constant, the magnititude of the irtercept will increase proportionately with increase in size of fish: the ratios here of intercepe the togarithm of total length are $0.571,0.570$.

\section{Family SYNGNATHIDAE}

The first Tasmanian catalogue, that of Johnston (1883), contajned 8 species of

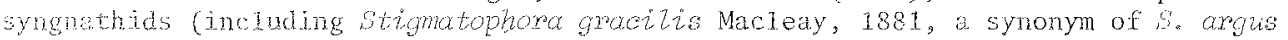
Kan, $385 \%$, his second list (1891) adding Syngnathes ortirostris Castelnau, 1872. Later local lists, those of lord $(1923,1927)$ and Lord and Scott (1924), included 12 species. However, only 7 speches were credited to this state in the check-ist (WeCl1och 1929) whie the Handbook Munro 1958) admits 15. The total now known from our waters amounts to 22 species: as the records of additions aro scattered through several periodicals, Australian and extxalimital - contributions in this sexies and in other joumals by Scott (1942a 1968) and Dawson (1977) - it may be useful to chunerate them hexe. (i) Leptomotus semistriatus Kaw, 1856 (1) Sygmothus curtirostis

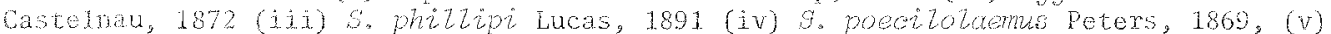

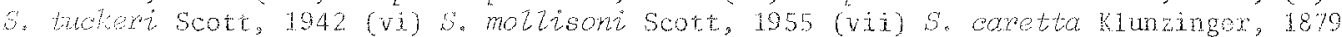

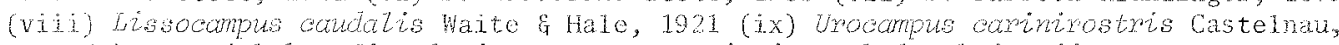
1872 (x) Leptoichthys fistulamius Kaup, (xi) Histiogamphezis briggsiz McCulloch, 1914 (vij) Stigmatophora argus (Richardson, 1840) (xiij) S. higra Kaup, 1853 (xiv) Lehthrocompus man (woitley, 1931 ) (xv) Solengnathus spinosissimus Günther, 1870) (xvi) 


\section{E.O.G. Scott}

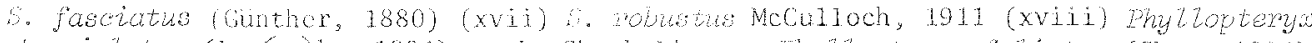
taeniolatus (Lucépede, 1804) - in Check-List as Mhyltoptema foliatus (Shaw, 1804) (xix) it. breviceps petexs, 1870 (xx) H. novochollandiac steindachner, 1966 (xxi) $h$. whitei Bleeker, 1855 (xxii) H. dodominalis Lesson, 1827.

The 17 species then on cho local 1 ist wore keyed in part $x$ (1961) ard a conspectus was provided giving synoptic values gathered from avajlable literature of the known ranges for five mexistic and four morphomotrie vayates togothex with a specification of the rostral crest an indication of the prosence or absonce of an opercuar ko and a note of the maximan recorded length. Extensions for several species of the runges there set out have from time to time been noted in later contributions in this series.

\section{Genus HLSTOGAMPHLLUS McCul Ioch, 1914}

Histiogomphelus McCulloch, 1914, Aust. 2002. 1(1), p.30. Type-species, Histiogamphezus briggsiz Mcculloch.

Histiogomphezus briggsii McCulloch, 1914

Histiogomphetus briggsiz McCulloch, 1914, Aust.Zoot., 1(1), p.30, fig.4. Type locality: Thouin or Wineglass Bay, Tasmania.

Histiogamphelus briggsiz McCulloch, 1929, Aust. Mus. Mem., 5(1), p.92; Scott, 1968, I'asm. Eisher. Res., 2(2), P.6: Whitley, 1964, Proc. Linn. Soc. N.S.W., 89(1), p.38.: Whitley \& Allan, 1958, SEA HORSE AND ITS RELATIVES, p.60, fig.16, 3. HistiogampheZus briggsi: Lord, 1923, Pap. Proc. R.Soo. Tasm. (1921), p.13, and J. PanPac. res. Inst. 2(4), p.13: Lord \& Scott, 1924, SYNOP. VERT. ANIM. TASM., pp.8 40 Histiogamphelus briggsiz briggsii: Munro, 1958, HANDBK FISH. AUST., 21, p.85, fig. 590: Scott, 1961, Pap. Proc.R.S00. Tasm., 95, p.59.

Histiogamphezus briggsiz orae Whitley, 1950, Rec. Aust. Mus. 22(3), p.238. Type locality: Thompsons Bay, Coogee, near Sydney, New South Wales.

Histiogamphelus briggsiz once: Munro, 1958, HANDBK FISH. AUST., 21, p.85: Whit1ey, 1964, Proc. Linn. Soc. N.S.W., 89(1), p.38.: Whitley \& Allan, 1958, SEA-HORSE AND I'TS RELATIVES, P.60.

\section{Material}

A specimen, Ls 180 Lt 186, dredged in 15 fathoms (17 m) 9 miles (14 km) north-west of Binalong Bay, east coast, in July 1979 by Mr Shane Down (Q.V.M. Reg. No. $1979 / 5 / 111)$.

This specimen exhibits some features stated to be characteristic of Histiogomphelus briggsii briggsii some stated to be characteristic of Histiogamphelus briggsiz orae and some not in agrement with the descriptions of either. After some consideration it is here referred to $H$. briggsi $i$ without subspecific specification, j.ts taxonomic status being discussed below.

\section{Meristic characters}

of the entries in parentheses the first in each case is that reported by MeCulloch (1914) for his Histiogamphezus briggsiz from Tasmania the second that reported by whitley (1950) for his Histiogamphelus briggsiz orae from New South wales. Anmuli. $22+39(22+36,21+35)$. Subdorsal annuli $5+3(5+2,6+2)$. Brood annuli $1-14$, at 0.70 .2 of annulus respectively. D. $25(23,25)$. P. 14/14 (13, 12)。 C. 6 (from figure $10 \rightarrow$ ), A. 3 ? (no data).

\section{Dimensions}

The following dimensions are given as millesimals of length to base of cauda] (Ls 180) with length in mm in parentheses. Total length 1 033(186). Head 108(19.5) Snout 53(9.5). Fye 19(3.4). Interorbita1 9.4(1.7). Length of operculum 46(8.2) width $23(4.1)$. Length to pectoral origin $111(20.0)$ length of fin $17(3.0)$ base 


\section{Tasmanian Fishes}

measured obliquely 14(2.5). Length to dorsal origin $358(64.5)$ to termination 449(80.9). Length of caudal 33(6.0). Length to vent $403(72.5)$. Length to origin of brood pouch $419(75.5)$ to ternination $613(110.3)$. Depth at midile of snout $4.8(27)$ front of eye 23 (4.1) back of eye $26(4.6)$ middle of operculum $30(5.4)$ hind border of operculum $29(5.2)$ vent $22(4.0)$ base of caudal 6.7 , maximum depth of head $30(5.4)$ of trunk $30(5.4)$. Width at sane seven points $8.9(1.6) 15(2.7) 20(3.6) 28(5.1) 22(4.0)$ $19(3.5) 7.2(1.3)$, maximum width of head $28(5.1)$ of trunk $22(4.0)$.

\section{Proportions}

Where avalabje proportions given by Mcculloch and whitiey or calculable from their recorded dimensions are shown in parentheses (former first). The set of proportions reported in specific diagnoses of syngnathids shows some variation with authors (e.g., head in trunk or in length to vent or in standard length): most variants in frequent use are here noted.

Head in trunk $2.72(3.62 .82)$ in length to vent $3.72(4.63 .8)$ in standard length 9.23 in total length 9.54 (- 8.82). Trunk in tail without caudal 2.03 in tail with caudaI 2.14 (-1.77) in total length 3.51 (-3.13). Head and trunk together in tail without caudal 1.48 with caudal 1.57 ('tail' 1.3 tail with caudal 1.31). Snout in head $2.05(2.12 .2)$. Eye in snout $2.79(2.51 .7)$. Interorbital in eye 2.00. Length to dorsal origin in standard length 2.79 length to termination in standard length 2.22 base of fin 11.0 in standard length or 3.93 (from figure about $4.6-$ ) in length to its origin. Pectoral length in head 6.50 (from figure about $6-$ ) base in head 7.8. Caudal length in head 3.25 ( 3 'nearly $3^{\circ}$ ). Maximum depth of head in head 3.61 (from figure about $3.4-$ ) in standard length 33.3 , maximum depth of trunk in head 3.61 (from figure about 2.2-) in standard 1ength 33.3. Length of brood pouch region in tail 3.07 in standard length 5.18 .

\section{Description}

Smooth, without cutaneous appendages. Trunk and tail subquadrangular, depth of trunk almost uniform that of tail decreasing evenly, at termination one third that at origin, depth of trunk 1.3 of tail 1.2 its greatest width, former 3.8 in head.

Body ridges are here denoted by a two-letter system thus: first letter either $\mathrm{T}=$ trunk or $\mathrm{C}=$ caudal, second letter one of these $\mathrm{S}=$ superior (superolatera1) $\mathrm{D}=$ dorsal (here and normally medial) $v=$ ventral (here and normally medial) $L=1$ ateral (if as here single then more or less medial) - for a discussion of notation inciuding a comparison of this with other systems see Part XXIII (1977, p.125).

TS well developed, exhibiting a somewhat unusual feature in being disjunct with a brief hiatus at the end of each annulus the interval usually including a minute rounded boss, terminating below dorsal fin at 0.8 of second dorsal annulus slightly (1eft) decidedly (right) closer to dorsal profile than to CS, which is similarly disjunct in some anterior annuli and which leaves dorsal profile at hind border of third caudal annulus (at level of dorsal fin termination) swinging down to end at 0.2-0.4 of penultimate trunk annulus, being there equidistant from TL and TS. TL similar in structure to TS, ending at 0.9 of penultimate trunk annulus, hence overlapped by CS for most of one annulus, tip a trifle closer to ventral than to dorsal profile, not turned down. TL continuous with CL both showing very brief interruptions at annulus junctions. TV subcontinuous and in general similar in structure to Ts but with some ridge sections presenting noticcable terminal dilatation, stronger than other trunk ridges. Ventral surface of tail shows some measure of collapse being deepest mesially, no clear evidence of the existence of $\mathrm{CV}$. Each plate with a doubly lyrate pattern of striae suggestive of the conventional karyokinetic spindle.

Head rather long stout. Snout stout its length subequal to that of rest of head. 


\section{E.O.G. Scott}

The conspicuous thin elevated rostral ridge begins at uppex 1 ip and rises rapidly strongly convexiy to attain its maximum height ( 2 m or about two-fifths total height of snout) near the first one-fifth of its length, thereafter running back, as far as can be determined (margin damaged for about 1 mil near middle of length) vjrtually horizontally, to level of front of eye beyond which it curves down increasingly rapidly though overall rather slowly to end $0.2 \mathrm{~mm}$ above supraorbital ridge just behind level of second one-third of orbit. Though the upper border of the ridge is briefly interrupted a tolerably reliable reconstruction would seem to make clear the absence from here of any such notch in the profile as is a diagnostic feature of e.g. subspecies of H. maculatus Hale, 1939. Though McCulloch expressly states 'the upper nargin of the ridge is entire" his figure would seen to indicate the presence of a minute notch separating the rapidly ascending anterior portion from the subhorizontal section following it (this feature not necessarily recognizable in reproductions of the original illustration). Such a nick is present in our fish, its location being emphasized first by the existence of a daxk slightly proconvex line running lown and slightly back from i.t, and sccondly by the fact that immediately behind it there is a compact series of striae, about a score in the intact region, running lown and back towards base of ridge, the anterior stria, with its tip at the notch, at an angle of about $45^{\circ}$ those behind it progressively more nearly upright the hindmost close to vertical, while in advance of the notch there are indications of a separate fan of striae the general sense of which is subvertical. There is thus some suggestion the rostral crest may represent the fusion of (at least) two plates. The whole external border is defined by a very slender ridge seen under a lens to be minutely denticulate.

Other cephalic ridges include: (a) a median one on dorsum in line with the rostral crest but separated from it by about one-third of an eye diameter extending back, rather feebly posteriorly, over occiput and nape to above middle of pectoral base behind the origin of TS (b) one defining upper border of the tubular snout terminating at middle of anterior border of orbit (c) one defining lower border of snout continuing, slightly below eye, almost to level of back of orbit (d) one immediately above eye its middle half part of orbital rim (well elevated throughout) its length subequal to an eye diameter, the pair viewed from above convex outward, a little wider apart at their posterior than at their anterior ends (e) on ventral surface two median ridges originating near tip of lip, very shortly approximating then diverging to a small max-m imum about at level of the nick in the rostral crest, thereafter running back subparallel for most of their length to diverge strongly below eye.

Eye rather large equidistant from dorsal and ventral profiles. Nostrils close together encircled by a common low rim shortly in advance of upper half of eye, anterior obliquely below posterior, feebly tubular. Operculum with many fine radiating striae and anteriorly a we11 developed keel lapsing to extinction in last one-third of length.

Dorsal with 25 simple rays on an elevated base covering five trunk and three tail rings. Pectoral with 13 simple rays, base strongly elevated obliquely down and back, proconvex. Caudal rounded apparently with 6 stout rays. Anal minute probably with 3 rays. Though no functional brood pouch is developed its location is clearly indicated by two folds of moderate height, originating on first caudal annulus diverging over less than the length of an annulus and continuing back paralle 1 to end on fourteenth annulus, the interval between then a little greater than half total ventral width. It is not certain whether the pouch has regressed ox is incipient; the coloration (see below) would suggest the former as more likely — some data on seasons of brood pouch development in various Tasmanian species are collected in Part XVIII (1970, p.123) and Part XXIII (1977, p.133). The presence in this specimen of the folds of a brood pouch immediately behind the vent at length substantiates for this species and it may reasonably be assumed for this genus the general 'Brood pouch (males) presumably 
subcaudet of the llandoook.

\section{Colorition}

Lateral surface of trunk palo frwn, an obscurely delimitod patch of whitish on each mnulus, anteriorly near middle posteriorly adjacent to th and loss extensive; ground color contimuing on to tail but there progressively deepening caudad to mid fawn. Dorsal surfaces of trunk and tajl much similar to lateral, trunk without whitish markings but most anterior annuli of tail with an inconspicuous lightish spot at midale of amulus junction. Whole lateral surface of trunk and of first half dozen annuli of tail with smali circles spots or amuli, now inconspicuous but possibly more evident in life, now dark brown but reported to have shown sone bluish earlior, 7-10 on anterior annuli there smallest, 1-2 on posterior, most annuli in last threequarters of trunk with one largish faintly annulated spot regularly developed near midalo shortly above $\mathrm{lL}$. Ventral surface of trunk basically light fawn a little lighter than lateral surface, each annulus with on eithor side an inconspicuous whitish spot often surrounded by some diffuse whitish. Whole brood pouch region including strips of ventral surface externad of the ridges at once identifiable by its dark brown in sharp contrast to the very much lighter trunk and the noticeably 1ighter portion of: tail behind it; section of transverse interannular ridges outside folds whitish, between folds with a whitish spot or diffuse patch at their middle, folds blackish in front Iightening somewhat behjnd. Head similar overall to trunk, upper anterior portion of rostral crest reddish brown, rest brownish except fine ridge constituting its distal border which is blackish, some touches of silvery on operculum particularly below. Pectoral rays concolorous with or a trifle lighter than trunk nearby. Dorsal rays pale straw, a small dark proximal smudge near front of fin. Caudal rays dusky gold throughout, membrane blackish.

Head, length to vent, standard length.

These lengths are satisfactorily specified both for the present specimen ( $t 541.237^{* *}$ ) and for the holotype of $H$. briggsiz orae ( $t 39.270^{*}$ ) by the subjoined equations in which $\#$ has successive values of 1510 .

$\log L=0.9757 \log N+1.2771$; measured (predicted) lengths $19.5(18.9) 72.5(73.2)$ $180(179)$

$\log L=0.9345 \log N+1.0469 ; 11$ (11) 42 (41) $94(96)$.

\section{Discussion}

As already observed the present specimon exhibits some features noted as characteristic of Histiogamphelus briggsiz briggsii in contrast to those of the other subspecies, some stated to be diagnostic for $H$. briggsii orae and some not in accord with the description of either.

It is first to be noted that the descriptions of Mcculloch and whit ley are in each case basod on a sing e individual and the relevant entries in the Handbook (Munro 1958) * species 590 591, merely repeat the original data without indication of a possible range of quantitative (or qualitative) items. Further, compounding the problem thus present. ed, an absence of such ranges characterizes the Handbook diagnoses of all other species of the genus thstiogamphezus there recognized, namely $592 \mathrm{ll}$. meraculus whit $1 \mathrm{ey}$, 1948 , $593 \mathrm{H}$. existatus (Macleay, 1882), $594 \mathrm{H}$. maculatus maculatue Hale, $1939,595 \mathrm{H}$. maculatus robensis whitley, $1948,596 \mathrm{H}$. gallinacenc Hale, 1941, the fixst two from Western Australia, the remaining three from South Australia. We are thus ieft without any information on the oxtent of individual variation within the genus, a circumstance that precludes a definitive judgemont of the systenatic status of the present specimen.

Our fish may be briefly compared with the published accounts of H. briggsiz briggsiz and 1. briggsit orae in respect of the more important features. Caudal annuli: at 39 


\section{E.0.6. $500 t$}

more runerous than in either and indoed thar in my othor species of this genus $27-36$

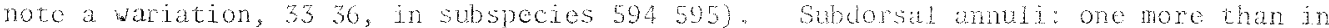

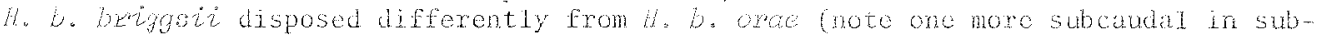
spocies 594 525). boxsal rays: one none than in llob.briggeiz same numer as in

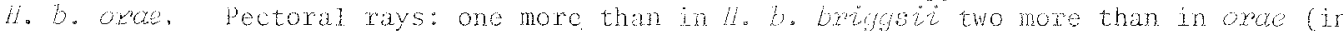
subspecies 59459512 14). Caudal reys: 6, from figure of 11.6 . briggsiz 10 . Form

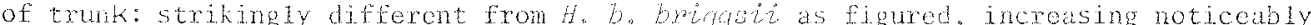
in deptr ciulad to a maxmon of about 2.2 in heal, while in our specimen trunk is of virtualy unifom depth throughout with a maxinum of 3.61 in head; no data for $h$. $b$. orae -... Mcculloch"s spocimen is a female (as apparotly also js Whitloy's), raising the possibility that here (as in, e.g., Leptonotus Kap, 1853) the marked differonce in body depth may be a sex character (our specjinen a male); no information of any possible sex dimorphism in the other species of histiogumphezus recognized in the Handbook, all accounts of which are based on fenales, oach entry including the notation. 'Brood pouch (males) presunably subcaudal'. Opexcular keel: no keel in 1 . b. briggeiz, in $H . b$. orae 'a short keel anteriorly' as in our specinen. Coloration: H. $b$. briggeit, 'with numerous dark edged, blue ocelii', $H$. b. orae "without blue spots, but witl some smudged small dark brown spots", oux specimen with numerous spots, some armulated, probably originally blue or bluish, covering whole of trunk but confined to anterior portion of tail as figured for $H$. b. briggsiz. Rostral ridge: in our fish in excellent agreement with illustration of $H . b$. briggsi - the form of this crest would appear to be the most important single qualitative character in species of this genus.

In the absence of data on possible intraspecific variation in HistiogampheZus the status of the present specimen is not definitely determinable. However, after review of all the available evidence, with very considerable weight given to the known and probable nature of the color pattern, it is suggested it may be expediently determined as Histiogamhetus briggsii. Further, as this fish exhibits some features character. izing cach of the two described subspecies and in some other features lies between then it is suggested these subspecies be abandoned, all presently known material being ascribed to Histiogcomphelus briggsi. McCulloch, 1914

Fanily KYPHOSTDAE

The family Kyphosidae in the broad sense adopted by Greenwood et al. (1966) in their provisional classification of living teleosts includes nine Tasmanian respresentatives comonly distributed in Australian texts among three spearate fanilies, Kyphosidae sensu etrototo (3 Iocal species) Scorpidae (sometimes rendered Scorpididae) (3) and Girenidae (3), The fish noticed below, Girezla triouspidata (Quoy g Gaimard, 1824 ) enters Girellidae, a key to the lasmanian representatives of which is given in Part XI (1963, p.22)

Genus GIRELIA Gray, 1835

Giretta Gray, 1835, ILLUSTR. TNDIAN 200L., 2(19,20), pi.98, fig.3. Type-species, Gretla punctata Cray.

Girezta tricuspiata (0uoy Gaimard, 1824)

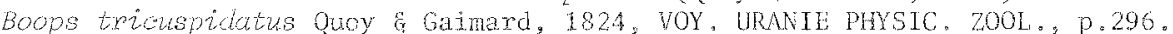

Type locality: "Shark Bay", Western Australia.

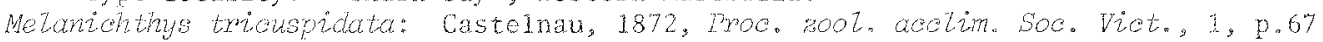
Giretza tricusotdata: Mcculloch, 1929, Aust. Mus. Mem, $5(2), 0.239$ (recerences and symonymy).

Xanthis individar

The generally dark overall color of this species suggested to Teminck G Schlegel (1850) the descriptive generic name Melanichthis (not recognized by Günther (1859) nor 
noted in the generic synonymy in the Check-List (McCuiloch 1929), but adopted after some consideration by Castelnau (1872). The fish goes under a variety of vernacular designations, most bearing reference to its normally sombre appearance. In a11 $10 \mathrm{ca}$. lists it is called black bream (a name in use also in New South Wales and Queensland); other names include nigger (New South Wales), blackfish (Queensland, New South Wales, South Australia), darkie (New South Wales), luderick (New South Wales, Victoria, South Australia; the official commercial name), black perch (Victoria). Marsha11 (1964, p.175) gave the Tasmanian vernacular name as cocky salmon; however this appears to be applied in this state chicfly if not exclusively to Armpis trutta esper Whit ley, 1951, family Arripidae (also known as black-back or Australian colonial or cocky salmon).

A xanthic example of this species, Ls 261 Lt 326, caught off the wharf at Stanley, northwest coast, in January 1979 by Mr J. Lales (Q.V.M. Reg. No. 1979/5/5) presented a sight at once curious and beautiful. Apart from the eye (pupil dark blue iris very pale orange with an obscure peripheral dusky annulus) the whole specimen was bright canary yellow. A striking feature was the uniform and pervasive nature of the coloration, fin spines fin rays and fin membranes bcing indistinguishable from the rest of the fish. The normal coloration is 'brownish above, lighter below with about 12 narrow, vertical dark bands on the back and sides, becoming indistinct on the lower parts (Scott 1962, p.204). In some individuals the dorsal surface comes close to black and the ground color of the flank is at times greyish rather than brownish: the dark bars of which there may be as few as 4 or 5 - noticeably narrower than those of the rather similar MeZambaphes zebra (Richardson, 1846) - usually become lost after death.

Marshall (1964, p.175) noted 'a pale canary-yellow tinge on cheek, lips and throat' and Castelnau (1872, p.67) mentioned a yellowish tinge on the anterior part of the head, and even on the operculum ' however such yellowishness is not always evident in Tasmanian examples.

After having been in a formalin fixing tank for a couple of weeks the fish exhibited considerable fading, bejng in large part pale yellow or whitish, the loss of the original color least marked on the upper part of the head and body, basally on the fins.

Remarks

In general xanthochroism is rare among fishes though it is well known among some freshwater forms. Thus the tench, Tinca tinca (Linné, 1758), occasional1y changes from its normal dull greyish color to a bright orange yellow, while the golden carp or common goldfish, Carassius auratus (Linné, 1758), a native of China and Japan that has now been introduced into all Australian States, changes, particularly under the influence of domestication, from its original dull brown or greenish, becoming in its first year melanistic later silvery and finally reddish gold (exceptional individuals exhibiting albinism). In a subject index prepared as an appendix to a presidential address to the Linnean Society of New South Wales whitley (1964, p.22) 1isted under Xanthism three references relating to eels, Anon (1956), Kershaw (1904), both localities Victoria, Scott (1942a) Tasmania; citing also without comment Haysom (1960) and Whitley (1952). In the last-mentioned paper Whitley stated that the Australiar Museum, Sydney has two xanthic fish both belonging to the present species, one 'canary-yellow almost all over, except for a few scattered blotches or spots of dark grey' the other' almost entirely canary-yellow', both caught at Malabar near. Sydney in 1951, the first in February the second in August. In a passage that appears to have been overlooked in this context Castelnau (1872, p,67) observed 'In the warm months, the color of this fish seems to become much lighter; and in December, I have seen many specimens almost white'.

In his 1964 account. Whitley noted a third xanthic fish in the Australian Museum collection, also a kyphosid, there cited as segutizum sydneyanum, but referred to in almost aI1 Australian texts as Kyphosis sydneyanus (Gunther, 1886), the genus segutizum Whitley, 1931, though maintained by its author in his latest list (1964), not having 


\section{E.O.G. Scott}

received general local recognition. It is certainly a matter of some general interest that members of the family Kyphosidae represent so high a proportion of the few available records of xanthochroism in Australian fishes.

Dimensions as TLE

Length to origin termination of first dorsal 314 670, second dorsal 690 854, anal 617900 . Length to origin total length of pectoral 230211 , of ventral 280180. Length to vent 571. Head 241. Snout 80. Eye 64. Interorbital. 65, internarial 57. Longest ray of dorsal 110 anal 137 pectoral 172 ventral 172 . Longest spine of dorsal 107 anal 100. Depth at operculum 149 at vent 130, maximum depth 161, depth of caudal peduncle 134 .

Aspects of form

(a) Head, Zength to vent, standard Length. On a loglog grid these three lengths are significantly linear ( $t 34.823^{*}$ ) on 123 .

$\log L=1.2881 \log N+2.3790$. Predicted lengths $239(241) 584(571) 1000$.

(b) Disposition of fin origins and teminations. In a $\log \log$ plot length to origin of first dorsal origin of anal origin of second dorsal termination of second dorsal termination of anal and origin of caudal ( $L s$ ) are highly significant ( $558.002^{* * *}$ ) on 2568910

$\log L=0.7116 \log N+2.2856$. Predicted 1engths 316607691848922991 (measured lengths above).

(c) Anal spines. As with many species in divers groups the logarithmic lengths of spines 123 are collinear on logarithms 123.

$\log L=0.6278 \log N+1.1199 ; t 24.387^{*}$; measured (predicted) 1engths, mu, $13.1(13.2) 20.7(20.4) 26.0(26.2)$.

(d) Ventral rays. In a pattern frequently encountered the logarithmic lengths of the four rays postaxial to the spine taken in order of ascending magnitude (starting from outermost) represent a linear function of their serial numbers.

$\log L=0.2622 \log N+1.4857 ; t 6.869^{*}$; measured (predicted) lengths, $\mathrm{mm}, 31.3$ (30.6) $35.0(36.7) 41.0(40.8) 44.9(44.0)$.

\section{Family SOLEIDAE}

Genus ZEBRIAS Jordan \& Snyder, 1890

Zebrias fasciatus (Macleay, 1882)

Synaptura fasciata Macleay, 1882, Proc. Linn. Soc. N.S.W., 7(1), p.14. Type locality:

Port Jackson.

Synaptura fasciata: Waite, 1899, Mem. Aust. Mus., 4(1), p.126, p1.31: McCu110ch, 1911,

Mem. Qzd Mus., 5, p.61, p1.8, fig.2: McCulloch, 1929, Mem. Aust. Mus., 5(2), p.285. Brachims fasciatus: Norman, 1926, Biol. res. Endeavour, 5(5), p.295.

Zebrias fasciatus: Munro, 1957, HANDBK AUST. FISH., 17, p.71, fig.494.

Tasmanian status of species

No member of the family of dextral or true soles, Soleidae, is noted in any published local catalogue, nor is any credited to Tasmania in either the Check-List (McCulloch 1929) or the Handbook (Munro 1957b), the first record of the present species in our water being given in Part XXI (1975), based on two examples, one, Ls 131, collected between East Sandy Cape and Thirty Day Island, one, Ls 96, obtained off Prime Seal Island, Furneaux Group, Bass strait. A third example, Ls 140 (Q.V.M. Reg. No. 1975/5/156), taken off St Helens, east coast, was reported without descriptive data in 
Part XXII (1976), together with two smalier soles in a poor state of preservation, probably referable to this species. Zebmas faseiatus hat previously becn known only from New South walos and Qucensland. An additional, larger example, Lo 158 Lt 174 , dredged by $M$ shane Down off Gedystone Point, east const, in 25 fathons (46 m) in June 1979 (Q.V.M. Reg. No. $1979 / 5 / 67)$ is here noticed.

\section{Meristic characters}

D. 85. A. 71. V. 4/4. B.6/6. These counts all fall within recognized rangos (Waite 1899, Mcculloch 1916, Munro 1957b); the larger of the two individuals desenibed in Paxt XXI had an oxceptionally low nubex of anal rays, 58.

Dimensions and proportions

Head (27.5 min) 5.7 in th or 6.3 in Lt. Depth at front of eyes (25) 6.3 . at back of eyes (38) 4.2 , at opercuium (50) 3.2, maximurn depth (53) occurring at about anterior one-third of iongth of fish 3.0 , chord of are of base of caudal rays (11) 14.4, all proportions in 6.8

Upper eye eyeball only (5.0) 5.5 including soft orbit (6.7) 4.2, 10 wer eye eyebali only (4.1) 6.7 including soft orbit (6.0) 4.6, interorbitul betweeen eyebal1s (4.6) 6.0 between inner edges of orbits (1.9) 14.5 snout to level of front eyeball (6.5) 4.2 , shortest distance (callipers) between upper eyeball and clorsal profile (3.9) 7.1, shortest distance between lower eyeball and ventral profile (5.1) 5.4, length of maxil1a (6.9) 4.0, length of lower jaw (13.9) 2.0, all proportions in head.

First dorsal ray (2.1) 13.1 ray at middle of fin (16.4) 1.7 1ast ray (14.8) 1.9, first anal ray $(6.6) 4.2$ ray at middie of fin (13.5) 2.0 1ast ray (11.0) 2.5, median caudal ray $(21.3) 1.3$, longest ventral ray of ocular side $(6.5) 4.2$ base of that fin (5.0) 5.5, longest ventral ray of biind side $(7.0) 3.9$ base of that $f i n(7.3) 3.8$, length of pectoral of ocular sicle (4.0) 6.9 transverse extent of that fin $(4.0) 6.9$, length of pectoral of blind side (3.4) 8.1 transverse extent of that fin (5.0) 5.5 , all proportions in head.

While in this set of proportions, which is essentially that adopted by Norman (1934) in his memoir on the flatfishes, there are not unexpectedly some differences from the values noted in part XXI for the two Tasmanian examples there considered, no noteworthy variations are apparent. The present fish, the largest of the three, is closer to the larger of the earlier specimens in more than two-thirds of the ratios.

\section{Coloration}

This shows some differences from that of the two examples reported upon earlier. ocular side virtually uniform slate ( $\rho f^{*}$. brownish), light brown where scales are missing; about two dozen dark cross bars of which four are on head, subvertical or slightly proconvex, mostly somewhat narrower than their interspaces. Blind side mainly cream, differing markedly from the uniform whitish of the earlier examples in having a con-spicuous well-delimited band of pinkish about $5 \mathrm{~mm}$ in width situated imnediately internad of the dorsal and anal bases and extending continuously from just behind head to caudal base. Light borders to dorsal and anal narrow, much as shown by wate (1899 p1.31) less extensive than as shown by McCulloch (1916, pl.8, fig.2), whose illustration was selected for reproduction in the Handbook (Munro 1957b). Right ventral very faintly dusky, first ray almost wholly white, left white. Right pectoral off-white touched with pale slate, left wholly white.

Remarks

Bases of the small pectorals relatively very wide, the connexion with the branchiostegal membrane somewhat less fumel-like on the ocular side, here approximating the condition that led Weber \& de Beaufort (1929, p.167) to reject Zebrias Jordan 
E. O. G. Scott

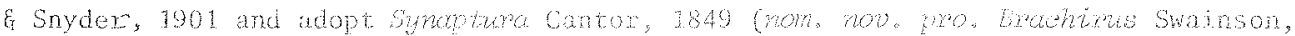

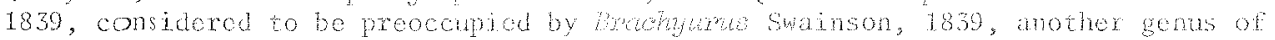
fishes). As in our other exmples of which doscriptions wero provided the candal has somewhat more the appodance of a separte structure and is rathor nore pointed than as depieted by MeCulloch, nowe noaxly appoxinating its appearance jn the jlustration of the rhetis spectmen by wite. Save for a subcircular aroa on operculum wholo of lower surface of hoad thickly beset with slonder tapering white cirri, most abundant and largest along vontral borler whexe thoir length may exeed haf total oyo, one or two series fringing hind margin of oporculum most of these sonewhat scouter than obewhere. In this individual the cirri extend beyond tho heat, briefly bordering tho upper half of the operculun and, exceptionaliy, occurring on the trunk in an elongte triangle dofined below by a line sloping back and up from uppen end of operculum to dorsal profite and above by the profile, total longth of this pennon about twice that of head

Hami ly ODALIDAE

Following the establishment by Castelnau (1875) of the genus Neoodurtho group of shallow-water mostly smal1 and commercially unimportant fishes vernacularly known as rock whitings or reedy whitings has generally been treated locally as the family Neoodacidae (variant, Neoodacidade). However, the earlier Odacidae was retained in the Check-List (McCu1loch 1929) and this is the designation recomended by Greenwood et al. (1966) in their provisiona1 teleost classification (as recognized by them it includes Siphonognathidae, usually treated in Australian texts as distinct.)

Four species are credited to Tasmania among the Odacidae in the check-List (a) Ozisthops cyanomelas Richardson, 1850 (appears in tho second local catalogue of Johnston (1891) as the synonymic OListherops brownit Johnston, 1884 - Otistherops Günther, 1862 a synonym of Ozisthops Richardson, 1840 - and the synonymic odax richardsonit Gunther, 1862, second binomen rendered Richordsoni by Johnston) (b) Neoodax semifaseiatus (Valenciennes, 1839) (now usually referred to Hatetta Whitley, 1947)

(c) $N$. balteatus (Valenciennes, 1839) (the synonymic Odow algensis Richardson, 1840 has Port Arthur, Tasmania as type locality) (d) N. attenuatus (Ogilby, 1897) - together with one species (e) Odax beddomei Johnston, 1885, relegated in the Check-List to Siphonognathidae (genus Siphonognathus Richardson, 1858). In Part XII (1964) (f) N. radiatus Quoy \& Gaimard, 1835) (type species of Sheardichthys Whit1ey, 1947) was added to the Tasmanian list, a key covering (a) (b) (c) (d) (f) being provided, and in Part XIV $(1966)(g) N$. frenatus was reported from our waters (though accepted as a valid species in the Check-List, $N$. frenatus is stated by J.K. Scott (1976) to be merely the female of $N$. radiatus). In Part XVI (1969) it was shown that the transference in the Check-List of (e) to Siphonognathidae - an action suggested by the publication by Whitley (1929a) of a sketch included among the R.M. Johnston memoranda that appears to show that the ventrals, of which no express mention occurs in the lescription (1885) were lacking (a siphonognathid feature) - was in error, the ventrals being present, though readily overlooked when adpressed, in a fish dredged between filinders and Cape Barren Islands, Bass Strait that was in all othor respects in satisfactory agreement with Johnston's account of his Odax beddomei from the River Derwent. A specimen of (d) $N$. attenuatis (Ogilby, 1897), a species that had been wholly lost sight of since its description, was described and figured in Part XTX (1974a), which also provided a key covering all seven local species.

Genus NEOODAX Castelnau, 1875

Neoodax Castelnau, 1875, VICT. OFFIC. REC. PHILAD. EXHIB., p.37. Type-species, iVeoodax waterhousiz Castelnau, $1875=$ Odax batteatus valenciennes, 1839

Haletta Whitley, 1847, Aust. Zoo2., 11(2), p.146. Type-species, Odax semifasciatus Valenciennes, 1839 . 
Sheardichthys whitley, 1947, Aust. Zool., 11(2), p.146. Type-species, Malacanthus radiatus Quoy \& Gaimard, 1835.

Neoodax attenuatus (Ogi1by, 1897)

Odax at temuatus Ogilby, 1897, Proo. Lim. Soc.N.S.W., 22(1), p.83. Type 1ocality: Tasmania.

Neoodax attenuatus: Scott (E.O.G.) 1974, Pap. Froc.R.Soc. Rasm., 107, P.280, fig.2: Scott (J.K.), 1976, Ree. W. Aust. Mus., 4(4), p.357.

\section{History of species}

Described after the publication of Johnston's second catalogue (1891), this species did not find its way into any subsequent local list, apparently being simply overlooked by Lord (1923 1927) and by Lord \& Scott (1924). Ogilby (1897a, p.84) stated of his single specimen, Ls 95 , "Type in the Tasmanian Museum, Hobart' and this statement appears in the Check-List. However, as noted above, Lord, at the time of compilation of his two Lists Director of the Museum, failed to take cognizance of this species; moreover it is not included in the list by Andrews (1971) of the fish type material in that institution: the holotype may be presumed lost.

Neoodax attenuatus has been keyed in Parts XII XIX (1964 1974a) also by J.K. Scott (1976). It may be identified at sight by its agreeing with $N$. bedtomei and differing from a11 other species in having depth more than 9 (about 9.5-11.0) in Ls instead of less than 8 (about 4.5-7.0) and in possessing a black marking on the caudal fin; but differing trenchantly from $N$. beddomei in its much shorter snout, subequal to eye and 3-4 in head as against 3-4 times eye and 2 or less in head, and in having the anal fin ending before dorsal by an interval subequal to its base instead of ending about below the penultimate dorsal ray.

In Part XIX (1974a, p.280, fig.2) an odacid, Ls 75, dredged in $30 \mathrm{~m}$ at Primrose Bay, east coast, on 13 October 1970 by Mr D.C. Wolfe, who recognized its unusual character, was described and figured as an example of Ogilby's long-missing odax attenuatus. Two specimens, Ls 47 69, from Geographe Bay, Western Australia, were reported by J.K. Scott (1976, p.357) in a review of the Odacidae of that State; his paper includes a description of a new genus Parodas in which supplementary canines are associated with the normal fused teeth of the upper and lower jaws.

\section{Material}

Three specimens, (a) $L s 94.0 \mathrm{Lt}$ 117.2, dredged in 25 fathoms (46 m) off Eddystone Point, east coast, 22 June 1979 (Q.V.M. Reg. No. 1979/5/74) (b) Ls 94.0 Lt 117.2 (c) Ls 100.0 Lt 128.5 , both dredged in 15 fathoms $(27 \mathrm{~m}) 9 \mathrm{miles}(14 \mathrm{~km})$ northnorthwest of Finalong Bay, east coast, 30 July 1979 (common Q.V.M. Reg. No. 1979/5/108), al1 co1lected by Mr Shane Down.

\section{Meristic characters}

D. XX,15; XX,13; XX,15. A. III, 8; III, 8; III, 10. P. 13/13; 13/13;14/14 v. 1, 4. C. main rays 141414 (10 1010 divided). Lateral line scales to level of hypural 434644 plus 1-6 (number may differ on two sides of fish) extending on to caudal. L. tr. 4/6. Br. VI. One of the two Western Australian examples reported by J.K. Scott (1976) has only XIX dorsal spines. In both dorsal and anal spines are not noticeably more rigid than rays and as the septa in the latter may not always be readily observable and branching may be minimal and then with the short limbs closely apposed, distinction between spines and rays may present some difficulty; however, the latter are regularly somewhat stouter.

In the course of a comparison of the type of $N$. attenuatus and Johnston's account of his $N$. beddome $i$ Ogilby observed (footnote, p.85), 'Mr. Johnston has recorded three 


\section{E.0.G. Scott}

spinous rays as being present in the anal fin in his example, but a most carefui examination under the microscope, both by Mr. Whitlegge and myself, has been unsuccessful in bringing to light more than a single spine in Mr. Morton's fish.' In the account of the Promise Bay example it was noted (1974a, p.283) there were two anal spines very closely approximated basally, the length of the first bejng about half that of the second. The same situation obtains in the present material but examination of these specimens kould seen to indicate that the third element, earlier interpreted as a ray, is in fact a spine. From time to time in this series it has been noted that for a wide range of species in which three anal spines are present their logarithmic lengths are collinear on $\operatorname{logs} 123$. Using mean spine lengths for the present specimen it is found such is the case here to a probability of better than P. 0.05 - an interesting instance of a systematic application of this formal relation. Three anal spines have been reported for Western Australian material.

\section{Dimensions}

Dimensions are given as millesimals of standard length with the present specimens cited in ascending order of $L e$ (94 100 110) followed in parentheses by the value for the Promise Bay specimen (Ls 75 ).

Total length $1247,1285,1264$ ( 1 229). Length to origin of first dorsal 233 243241 (241) to termination (base of last spine) 553606591 (595). Length to origin of second dorsal (base of first ray) 565627607 (613) to termination (base of last ray) 777840814 (847). Length to origin of anal 638676649 (660) to termination (base of last ray) 739794745 (760). Pectora1, length to origin 201216219 (267) length of longest (8th) ray 132132120 (139) length of whole fin 154149137 (164). Ventral, length to origin 269260272 (267) length of longest ray $127 \quad 135$ 110 (92) length of whole fin 9489107 (105). Length to vent 622656627 (647). Length of first dorsal spine 484163 (57) of second spine 656573 (72) of 1 ast spine 657072 73 (72) of last spine 657072 (65). Length of first dorsal ray $657072(65)$ of seventh ray 7680103 (78) of last ray 646164 (73). Length of first anal spine 29 2128 (27) of second spine 494554 (53) of third spine 777771 (-). Length of first ana1 ray 888080 (72) of third ray (about longest) 839091 (80) of last ray 51 5055 (40). Head with soft opercular lobe 223223227 (231) without lobe 204202209 (213). Snout 777071 (67). Eye 565149 (61). Orbit 716056 (67). Interorbital, soft $364750(51)$ bony $324346(-)$. Depth at front of eye 527055 (64) at back of eye 648065 (80) at operculur 748780 (83) at vent 859187 (81), maximum depth 95 110102 (93), depth of caudal peduncle 515059 (53). Width at front of eye 495155 (65) at back of eye 596866 (65) at operculum 697073 (80) at vent 434955 (45), maximum width $758082(80)$, width of caudal peduncle at caudal base $11 \quad 1316$ (13).

\section{Proportions}

The overall range for the present specimens together with the Promise Bay individual is followed, where the variates are available, by the range ( 2 specimens) reported (J.K. Scott 1976) for Western Australian material.

Head 4.34-4.52 3.9-4.3 trunk 2.30-2.51 tail (without cauda1) 2.65-2.92 greatest depth 9.09-13.2 9.9-10.8 dorsal base 1.65-1.84 1.7-1.8 all in standard length. Length of pectoral 1.41-1.66 2.0-2.7 1ength of ventral 2.12-2.48 2.8-3.5 base of anal 2.21-2.36 $1.7-24$ snout $2.92-3.46$ eye $3.76-4.63$ orbit $3.13-4.03$ al1 in head. Eye in snout $1.09-$ 1.44 0.8-1.1 Interorbital soft 0.98-1.56 bony 1.06-1.77 in eye. Interorbital soft $1.32-3.11$ bony $1.53-2.40$ in snout - without specification of interorbital 1.0-1.1. The lesser value for pectoral and ventral lengths relative to head length reported from Western Australia may be attributable to differences in measurement procedures, our convention for the paired fins (origin taken as anterior border of fin root) being such as to yield a maximum length. When the Western Australian figures are compared with our values for length of longest ray the ranges overlap, ours being $1.66-2.03$ for 
pectoral 2.50-2.99 ventral.

\section{Coloration}

J.K. Scott (1976) has the following note on coloration, 'The basic color of fresh specimens is red-brown with a prominent black spot on the caudal fin'. Both the individual described in Part XIX (1974a) and specimen (a) of the present series had suffered considerable decolorization as a result of preservation. However, while (b) and (c), examined after two days in alcohol, had already tinged the fluid pale orange, they retained sufficient of the original coloration to provide some useful information. A summary of notes then made follows.

Overall rather sharply bicolor, on dorsum and on side above the midlateral line trunk and tail warm brownish tinged with pinkish, below pale orange. In upper region scales abundantly peppered with dark brown, the punctulation more intense near the hind border thus providing each scale with a distinct rounded dark spot occupying rather less than half the exposed area; scales in Iower region macroscopically immaculate though bearing in some parts, particularly immediately beneath the lateral line, some disperse minute brown chromatophores. Ventral surface of trunk and tail pale orange except for a conspicuous bright pink patch on either side behind the branchiostegal membrane, extending back just beyond level of pectoral base and continuing upward partIy to embrace it, between these patches burnished silver. Head in general Iike trunk similarly bicolor, some pinkish lights on side of snout, silvery on parts of operculum and preoperculum; iris silvery pink with internal and external dusky bounding annuli, pupil silvery.

Dorsal pink, in (b) with five subvertical black streaks on first five membrane panels and some smoky spots or smudges on rest of membrane in anterior two-thirds of fin. Anal and pectoral both pale pink immaculate. Ventral whitish or pinkish, a blackish area near tip not involving outer ray and of diminished intensity on adjoining ray. Caudal minutely and in general rather sparsely punctulated with dark brownish or blackish but overall mostly off-white, a conspicuous mark intensely black with indications of a pink annulus in upper half just behind middle of length, in (a) in the form of a longitudinal elliptical spot with major diameter $3.5 \mathrm{~mm}$, in (b) of similar size but consisting of two longitudinal streaks separated by an uncolored ray, in both specimens an irregular dark patch shortly behind base near upper margin, some faint duskiness at middie of base.

Markings on the caudaI in (a) are overall quite similar to those in the illustration of the Promise Bay fish in Part XIX (1974a, fig.2) though the dark median basaI spot there shown is only faintly indicated here. This figure, the only representation of the species at present availabie, provides no indication of the strong pigmentation found in the upper half of the trunk and tail in both the present examples or of the dark markings on the dorsal fin evident in (a).

\section{General features}

The general features have been tolerably well dealt with in the detailed account of the Promise Bay specimen in Part XIX. However, two additional points caII for notice.

Beyond the fact that they are there noted as being cycloid no information on the scales is recorded. A typical scale exhibits an unusual and highly characteristic form, being subelliptical and notably elongate, modally with the major (longitudinal) axis about $5 \mathrm{~mm}$ the minor axis about $1.5 \mathrm{~mm}$, exposed margin acutely pointed, briefly free of striae; anterior (embedded) border rather more rounded with about a dozen scallopings from which strong primary striae run backward to converge almost to a point at a small ovate focus at about the middle of the length of the scale, the chord of the arc formed by their free extremities one-fourth or less the Iength of the Iongest 


\section{E.O.G.Scott}

(median) stria; closely set between these ridges the usual minute wavy tertiary striae; rest of scale, apart from free tip, with two series, each from about a dozen to about a score, of somewhat sinuous longitudinal secondary striae.

A feature exhibited by the present species and widespread if not universal in the genus Heoodax that has not been the subject of general notice is the presence between the eye and the inferior profile (frequently extending forward in advance of the level of the front of the orbit) of a longitudinally elongate smooth platform suggestive of a facet on a cut gem. This is seldom evident in illustrations such as those in the State catalogues of McGulloch (1922) and of Scott et al. (1974) for New South Wales and South Australia respectively or in the figures in the review of western Australian Odacidae by J.K. Scott (1976). It may be clearly seen (with some undue clarity incidental to the nature of a line drawing) in Part XIX (1974a, fig.2).

\section{Aspects of form}

(a) Head, length to vent, standarl Zength. When these three dinerisions are plotted on a $\log \log$ grid at abscissal values of 1510 they fall effectively collinear. As is usual in comparable computations for other species the full length of the head is taken including the opercular lobe. Of the subioined equations the first is that for the earlier Promise Bay specimen.

$\log L=0.6370 \log N+2.3641 ; t 231.086^{\star *} ;$ measured (predicted) 1engths as mil lesimals of standard length 231(231) 647(645) $1000(1003)$

$\log L=0.6492 \log N+2.3464 ; t 54.901 * ; 233(222) 622(631) 1000(990)$.

$\log L=0.6550 \log N+2.3508 ; t 47.428^{*} ; 223(224) 656(644) 1000(1013)$.

$\log L=0.6429 \log N+2.3553 ; t 143.961^{* *} ; 227(227) 639(638) 1000(996)$.

It is of interest to note that in the other very elongate form, $N$. beddomei, the greater relative length of head ( 340 TLs units as against $223-237$ mean 228.5 for four examples of $N$. attenuatus) is compensated by a decrease in relative length of trunk (343, ef. 399-413.8) of such a magnitude that the logarithmic dimensions length of head length to vent standard length yield a good approximation to linearity $\left(t 17.261^{*}\right)$ when they are plotted on the same abscissal points (logs 1510 ) as those specified above for the present species; though a marginally better fit ( $t$ 19.732*) is found with abscissal logs 1410 . The range of $N$. beddomei, till recently known only from the (lost) holotype and the second Tasmanian specimen described and figured in Part XVI (1969), has now been considerably extended by the report (J.K. Scott 1976) of four examples, Ls 59-98, from Carnac Island and Canal Rocks, Western Australia.

(b) Location of unpaired fins. The locations of the fin origins and terminations along the general anteroposterior axis of the fish are such that in a loglog plot they are significantly linear on 267810 . First equation that for Promise Bay specimen, al1 dimensions as TLS.

$\log L=0.8959 \log N+2.1163 ; t 53.017$; measured (predicted) lengths 241(243) $660(650) 760(747) 847(842) 1000(1028)$.

$\log L=0.8976 \log N+2.0992 ; t 36.039 ; 233(234) 638(628) 739(721) 777(812)$ $1000(993)$.

$\log L=0.8941 \log N+2.1235 ; t 27.492 ; 243(247) 676(660) 794(757) 840(853)$

$1000\left(\begin{array}{ll}1 & 041\end{array}\right)$.

$\log L=0.8852 \log N+2.1178 ; t 76.202 ; 241(247) 649(641) 745(734) 814(826)$ $1000(1007)$. 
Four uranoscopids are known from Tasmania: (a) Kathetostoma Zaeve (Bloch \& Schneider, 1801) (b) Kathetostoma giganteum Hast, 1873 (c) Geryagnus monopterygius (Bloch \& Schneider, 1801) (d) Gnathagnus innotabilis Waite, 1904. Of these (a) appears in all published local lists and was included in the earlier still-unpublished list of Allport, and is not uncommon in our waters, (b) was first reported from this State in Part XX (1974b), (c) is not included in the local catalogues of Johnston (1883, 1891) Lord $(1923,1927)$ Lord \& Scott $(1924)$, but is credited to Tasmania in the Australian Check-List (McCulloch 1929) (no recent occurrences are reported), (d) appears first to have been noted by Mr A.P. Andrews, Curator of Vertebrates, Tasmanian Museum, Hobart, who mentioned to the writer in a letter dated 6 May 1972 he had recently examined an example - Mr P.R. Last, Tasmanian Fisheries Development Authority, informs me this species is noticed in a paper by him the publication of which is expected to precede that of the present communication.

Two specimens of Kathetostoma giganterm recently added to the collections of the Queen Victoria Museum, Launceston are here noticed and observations are made on three examples of Gnathagnus innotabizis from Tasmania and four from New South Wales, including a syntype, courteously made available for examination by the Australian Museum Sydney.

\section{KEY TO URANOSCOP IDAE RECORDED FROM TASMANIA}

1. Scales present. No spine in front of ventral fin.....2

Scales absent. A strong forwardly directed spine

(often concealed in flesh) in front of each

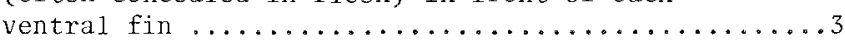

2. Lower jaw normal. A barbel on chin.............. Genyagnus monopterygius

Lower jaw with a pair of large processes meeting in front of chin. No barbel on chin............... Gnathagnus innotabilis

3. D. 13-16. A. 13-15. P. 15-20. With broad clark cross bars, dark blotch on the preoperculum, side not or faintly and unextensively marbled, no white streak

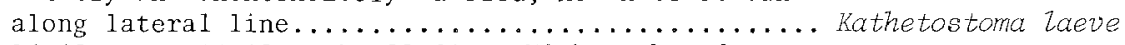

D. 16-18. A. $16-18$. P. 20-21. Without broad

dark cross bars, without dark blotch on the preoperculum, side strongly and extensively marbled usually with inclusion of some white spots or blotches, a white streak along lateral line..... Kathetostoma giganteum

The third Australian species of Kathetostoma, the deep-water $K$. nigrofasciatum Waite \& McCulloch, 1915, known from Western Australia and South Australia, might perhaps be met with in our waters with an increase in trawling. It can be distinguished from the two species keyed above by its having the interoposterior border of the orbit rounded instead of pointed and the minimum width of the naked interorbital region about one-third instead of half or more the total interorbital width.

Genus KAT'HETOSTOMA Günther, 1860

Kathetostoma Günther, 1860, CAT. FISH. BRIT. MUS., 2, p.231. Type-species, Uranoscopus Zaevis Bloch \& Schneider, 1801.

Kathetostoma giganteum Haast, 1873

Kathetostoma giganteum Haast, 1873, Trans. N.Z. Inst., 5, p.274, p1.16, fig.2. Type locality: Heathcote estuary, near Sumner, New Zealand.

Kathetostoma giganteum: Waite, 1911, Ree. Canterb. Mus., 1(3), p.241: Waite \& McCulloch 1915, Trans. R. Soc. S. Aust., 39, p.471: Phillipps, 1921, N.Z.J. Sci. Tech., 


\section{E.O.G. Scott}

4(77), p.123, and 1927, N.Z. Mar. Dept Fisher. Buzl., 1, p.43 (N.Z. references): Mees, 1960, J.R. Soe.W.Aust., 49(3) pp.47 56: Whitley, 1968, Aust. Z002., p.69: Scott, 1974, Pap. Proc.R. Soc. Tasm., 108, p.187.

Kathetostoma Zaeve: Hutton, 1872, CAT. FISH. N.Z., p.23. Non Uranoscopis Zaevis Bloch \& Schneider.

\section{Distribution}

The range of this species was extended from New Zealand to Tasmania by the record in Part $X X$ (1974b, p.187) of a specimen, Ls 316 Lt 390, netted at Coles Bay, east coast, in November 1972 by Mr R. Standage (Q.V.M. Reg. No. 1972/5/617). It was noted that the specimen, which differed strikingly in general appearanco from all 9 examples of Kathetostoma Zaeve (B1och \& Schneider, 1801) on which observations were presented earlier in the same paper, was determined on criteria set out by Waite $\&$ McCulloch (1915), rather than on those of Hast's original account - some difficulties in that account are considered below.

Material

Two specimens (a) Ls 195 Lt 240, trawled off the east coast, $147^{\circ} 32^{\prime}-148^{\circ} 25^{\prime}$ $\mathrm{E}, 41^{\circ} 31^{\prime}-43^{\circ} 10^{\prime} \mathrm{S}$, in 78-107 $\mathrm{m}$ by the Tasmanian Government fisheries vesse 1 Chalzenger in August 1979 (Q.V.M. Reg. No. 1979/5/164) (b) Ls 225 Lt 310, taken by Mr Shane Down in 22 fathoms $(40 \mathrm{~m})$ north of Eddystone Point, east coast, $18 \mathrm{Ju} 1 \mathrm{y} 1979$ (Q.V.M. Reg. No. 1979/5/90).

Meristic characters
D. 16,16 .
A. 17,16 .
P. 20,21 .
C., main rays 11,11 .
V. 1,5 .
of these counts A. 16 and P. 16 are each one fewer than the smallest number given in what is effectively the definitive account of this species, that of Waite (1911).

Dimensions as TLS

A series of 31 measurements made on the specimen of this species reported in Part XX (1974b, p.186) and there recorded along with ranges, means with standard error and coefficient of variation for a sample of 9 examples of Kathetostoma Zaeve have been repeated for the two present fish and are noted below (values of earlier example in parentheses].

Length to origin termination of dorsal 569553 (611) 892851 (927), of anal 545 528 (581) 910939 (927). Length to origin of pectoral 297240 (193), length of fin 374353 (386). Length to origin of ventral, at anterior of girdle 9269 (57) [this measurement is here taken from anteroexternal angle of pre-fin rhomboidal region], at insertion of spine 128118 (95), length of fin, from anterior border of girdle 256271 (282), from insertion of spine 2362.2 (186). Length of caudal 231230 (234). Length to vent (middle) 492536 (541).

Head, to hind border of operculum 297310 (294), to midpoint on hind border of armature 241235 (259). Length to base of humeral spine 385337 (389). Eye, with fleshy rim 5148 (41), without rim 4731 (38). Bony orbit, between midpoints of anterior and posterior borders 5349 (46), between midpoints of lateral borders 5538 (48). Interocular 8789 (85). Snout, from [mesial] tip of upper jaw 2426 (25), from most advanced point (chin) 8578 (79), latter in advance of former by 6152 (54). Depth, maximum 221200 (228), at vent 210196 (209), at caudal peduncle 8786 (87). Width, maximum 297333 (364), at front of eyes 205212 (209), at back of eyes 210255 (275), at vent 236220 (225).

Some other relevant proportions may be noted. Dorsal base 3.10 3.14 (3.16) anal base 2.732 .43 (2.89) in standard length. Dorsal base 1.131 .29 (1.09) in anal base. Length of pectoral 1.261 .14 (1.31) head. Length of ventral 1.391 .46 (1.58) in head. 
122

Tasmanian Fishes

Length to vent $2.031 .96(1.84)$ in head. Maximum depth $1.351 .67(1.60)$ in maximun width.

Specimen $(a)$. Trunk and tail: dorsal surface, its margins virtually defined by the lateral line, with some brief greyish marbling immediately behind head, then wholly black back to level of dorsal origin, beside first one-fourth of dorsal base marbled greyish and brownish, along rest of very narrow strip between lateral line and fin blackish, finally behind fin, where lateral line dips down on caudal peduncle, heavily narbled with very pale greyish; lateral line ovcrall a whitish streak, constituted by small largely confluent or contiguous subeliptical or subcircular whitish patches; upper half of lateral surface wholly mottled with mid brown and pale grey or white, the brown more extensive in one obscure bar back to level of dorsal origin and one below most of hinder two-thirds of the fin base (these dark areas apparently rudiments or vestiges of the distinct dark cross bars found in $K$. Zaeve and in an even more pronounced form in $K$. niarofasciatim); rest of lateral surface and whole of ventral surface pearly white. Head: general color of dorsal surface light greenish brown, naked interorbital basin somewhat more dusky, supraorbital ridges and in lesser degree rest of bony orbit very pale yellowish; that part of lateral surface covered with amount concolorous with dorsal surface, thence greyish mottled with dark brown down to midlateral line, below this more or less whitish with a few obscure greenish brown smudges, no dark patch on preoperculum this region concolorous with rest of head, ventral surface white, lips pale somewhat yellowish green obscurely marbled with greenish brown, inside of mouth white.

Fins: dorsal mostly dark grey, whole of first ray, outer parts of other rays with a brownish streak, occupying half second ray decreasing in extent in remaining rays, absent in last, tips of rays white or off-white; anal whitish, minutely punctulated with brownish or brownish green, this pigmentation wholly absent from ray tips, a very narrow brownish streak just below the small scallops of the membrane; pectoral base and first one-fourth of fin white, rest dark brownish save for white tips to all rays; ventral almost wholly white or whitish, two (right fin) or three (left) faint darkish smudges between rays distally; caudal much like pectoral, tipped with white.

Specimen $(b)$. In general pattern the larger individual closely resembles the smaller. Chief differences: dorsum in advance of dorsal origin not so dark and lacking the brief anterior mottling; marbling on flank not quite so well defined, extending further down, on tail right down to ventral profile; ventral surface isabelline; anal more dusky, especially proximally; pectoral base briefly greyish the light color not extending noticeably on to rays; ventral witn much more extensive dark smudging, overall dark grey except for off white tips of rays.

Aspects of form

(a) Head, length to vent, standard Zength. In both the present specimens and the Coles Bay individual the logarithms of length of head length to vent standard length are significantly collinear on the logarithms of 125 (dimensions below as $T L S$ ). $\log L=0.7544 \log N+2.4704 ; t 57.583^{*}$; measured (predicted) lengths 297(295) $492(498) 1000(997)$.

$\log L=0.7252 \log N+2.4984 ; t 23.578 * ; 310(315) 536(521) 1000(1012)$

$\log L=0.7315 \log N+2.4960 ; t 17.386^{*} ; 293(313) 540(520) 1000(1017)$.

It is of interest to note that when the mean lengths for the 9 individuals of Kathetostoma Zaeve recorded in Part XX (1974b) are similarly treated the graph is 1 inear on 126 .

$\log L=0.6367 \log N+2.5058 ; t 77.486^{* *} ; 320(320) 502(498) 1000(1008)$.

(b) Head in plan. With measurements made at 10 equal intervals ( $N$, counting caudad) and expressed as percentages of length to level of lower lobe of operculum ( $W$ 
the equations for the head in plan of the present specimens are as set out below, together with the corresponding equation for an example of Kathotostoma Zaeve, Ls 375 , from Sandy Beach, Tamar River (Q.V.M. Reg. No. 1972/5/660).

$W=45.18+15.878 N-0.929545 N^{2} ; R 0.9916$; measured (predicted) widths 59(59) $75(73) \quad 84(84) \quad 93(94) \quad 100(101) \quad 107(107) \quad 113(113) 113(113) 111(110)$.

$W=35.52+20.165 N-1.20076 N 2 ; R 0.9981 ; 53(52) 68(68) 79(83) 94(94) 105(103)$ $113(110) 114(115) 115(11.7) 118(117) \quad 114(114)$.

$W=50.78+18.262 N-0.81932 N^{2} ; R 0.9964 ; 72(68) 81(84) 96(98) 110(111)$

$121(111) 121(122) 135(139) 144(144) 148(147) 151(151)$.

Hence for the present examples of K.gigantewm $d W=15.878-1.8591 \mathrm{~N}$ and $20.165-$ $2.4015 \mathrm{~N}$; equating to zero gives maxima for $W$ at $8.54 \mathrm{~N}$ and $8.40 \mathrm{~W}$, the greatest width thus being found at $85.4 \%$ and $84.0 \%$ of the relevant anteroposterior lengths (57 80 rnm), i.e., at 47.7 and $67.2 \mathrm{~mm}$ from snout tip. At -1.86 and -2.40 the tangents are indicative of a decidedly obtuse head, though less obtuse than that of the specimen of $K$. Zaeve examined ( a larger individual LS 375, ef. 195 225) with a tangent of - 1.64. For this material the maximum width in K. giganteum is 1.131 .18 length from tip of snout to level of lower angle of opercular lobe, in $K$. Zaeve 1.51. It should be observed, however, there is some evidence to suggest the possibility that the outline of the head may vary to some extent with overall size of fish (cf. table 5); further investi-ation involving larger samples with wider length ranges is needed before satisfactory interspecific comparisons can be instituted.

(c) Girth. The girth as represented by 10 measurements made at equal intervals from just behind level of insertion of humeral spine to caudal origin is satisfactorily fitted $(R \quad 0.99680 .9990)$ by the following equations, dimensions being given as percentages of the anteroposterior lengths involved (130 $150 \mathrm{~mm})$.

$G=130.24-11.335 N+0.16212 N^{2}$; measured (predicted) girths 123(119) 105(108) $96(98) \quad 85(87) \quad 78(78) 69(68) 62(59) \quad 52(50) \quad 42(41) \quad 31(33)$.

$G=138.94-8.280 \mathrm{~N}+0.15745 \mathrm{~N}^{2} ; 131(131) 121(122) 110(113) 103(103) 95(94)$ $85(84) 73(73) 61(63) 50(52) 41(40)$.

\section{Discussion}

In general form $K$. gigamteum differs little from $K$. Zaeve and K.nigrofasciatum. Unfortunately the history of Haast's species has not been free from uncertainty and indeed error. His original account, which included only one proportional dimension ('length of the head is four times in the total'), instituted no comparison with any other species of the genus (neither of the Australian species $K$. Zaeve nor the subsequently described $K$. nigrofasciatum occurs in New Zealand (Whitley 1968), but $K$. fluviatizis Hutton, 1872, with type locality Manawatu River, New Zealand, predated K. giganteum by a year). The reported fin counts were D.16. A. 16. P.22. C.11; however, Waite (1911, p.243) stated 'an examination of the type specimen shows the formula of the fin rays has been incorrectly rendered in the description', and gave D.18 A.17 or 18. V.I,5. P.22. C.11 (earlier, on p.241, he had noted for his own material P.21). In his basic New Zealand list Waite (1907) omits K. giganteum incorrectly including $K$. Laeve. The ascription to the ventral of five rays (without a spine) is understandable, the spine being wholly included in flesh with the adjoining ray.

Attention may be appropriately called at this point to the question of variability in fin counts met within this genus. A key by scott et al. (1974, p.264) to the three uranoscopids recorded from South Australia (including Ichthyoscopus barbatus Mees, 1960) specifies for $K$. Zaeve 'Dorsal fin with $15-16$ rays; orbit pointed behind' [i.e., at posterointernal border] and for $K$. nigrofasciatum 'Dorsal fin with $13-14$ rays; orbit rounded behind'. Further, in the text the pectoral count for $K$. Zaeve, at 15-16, differs trenchantly from the 19 given for $K$. nigrofasciatum, and there is a difference also in anal counts, namely 14-15 and 13-14. However, in an examination of 9 examples of 
K. Zaeve reported in fart $X X$ (1974b) counts of 13-16 were found for dorsal rays 13-15 for anal rays and 15-20 for pectoral rays. It is thus apparent some current specific diagnoses lack validity in the absence of more satisfactory information on fin counts. An added uncertainty has been noticed by Mees (1960, p.56) 'Günther's (1860) count for $K$. Zaeve is also high, higher than one would expect for that species, and if this count correctly represents the fin-ray formula of his specimen, they are likely to belong to $K$. gigantewn, a species not described at that time, and not to K. Laeve'. A similar confusion surrounds (Philiipps 1927) the count given by Hutton (1872). On the basis of our present knowledge as set out above in the key to uranoscopids recorded from Tasmania the ray counts for $K$. gigarteum and $K$. Laeve are disjunct only in the case of the anal (16-18 13-15) with intersection in the dorsal (16-18 13-16) and the pectoral (20-21 15-20), including, however, for both of these fins a higher maximum for $k$. giganteum.

The illustration provided by Haast $(1873, \mathrm{p} 1.16)$ is clearly inept and is in some features erroneous: Thus the dorsal is shown as originating woll in advance of the anal, while actually, as reported by Waite (1911, p.242), the anai has the more anterior beginning: in the figure the anal originates at about $62 \%$ of the standard length, in our specimens at $5557 \%$. In the figure the dorsal base is approximately 1.2 of the anal base (measured between parallels), whereas in the present examples the shorter dorsal base is 0.880 .74 that of the anal.

Waite \& McCulloch (1915, p.471) state the surface of the exposed bone on the head is sculptured into 'reticulating ridges' in $K$. Laeve into 'tubercles' in $K$. nigrofasciatum, while $K$. giganteum is noted as being distinct from both by virtue of the 'granular' seulpture. While the features mentioned tend to predominate in the three species as described some admixture of the modes occurs so that the nature of the sculpture does not present an absolute criterion.

Together with the regularly greater number of rays in the anal and the generally greater number in the dorsal and the pectoral, $K$. gigantew is most readily distinguished from both the other Australian species of the genus by the color pattern, particularly in the absence of the distinct dark cross bands on the body and in the presence of the marbling on the upper part of the trunk and tail and of a white streak along the lateral line (not reported by Haast); further, from $C$. laeve in the absence of the dark subopercular patch.

\section{Genus GNATHAGNUS Gi1l, 1862}

Gnathagnus Gill, 1862, Proe. Acad. Nat. Sci. Phizad. (1861 session), pp.111 115. Type-species, Uranoscopus elongatus Temminck \& Schlege1.

Gnathagnoides Whitley \& Phillipps, 1939, Trans. R. Soc. N.2., 69, p.235. Type-species, Gnathagnus innotabilis Waite.

\section{Gnathagnus innotabilis Waite, 1904}

(plate 2)

Gnathagnus innotabizis Waite, 1904, Ree. Aust. Mus., 5(4), p.238, pl.16, fig. 1. Type locality: Off Narrabeen, New South wales.

Gnathagnus imotabilis Waite, 1911, Rec. Canterb. Mus., 1, p.243: Phillipps, 1927, N.Z. Mar. Fisher. Buzz., 1, p.43: McCulloch, 1922, Aust. Zool., 2(3), p.102, pl.32,

fig. 28la and 1929, Aust. Mus. Mem., 5(3), p.335: Mees, 1966, J. R. Soc. W. Aust., $43(1), p .47$.

Gnathagnoides innotabilis grandior whitley \& Phillipps, 1939, Trans. Proc. N.Z. Inst., 69, p.235. Type locality: New Zealand.

Gnathagnoides innotabilis grandior: Mees, 1960, J. R. Soc. W. Aust., 43(1), p.47: Whit1ey, 1968, Aust. Zool., 15(1), p.69.

Gnathagnoides innotabilis Whitley, 1964, Proc. Linn. Soc. N.S.W., 89(1), p.53. 
Note on synonymy

With regard to the status of Gnathagnoides whitley \& philipps the writer finds himself in agreement with the view expressed by Mees in his important review of the Uranoscopidae of Western Australia that the differences between Gnathagnus innotabizis and the type species of Gnathagms Gill are 'much too siight to justify generic separation' (1960, p.47); while, again as observed by Mees, the establishment of GnathagGnathagnoides innotabilis grandion solely on the ground of greater size of specimens taken in New Zealand (presumably those noted by waite (1911, p.244), no mention being made of additional material examined) would clearly seem to be unacceptable. (It may be noted in passing that the relevant page number in the 1939 paper of whitley $\&$ Phillipps is given by a typogxaphical error in Mees paper as 225 instead of 235 near the top of $\mathrm{p} .47$, though correctly cited lower in the page.)

Distribution

Originally described from New South Wales - where later McCu11och (1922, p.102) noted it as not uncommon in moderately deep water - it was subsequentiy reported by Waite (1911, p.243) as being represented in five of nine hauls made at 25-94 fathoms (46-172 m) by the New Zealand Government trawling expedition in the Bay of Plenty in 1907. No other localities appear in the Check-List (McCu1ioch 1929). Though it is not inciuded in any of the published Tasmanian catalogues, it is now known to occur here (see note above on the family Uranoscopidae).

\section{Material}

Eight examples, (a) Ls 125 Lt 155, 4 miles ( $6 \mathrm{~km}$ ) southeast of Eddystone Point, east coast, Tasmania, in 20 fathons $(37 \mathrm{~m})$, July 1979 , Mr S. Down (Q.V.M. Reg. No.

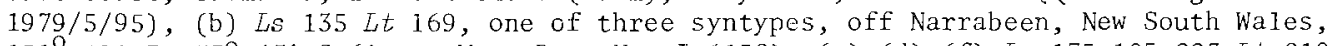
$151^{\circ} 19^{\prime} \mathrm{E}, 33^{\circ} 43^{\circ} \mathrm{S}$ (Aust. Mus. Reg. No. I. 6152), (c) (d) (f) Ls 175185223 Lt 218 223 272, northeast of Babel Island, Bass Strait, in 70-100 fathoms (130-180 m) (Aust. Mus. Reg. Nos. E 4939 E 4940 E 4941, registered 1914, Endeavour), (e) (g) Ls 209225 Lt 255.5 278, off southeast coast, Tasmania, $147^{\circ} 32^{\prime}-148^{\circ} 25^{\prime} \mathrm{E}, 42^{\circ} 31^{\prime}-43^{\circ} 10^{\prime} \mathrm{S}$, trawled in 78-107 $\mathrm{m}$ by the Tasmanian Fisheries Development Authority's vessel Chazlenger, Mr P.R. Last, August 1979 (Q.V.M. Reg. No. 1979/5/163), (k) Ls 252 Lt 310, off St Helens Point, east coast, Tasmania, in 5 fathoms (9 m), Mr S. Down, 1 August 1978 (Q.V. (Q.V.M. Reg. No. 1978/5/101). The courtesy of the Australian Museum in making available for examination specimens (b) (c) (d) (f) is gratefully acknow1edged.

\section{Meristic characters}

D.12 (7 specimens) 13(1). A.15(1) 16(7). P.19(3) 20(1) 21(4). C. total rays 15(2) $16(3) 17(3)$, branched $10(4) \quad 11(4)$, reaching distal border 10(1) $11(7)$. Gi11 rakers on lower limb of first arch about 17-20, low mounded each with several acute processes.

Dimensions

A set of dimensions of 1118 examples is set out in table 3 , the first line, standard length (LS), being in millimetres all other lines as thousandths of standard length (TTSS).

\section{Proportions}

For al1 the 11 proportions selected by waite for record in the original account of the species there are here given the range and the mean (with standard error) for our material with Waite's variates in parentheses. Head in total 1ength 3.2-3.7

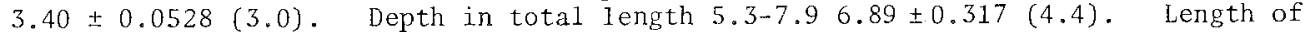
head in width of head $0.8-1.10 .87 \pm 0.306$ (width one-fourth more than length). Eye in head 5.4-6.9 5.84 $\pm 0.179(4.3)$. Interorbita1 in head 2.6-3.3 2.99 $\pm 0.0883(2.2)$. Snout in head, measured from midpoint of front of upper jaw 6.3-9.6 8.19 \pm 0.363 , from level of front of maxilla 4.7-6.9 5.68 \pm 0.274 , from most advanced point (chin) $3.0-3.7$ $3.33+0.079$ (convention of measurement not specified 6.5 ). Depth of caudal peduncle 
in head 4.2-5.2 4.77 \pm 0.128 (3.5). Length of pectoral in total length 3.3-6.5 4.67 $\pm 0.425(4.0)$. Length of vontral in total length $5.0-7.26 .25 \pm 0.231$ (5.2). Length of cauda I in standard length $4.1-5.04 .47 \pm 0.117$ ('4.3 in the body'). Anal base in head $0.9-1.11 .02 \pm 0.0265$ ('slightly more than the length of the head').

Some further significant ratios may be noted. Dorsal base in standard length 3.9-4.6 4.17 \pm 0.0712 . Nnal base in standard length 2.6-3.1 2.85 \pm 0.785 . Dorsal base in anal base $1.3-1.61 .44 \pm 0.0354$. Length of pectoral in head $0.9-1.41 .13 \pm$ 0.0554 , of ventral 1.5-2.2 1.85 \pm 0.213, of cauda1 1.6-1.7 1.61 \pm 0.0176 . Maximum depth of head in head length $1.6-2.52 .0 \pm 0.102$, in maximum width of head 1.5-2.0 $1.75 \pm 0.470$.

Of the above ratios four exhibit significant positive correlation with standard length, namely, length of pectoral in head $r 0.912$ ( 31.540 ) $t 5.442 * *$, length of ventral in head $r 0.941(z 1.746) t 6.804^{* * *}$, length of ventral in total 1 ength $r 0.865$ ( $z 1.314) t 4.230^{* *}$, maximum depth of head in head length 20.871 ( $z 1.337$ ) $t 4.343^{* *}$. One ratio, length of head in width of head, is correlated negatively with standard length, $x-0.795(z-1.084) t 3.206^{*}$.

General features

Our basic knowledge of this species is afforded by the original description (Waite 1904) based on three syntypes from New South wales, the subsequent notice by Waite (1911) in his report on the New Zealand Government trawling expedition of 1907 merely extending range and overall size, and no additional information on external features being provided by Whitley \& Phillipps (1939) in establishing their genus Gnathagnoides and in proposing a New Zealand subspecies G. innotabizis grandior. immediately following observations, based primarily on the largest Tasmanian individual, supplement and make minor emendations to the original account, while a later section, Aspects of form, explores some characters not previously investigated.

More or less fusiform. Pectoral reaching to level of vent or to just beyond anal origin. Ventral reaching about to level of pectoral base. Caudal truncate.

A characteristic feature is the presence on the head of the curious plectroid processes that cover most of the chin, constituting the effective front elevation of the head. The greater part of each process is tolerably rigid, brown mottled with grey; upper border of each in contact with outer one-third of lower lip, extending down and back beyond lip to end of mandible, in upper one-third remaining in contact with one another, in lower one-third their bluntly rounded free ends meeting and touching or freely overlapping, in middle one-third largely continuous but leaving a median elliptical opening, its width twice its height subequal to length of orbit, the chin here being exposed to view as through a window; greater part of each process tolerably rigid, brown irregularly mottled with grey, lower border from middle of lower margin of window down and back to vertical level of end of lower lip constituted by a white and off-white strongly denticulate and ridged soft fleshy edging. Mouth cleft large, vertical, lips wholly lacking cirri. Nostrils minute, approximately in line with highest point on orbit, anterior subcircular with low rim and very small tentacle, posterior a slit with a low rim with an obscure fleshy fringe. Teeth in upper jaw rather widely spaced small slender acute recurved depressible, mostly in two rows those of inner row larger (several near median line larger than remainder) and often set alternately with those of outer; in lower jaw much as in upper but somewhat larger; on vomer two ovoid patches, interspace subequal to width of one, each with half a dozen small teeth similar to those in jaws interspersed among more numerous small mammilliform elevations (contrast Waite 'villiform'); on pharyngeal on each side a patch much as on a moiety of vomer. Tongue with minute ridges or lines of papillae, chiefly transverse. A minute fleshy lobe, usually wholly white, at the symphysis of the premaxillae. 
E.O.G. Scott

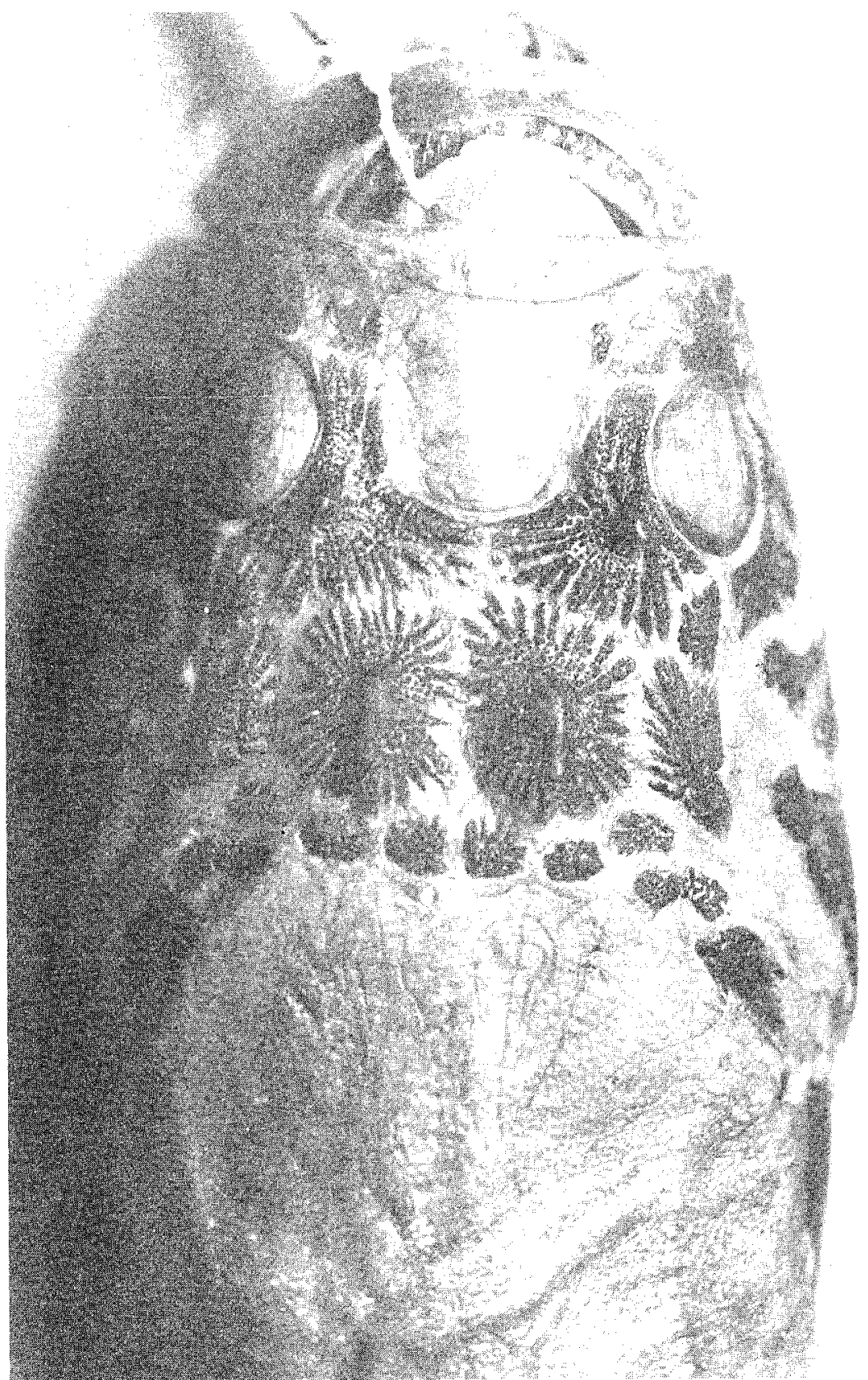

PLATE 2. Gnathagnus imotabilis Waite, 1904. Dorsal aspect of head of a specimen, standard length $223 \mathrm{~mm}$, total length $272 \mathrm{~mm}$, northeast of Babel Island, Bass Strait, in 70-100 fathoms (130-180 m) (Australian Museura Reg. No. E 4941, registered 1914, Endecnour), x 1 1/2. (Photograph R.H. Green). 
Bony armour on head as illustrated (plate 2). Most important features: a pair of apposed occipital plates together constituting a trapezoid, its wider (posterior) border half width of head here, each with a short thick median ridge or longitudinally elongate boss occupying middle thjer of the length ('a longitudinal ridge passing from its middle backwards') from which radiate upwards of two dozen short straight much lower ridges forming a rosette; an ill-defined broken ridge running back and out from posterolateral angle of orbit towards humeral spine; inside this and in advance of occipital rosette of fan of 10-12 ridges; a fan of about a dozen ricges radiating from top of operculum to its lower margin; a smaller fan directed in opposite sense on preoperculum; preorbital rugose with $2-3$ small upwardly convex ridges reaching its anterior border; a rugose strip with 2-3 ill-defined ridges running from near posteroexternal angle of occipital plate towards humeral spine, the latter small flattened blunt, or moderately pointed directed back and slightly down, almost flush. In the syntype and the Tasmanian specimens 4-5 small rather obscurely defined mostly subcirculax plates with rosettes of ridges can be made out along and somewhat beyond hind border of each occipital plate with which the inner ones are continuous: in the Endeavour specimens (b) (c) (d) these plates are islands and being dark purplish or almost black on a light brownish background form a conspicuous part of the ornamentation (plate 2). Interocular basin occupied only by naked integument more or less trapezoidal, somewhat rounded at its posterior border, its width behind one and a half times that in front, latter about four times shortest distance from the side to supraorbital ridge.

Scales occur on dorsal and lateral surfaces of trunk and tail, being absent from a small median patch, sonewhat larger than eye, just behind occipital plates, from a narrow strip along each side of dorsal and anal bases and from inner surface of pectoral base; on ventral surface present backwards from near level of vent; continued on to caudal base and up the rays and membrane for some two-thirds of fin length. Waite observes they 'lie in depressions resembling the pits of a thimble'; however, these pits occur oniy on the dorsal surface, scales on ventral surface of tail. being quite flush. A scale from dorsum shortly behind head is cycloid lanceolate, rounded at exposed pointed at embedded end; length about $1.7 \mathrm{~mm}$ about three times greatest width; exposed pigmented portion accounting for only about one-sixth of length; focus of striae shortly behind pigment: a scale from ventral surface near anal origin similar but sonewhat smaller, lacking patch of pigmentation.

The lateral line is noted by waite as arising above the humeral spine and running an undulated course to the middle of the caudal fin. In the largest Tasmanian example the two lines originate $53 \mathrm{~mm}$ apart above the humeral spine by about the spine's 1 ength, run almost straight approximating backwards to be 40 apart an eye diameter in advance of dorsal origin, continuing in a course at first gently concave inwards then gently convex to level of dorsal termination, here 20 apart, thereafter turning slightly downward to meet the caudal base equidistant from dorsal and ventral borders of the peduncle.

Aspects of form

(a) Head, zength to vent, standard length. On a $10 \mathrm{~g} 1 \mathrm{~g}$ plot these three cardinal lengths are collinear when the abscissal values are 127 . The relevant statistics are exhibited in table 4: it will be seen that in one of the eight cases significance falls just short of the formally acceptable level of $\mathrm{P} 0.05$.

(b) Head. From the most advanced point of the head, the chin, modally located at some three-sevenths of the height between the distal border of the maxilla and the top of the lips, the dorsal profile rises briefly but sharply in a convex or biconvex curve to level of mouth cleft behind which the remaining head profile is virtually horizontal, while from the chin the lower part of the profile slopes back and down at an angle of $40^{\circ}-50^{\circ}$ to below the much-expanded maxilla thereafter continuing horizontally. 
As table 3 renders evident the anterior border of the maxilla extends in advance of the level of the midale of the upper lip.

In plan the head is parabolic. Widths $(W)$ have been measured at 10 equal intervals ( $N$, numbered caudad) between most advanced point and level of opercular at visual ventral plane for all specimens and second-degree equations calculated - statistics being set out in table 5 . In these equations and in the discussion below widths are expressed, to permit valid comparison between individuals, as percentages of the relevant anteroposterior longths.

Though highly acceptable fits in genexal result $(R 0.8649-0.9989, \bar{x} 0.9759)$, the parameters exhibit some noticeable variation and the general head outline differs greatly in small and larger individuals, the anterior border of the snout being quite obtuse, almost transversely linear, in the former and well rounded in the latter: indeed, a comparison of our specimens (a) and (h) without reference to other examples of intermediate size might well suggest the existence of two species. Reference to the table shows the tangent manifests a general trend towards decrease in magnitude from the smallest fish to the largest but one, the largest apparently being an outlier. With the omission of the last-named value the remaining 7 entries show significant negative correlation with standard length indicative of increase in pointedness with overall size (and presumably age); $x^{*}-0.854(z-0.636) t 4.868^{* *}$. The greater relative width anteriorly in the smaller examples is strikingly evident in the following data: relative width (percentage of head length) at the level of the most anterior measurement ( $N=1$ ) ranges from 65.1 in the smallest individual to 34.7 in the largest and is significantly correlated with standard length, $r-0.923(z-1.161) t 5.893^{* *}$; similarly for $N=2, r-0.908(z-1.515)$ t $5.300^{*}$; for $N=1$ as a fraction of maximum value of $N, r-0.799(z-1.097) t 3.259 *$

Not only the form of the outline of the head but also the relative area of the dorsum as a whole is age (or size) related. Thus the sum of the 10 widths expressed as percentages of the conventional length of the head ranges down from 98.51 in the smallest fish to 73.92 in the largest, the correlation with standard length being $r-0.794(z-0.885)$ t $3.202 *$.

(c) Disposition of fins. The lengths from snout tip to the origins of the pectoral anal dorsal, to the terminations of dorsal anal and to the origin of the caudal are such that when plotted in that sequence on a loglog grid they fall collinear when given as abscissal values the integral numbers 1347810 . The relevant regression equations are set out in table 6 , al1 dimensions being given as thousandths of standard length.

(d) Trunk and taiz. The single visual unit presented by the combined trunk and tail is a simple one. Though viewed from above the sides are very slightly convex the general outline comes very close to a briefly truncated triangle with the widths at the middle and the posterior end of the region being 0.60 .1 that at the anterior end. In the largest Tasmanian specimen the first-degree equation derived from 10 measurements of width taken at equal intervals, $W=0.4061 \mathrm{~L}+78.9$ (measurements in mm) reaches a correlation of $\gamma^{\prime} 0.997$ ( $t 38.942^{* *}$ ). The anterior one-third od the dorsa1 profile scarcely departs from the horizontal line of the head but thereafter slopes down to a progressively greater but never large degree.

The resultant girth presents a gently sigmoid curve. With $G=$ girth as percentage of length from back of head to caudal origin (171 mm) $N=$ serial number of measurement (10 taken at equal intervals) $G=112.39+3.813 \mathrm{~N}-0.5054 \mathrm{~N}^{2} ; R 0.9361$; measured (predicted) girths $108(108) \quad 102(103) \quad 95(96) \quad 90(89) \quad 83(81) \quad 73(71) \quad 61(59) \quad 46(50) \quad 35(37)$ $27(24)$. 
(e) Ventral surface, mouth. From the ievel of the mouth to the caudal origin the ventral surface is virtually plane. The broad flat fleshy character of the ventra1s, their mode of attachnent without an elevated base and the presence of a slight depression into which they fit when adpressed combine to make them in the prone position effectively rlush with the surrounding surface; the anal when folded to one side produces a negligible departure from the general homaloidal condition; while the lowermost ray of the caudal continues (even when the fin is fully expanded) as near as may be collinear with the lower margin of the caudal peduncle. These features may be presumed to represent a very efficient adaptation permitting the fish to rest in full and $\mathrm{close}$ contact with the bottom when observing the general habit of members of this family of lying motionless in wait for prey. It is of interest to note that in the common Tasmanian uranoscopid, Kathetostoma Zaeve (Bloch of Schneider, 1801), in which the ventral fin is insorted partly on the lateral surface the presence of a depression into which it can fit serves again to maintain the planar character of the fish's ventral surface. Also related to the specialized feeding habit is the large and unusually positioned mouth, the anterior border of the upper $j \mathrm{dw}$, which extends through more than two-thirds of the height of the head, being quite vertical.

(f) Fins. While the general observations here made are applicable to all five specimens examined, metrical data for the dorsal anal and pectoral fins are recorded for the largest Tasmanian individual only.

The dorsal has the first 3 rays simple, the remainder to the 11 th dividing for an increasing fraction of their length up to a maximum of about a ha1f; last 2 rays only briefly divided. The length increases from 1st to 5th then decreases to 13th (last), which is very slender and very close to the $12 \mathrm{th}$, separated from it by an interval, less than one-sixth that between 12 th and 11 th. For the ascendant series $L=b N^{k}$ for the descendant $L=b N^{\prime k}$, where $L=1$ ength, $\mathrm{mm}, N=$ serial number of ray counting caudad, $N^{\prime}=$ serial number counting dephalad.

$\log L=0.3232 \log N+1.3374 ; t 7.656^{* *}$; measured (predicted) lengths $21.5(21.7)$ $27.5(27.2) \quad 31.5(31.0) 34.2(34.0) 35.9(36.6)$.

$\log L=0.8217 \log N+0.7693 ; t 37.665^{* *}$; measured (predicted) lengths $6.0(5.9)$ $10.7(10.4) 13.1(14.5) \quad 18.5(18.4) 22.5(22.1) 26.5(25.6) 28.7(29.1) 33.0(32.5)$.

Anal membrane more nearly opaque than dorsal; rays strongly recurved having much the general appearance of a hockey stick, much stouter than those of dorsal, consisting of a rachis, fairly rigid in proximal but quite flexible in distal half, divided in distal one-third or so the rami running close together, as in dorsal ramal tips projecting beyond membrane but here only microscopically. Length increasing to 9 th, this ascendant set comprising two subsets, the loglog graph after being linear over logs 1-5 then becoming interrupted to continue as a second linear segment, with a greater gradient, on logs 6-9. This pattern is an unusual one. It is in general found that where the ascendant or descendant rays (or spines) do not constitute a single series either they represent two separate series characterized by the fact that the first element of each is appropriately plotted on $\log 1$ or if the whole sequence of logarithmic abscissae is a continuous one it presents a point of inflexion, not being disjunct as here. Behind the 9 th the rays regularly decrease in length caudad, their logarithms being linear on $\log s$ 1-7 when plotted in reverse order, i.e., cephalad $\left(N^{\prime}\right)$. Lengths below in $\mathrm{mm}$.

$\log L=0.2724 \log N+1.1296 ; t 16.443^{* * *}$; measured (predicted) lengths $13.4(13.5)$ $16.4(16.3) \quad 18.5(18.2) \quad 19.1(19.7) 21.1 .(20.9)$

$\log L=0.4525 \log N+1.0152 ; t 10.622 * ; 23.5(23.2) 24.6(25.0) 26.6(26.2) 28.8$

$\log L=0.1364 \log W^{\prime}+1.3241 ; t 21.120^{* * *} ; 21.1(21.1) 23.2(23.2) 24.5(24.5) 25.5$

(25.5) $26.1(26.3) 27.1(26.9) 27.5(27.5)$. 
Pectoral membrane tolerably opaque and fleshy; rays dimorphic the 11 lower with broadly rounded or bluntiy pointed tips the outline wholly provided by the membrane, the rest noticeably more slender and with the $2-4$ ramal tips slightly projecting. In $\log \log$ plots for the largest Tasmanian specimen the rays of the upper border are significantly linear when plotted in the sequence 9-1 on their inverse serial numbers $1-9$ $\left(N^{\prime}\right)$ giving a negative slope while those of the lower border plotted in the sequence 20-10 on their inverse set serial numbers 1-9 yield a significant positive slope.

$\log L=-0.1051 \log N+1.7342 ; t 14.090^{* * *}$; measured (predicted) lengths, mm,

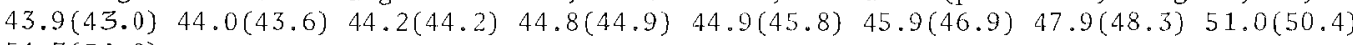
$54.7(54.2)$.

$\log L+0.8497 \log N+0.8654 ; t 77.162^{* * *} ; 55.2(56.3) 53.0(51.9) 49.0(47.5) 41.6$ (42.9) $35.0(33.6) 28.8(28.8) 24.0(23.8) \quad 18.7(18.7) \quad 13.9(13.2) 7.1(7.3)$.

The fin is set low, the bottom of the base being actually on the ventral surface the top about at half the total height at that level.

The ventral fins are massive fleshy organs markedly dissimilar from the tolerably fine and delicate ventrals of most of the Jugulares; rays flattened blunt much divided enclosed in membrane, spine wholly bound up with adjoining ray recognizable only with difficulty, fin bases set close together separated by an interval less than (modally about half) base width, inserted about at level of hind border of orbit. The total restriction of the two fins to the planar ventral surface has already been noted.

With 1st ventral ray defined, as proposed in Part XIX (1974a, p.248) as that nearest to medioventral line of fish (postaxial, farthest from spine), in the most frequently encountered fin pattern the rays increase from $15 t$ to 4 th, 5 th being somewhat shorter than 4 th but noticeably longer than spine. (While the preaxial location of the ray nearest the spine might suggest its selection as the conventional 1 st as a logical one, the usual increase in length of the rays taken outwards influenced the choice made, account being taken of the convenience of having this length-number graph, like others then under observation, exhibiting a positive slope.) The pattern here met with is quite dissimilar, five elements, including the spine, increasing in length in sequence postaxially, with the ray here designated the 1st slightly shorter than its neighbour. With lengths of spine and rays 5 th-2nd plotted on a $\log \log$ grid against the natural numbers $1-5$ the graph is significantly linear: the data for al1 8 fish are recorded in table 7, lengths being presented as millesimals of standard length. It is to be noted the formula here employed is not a precise one, predicted values for the 2nd ray being consistently higher than measured lengths (difference 3-6 mean 4.5 percent), with predicted values for the 3 rd ray concomitantly consistently lower (difference $0.6-5$ mean 2.8 percent).

The tabulated relative (TLS) lengths are seen immediately to tend to be larger among the smaller individuals: indeed the sum of the lengths of the spine and the four radial elements considered decreases consistently from specimen (a) to (g), with an increase being shown by (h). The correlation of this sum of lengths with standard length gives $r-0.784(z-1.065)$, significant at better than $P 0.05(t 3.096)$.

\section{Coloration}

Some differences in coloration are found between the Tasmanian specimens (a) (e) (g) (h) and the Australian Museum specimens (b) (syntype) (c) (d) (f) (these latter having perhaps suffered some decoloration consequent upon longer preservation) and between all of these and the coloration as described by Waite. The immediately following account is based on the local examples.

Dorsal surfaces of trunk and tail and lateral surface down to midlateral level or somewhat below dark brownish or slate, more or less uniform in (a) (h), in (e) with a number of small subcircular dark grey spots in (g) with some obscure dark splashes. 
Waite noted body brown 'with indistinct brown spots'; no such markings evident in our material. Lower lateral surface and whole ventral surface immaculate white in (a), off-white in others with dusky or smoky smudging, most pronounced in (e) confined in (h) to less than half total surface; line of demarcation between dark upper and light lower flank very sharp in (a) well defined in (h) rather indefinite and obscure in others. Waite reported 'sand-coloured areas, below the head, at the base of the ventral fins and on the belly'; such areas not identified here. Dorsal surface of head in general much like that of trunk, but in (h) plated areas warm brown with the conspicuous ridges dark yellowish; naked interorbital rogion uniform and concolorous with dorsum of trunk in (a) and (h) but in (c) with an extensive splash in (g) with several smaller splashes of light grey; lateral and ventral surfaces resembling those on trunk, distinctly lighter approaching white on hind part of operculum in (a) and (h). Lips concolorous with snout. Irside of mouth white in (a) whitish in others.

Dorsal rays usually light or dark grey except for white divided tips, in (h) with noticeable darkening in distal one-third or less; membrane whitish or pale grey, in (a) somewhat darker in first two interradial panels, in (g) each panel with a triangular dark slip widest distally extending down through whole height between posterior rays and for about an equal absolute distance between anterior rays. Anal rays white in (a) and (e) off-white in (h) reddish brown in (g); membrane wholly white in (a) in others off-white with variable amounts of sparse minute dark punctulation; Waite 'the anal has a median longitudinal brown band'. Pectoral in (a) blackish, lower rays a little lighter, very clearly defined external border of white, in others mostly brownish or dark greyish, some irregular areas lighter than the rest, ray tips close to white; fin base white or whitish, light color extending variably on to bases of rays. Ventral wholly white in (a) in others whitish or light grey with some dusky smudging most pronounced in (h). Caudal much like pectoral but overall somewhat lighter, tipped white, in (a) (e) (h) lowermost ray white sharply contrasting with others.

Specimens (b) (c) (d) (f), which have been subjected to longer preservation, tend in general towards brownish, the smallest (syntype) noticeably lighter than the rest in parts approaching straw. The Endeavour specimens differ strikingly from the syntype and from all the Tasmanian fish in having the main plated areas on the dorsum of the head dark purplish or blackish; the small detached shields forming a line immediately behind the posterior border of the large continuous armoured region that in the syntype and in the local examples are concolorous with the trunk and barely evident are here also dark purplish almost black, constituting a conspicuous feature of the color pattern.

Comparison with Kathetostoma zaeve

Gnathagnus innotabilis is at once distinguished from the common Tasmanian uranoscopid Kathetostoma Zaeve (Block \& Schneider, 1801) by its possession of scales (though these are inconspicuous) and of the remarkable mental processes that obscure all save a small elliptical area of the chin. Some other important differences may be noted. For typographical convenionce the two forms are here denoted by $G \cdot i$. and $K$. $Z$. respectively.

G. $i$. has fewer dorsal rays $(12-13 \mathrm{cf}, 15-16)$ : the pectoral count (19-21) stands wholly outside that $(15-16)$ conventionally given, e.g. Scott et al. (1974) for K.2. but decidedly higher values for that species (18-20) have been reported in Part XX (1974b). A feature originally usefully employed by Waite \& McCulloch (1915, p.471, figs 1,2, p1.13) in differentiating between $K .2$. and their Kathetostoma nigrofasciatum is the form of the naked basin-like interorbital region, and this criterion has since been extended to cover other species (Scott et al., fig. on p.264, Mees 1960, fig.5). In $G . i$. the posterior border of this region lies in advance of level of posterior border of orbit, modally by about one-fourth eye diameter, in $K .2$. behind it by an eye diameter 


\section{E.O.G. Scott}

or more; further, whereas in G.i. ( $\varepsilon$ in $k$. nigrofaseiatum) the orbit as defined by the well developed circumorbital ridge is complete, in $k .2$. it is interrupted at the posteroexternal angle by a small spur. In G.i. the occipital region presents a pair of conspicuous longitudinal ridges or elongated knobs set side by side with radiating from each a conspicuous series of short ridges; in K. 2 . this area wholly lacks these structures, having the form of a single flat or somewhat concave subquadrangular plate defined by low ridges. Circumoral cirri are absent in $G . i$. well developed and in $K . Z$ (and in $X$. giganteum).

In $G . i$. the ventral fins are inserted wholly on the ventral surface, so positioned that the outline of the body from the pectoral runs forward wholly externad of the fins, the lines of the right and left sides meeting at a tolerably sharp point; in $K .2$. the insertion of the ventral fins is in some measure lateral so that when normally disposed they obscure part of the body outline, while in advance of the fins the ventral surface tends to widen, with some straightening of the two sides, thus terminating anteriorly not in a triangle but in a truncated pyramid around the front of which the branchiostegal membranes make a broad slow curve (in specimens comparable in size with our largest $G . i$. there is here developed a platform the area of which exceeds that of the orbit). In K.Z. two stout tolerably pungent forwardly directed spines, often embedded in the flesh, occur at the lateral borders of the prepelvic region; these are not present in G.i. and are a generic character of Kathetostoma. The lateral lines converge caudad less noticeably in $G . i$. in which the intervals between them at the levels of dorsal origin and dorsal termination are around 0.70 .4 that at their anterior ends, the corresponding figures for $K . Z$. being around 0.40 .2 . The presence in $G$. $i$. of the strong plectroid processes developed on either side of the chin leads to the anterior profile of the head in side view taking the form of a markedly convex curve; in $K$. $Z$. it is not far from being rectilinear. In $G . i$. the length of the dorsal base is about one-fourth of the standard length and is modally less than the interval between the origin of the fin and the posterior border of the dorsal cephalic armour, in $K$. $z$. about one-third and modally equal to or greater than that interval. The large fan-shaped opercular plate with about a dozen ridges, ranging from moderate to strong, radiating from the upper angle that forms a conspicuous part of the armature in $G . i$. is in $K . l$. normally covered with skin, the whole region being smooth and superficially soft. In K. 2. the eyes are wholly dorsal, in G.i. partly lateral. The color patterns are characteristic, the most obvious points of difference being the dorsal mottling on the body in $G, i$. and the dark subopercular dark blotch in $K . Z$.

Comparison with other species of Gnathagnus

Three species of Gnathagnus Gil1, 1861 are now recognized (Mees 1960): (a) Uranoscopus elongatus Temminck \& Schlege1, 1843 (type species of Gnathagnus type locality, Japan) (b) Gnathagnus innotabilis Waite, 1904 (type 1ocality, off Narrabeen, New South Wales) (c) Benthoscopus Laticeps Longley \& Hildebrand, 1940 (type species of Benthoscopus Longley G Hildebrand, 1940 type locality, off Tortugas, Florj.da). Species (c) has been clearly shown by Myers (1946) to belong to Gnathagnus with which its authors in proposing Benthoscopus did not compare it. In contrasting his species with $G$. elongatus as described by Jordan \& Snyder (1902) Waite remarked 'In their generic diagnosis these authors write "humeral spine obsolete", yet describe the species as having a "partly concealed humeral spine"': the original account (Temminck \& Schlegel 1843, p.27) stated clearly enough 'L'os de l'épaule sort de la peau en forme d'épine conique et un peu dirigée en haut'. It may be remarked in passing that while in his general description Waite characterized the spine as 'of moderate size, fully exposed' in some of our specimens a noticeable portion of it is embedded in flesh. Waite's statement 'there is a blunt prominence at the angle of the preopercle' would seem to imply, in the context in which it occurs, that this feature was not noticed by Jordan \& Snyder: the original figure (p1.9, fig.2) appears to depict a largish bluntly rounded prominence at the angle. The plectroid mental dilatations of (b) are noted by waite 
as rounded, lacking the 'free pointed tip above' described and figured for (a): in our material the upper angle of the distal border while not produced into a distinct process is nevertheless in some individuals tolerably pointed. Some comparison of the three species was made by Myers in the paper in which he identified Longley \& Hildebrand's fish as a member of the present genus. In the subjoined assessment the data for (a) and (c) are derived from the literature, without examination of specimens.

Teeth biserial in both jaws in (a) (b), in (c) stated to be 'in a single series in lower jaw' (Longley \& Hildebrand 1940, p.266). The humeral spine in (a) and (b) has been discussed above; in (c) it is larger and more conspicuous, strongly curved upward. Dorsal with 12 rays in (b) 13 in (c) 14 in (a); fin base in (b) $3 \frac{1}{2}$ in total length and about 1.5 in head measured from upper jaw, in (b) (c) 3 and about 1.0 ; 1 owest in (a) height about 3 in head length as before, in (b) (c) about 2 . In (a) (c) ventral figured with spine well separated from adjoining ray, in (b) figured as closely apposed to ray but in our material bound up with it in common integument. Gi11 rakers on lower limb of anterior arch 14 in (c), in (b) not reported for type in our specimens $\$ 17$. Pectoral in (a) strongly rounded in upper two-thirds partly straight and partly gently convex in lower one-third, in (b) figured much as in (a) but in our examples more or less squared off or somewhat concave in greater part of lower half, in (c) with upper and lower quarters convex middle half concave (outline quite an unusual one and highly characteristic). In the illustration of the upper surface of the head of (c) (fig.21) the two large occipital plates are asymmetric, partly separate, with the right well in advance of the left: in our material of (a) they are in full contact in the Tasmanian but not in the Endeavour examples and constitute a pair in respect both of form and of location. Chief elements of color pattern in (a) very numerous subequal ovoid spots about their own diameter apart ('parsemé de petites taches foncées, très nombreuses et très serrées'), in (b) indistinct brown spots present or absent, in (c) 'very many fine spots and dashes of olive scattered at random.' The line of about half a dozen small separate plates lying behind the large paired occipitals and extending out on either side towards the plate in the supratemporal region noted for (a) ('à la base de la crête occipitale, une rangée transversale d'assez petits') is in (b) for the most part contiguous with the posterior borders of the occipitals in the syntype and in the Tasmanian examples, but is clearly separate from them in the Endeavour fish; no plates are figured in this region in (c). The occurrence in (a) of naked regions between elements of the cranial armour is the subject of comment both in the description of type material ('ces plans sont en grande parte isolés, ils sont séparés les uns des outres par une peau nue, à surface lisse, laquelle est diversement coloriée que les plans-mêmes, qui sont par cette raison assez

apparents') and in the diagnosis of Gnathagnus with (a) as type-species, 'Head with the osseous compartments of its superior surface mostly separated by smooth intervals' (Gi11, 1861, p.115); in (b) the relative area of these would appear to be no greater than that found in, for instance, Kathetostoma laeve (indeed, if the operculum be included for comparison it is less), and the distinction in color between plates and the intervals between them while pronounced in the Endeavour specimens is in general barely evident in the others; in (c) as figured the naked area is proportionately somewhat larger than in (b). 


\section{E.O.G. Scott}

TABLE 3

GNATHAGNUS INNOTABILIS WAITE, 1904

Dimensions of 8 specimens, (a) off Eddystone Point, east coast, Tasmania (b) off Narrabeen, New South Wales (one of three syntypes) (c) (d) (f) off Babel Island, Bass Strait (Endeavour) (e) (g) off southeast coast, Tasmania (h) off St Helens Point, east coast, Tasmania. First line in millimetres all other lines as thousandths of standard length.

\begin{tabular}{|c|c|c|c|c|c|c|c|c|}
\hline Dimensions & (a) & (b) & (c) & (d) & (e) & $(f)$ & $(g)$ & (h) \\
\hline Standard length & 125 & 135 & 175 & 185 & 209 & 223 & 225 & 252 \\
\hline Total length & 1240 & 1252 & 1246 & 1205 & 1222 & 1220 & 1236 & 1230 \\
\hline Length to origin of dorsal & 648 & 578 & 623 & 605 & 603 & 628 & 609 & 619 \\
\hline Length to termination of & & & & & & & & \\
\hline dorsal & 896 & 807 & 846 & 849 & 856 & 868 & 844 & 861 \\
\hline Length of longest dorsal ray & 144 & 156 & 131 & 111 & 132 & 126 & 113 & 142 \\
\hline Length to origin of anal & 584 & 541 & 526 & 573 & 555 & 561 & 560 & 556 \\
\hline Length to termination of & & & & & & & & \\
\hline ana1 & 976 & 874 & 920 & 908 & 934 & 942 & 884 & 933 \\
\hline Length of longest anal ray & 108 & 104 & 111 & 97 & 103 & 94 & 98 & 114 \\
\hline Length to origin of pectoral & 320 & 282 & 286 & 292 & 301 & 287 & 298 & 298 \\
\hline Length of pectoral, whole fin & 384 & 363 & 360 & 292 & 321 & 287 & 307 & 274 \\
\hline Length of longest pectoral & & & & & & & & \\
\hline ray & 312 & 237 & 291 & 224 & 246 & 242 & 244 & 230 \\
\hline Length to origin of ventral & 196 & 163 & 171 & 168 & 158 & 143 & 169 & 159 \\
\hline Length of ventral, whole fin & 248 & 230 & 240 & 249 & 199 & 238 & 189 & 222 \\
\hline Length of longest ventral & & & & & & & & \\
\hline ray & 208 & 193 & 205 & 175 & 175 & 169 & 169 & 173 \\
\hline Length to vent (middle) & 544 & 526 & 537 & 535 & 536 & 525 & 529 & 536 \\
\hline Length of head & 376 & 326 & 383 & 346 & 349 & 359 & 364 & 381 \\
\hline Length to base of humeral & & & & & & & & \\
\hline spine & 352 & 319 & 366 & 357 & 330 & 363 & 351 & 345 \\
\hline Length of eye & 64 & 60 & 69 & 64 & 63 & 63 & 58 & 56 \\
\hline Height of eye & 62 & 52 & 68 & 57 & 48 & 58 & 57 & 48 \\
\hline Interorbital & 138 & 127 & 126 & 114 & 117 & 120 & 112 & 115 \\
\hline Snout, from midpoint of front & & & & & & & & \\
\hline of upper jaw & 42 & 52 & 45 & 38 & 46 & 45 & 47 & 40 \\
\hline Snout, from level of front & & & & & & & & \\
\hline of maxilla & 72 & 65 & 57 & 59 & 74 & 67 & 63 & 56 \\
\hline Snout, from most advanced & & & & & & & & \\
\hline point (chin) & 112 & 104 & 120 & 106 & 99 & 121 & 100 & 111 \\
\hline Depth at front of eye & 204 & 152 & 154 & 146 & 158 & 148 & 151 & 143 \\
\hline Depth at back of eye & 216 & 163 & 171 & 151 & 172 & 155 & 160 & 147 \\
\hline Depth at operculum & 232 & 185 & 174 & 162 & 172 & 157 & 187 & 147 \\
\hline Depth at vent & 208 & 143 & 154 & 146 & 172 & 157 & 187 & 151 \\
\hline Maximum depth of head & 240 & 185 & 177 & 162 & 177 & 157 & 187 & 155 \\
\hline Maximum depth of body & 232 & 200 & 171 & 162 & 170 & 152 & 191 & 151 \\
\hline Depth of caudal peduncle & 72 & 74 & 80 & 76 & 83 & 72 & 71 & 73 \\
\hline Width at front of eye & 276 & 252 & 229 & 205 & 215 & 206 & 196 & 206 \\
\hline Width at back of eye & 328 & 307 & 286 & 254 & 258 & 247 & 236 & 254 \\
\hline Width at operculum & 336 & 333 & 314 & 276 & 282 & 285 & 289 & 298 \\
\hline Width at vent & 216 & 200 & 246 & 216 & 210 & 220 & 227 & 238 \\
\hline Maximum width of head & 368 & 341 & 320 & 286 & 282 & 291 & 293 & 310 \\
\hline Maximum width of body & 304 & 326 & 309 & 273 & 282 & 274 & 284 & 282 \\
\hline
\end{tabular}


TABLE 4

GNATHAGNUS INNOTABILIS WAITE, 1904

$L=b N^{k}$ (rectified as $\log L=k \log L+\log b$ ) for 8 specimens; $L=$ \{length of head, length to vent, length to caudal origin, expressed as thousandths of standard length $\}$, $N=\{1,2,7\}$.

\begin{tabular}{|c|c|c|c|c|c|}
\hline Specimen & $\underset{\mathrm{mm}}{\text { Standard length }}$ & $\begin{array}{l}\text { Slope } \\
(k)\end{array}$ & $\begin{array}{l}\text { Intercept } \\
(\log b)\end{array}$ & $t$ & $\begin{array}{l}\text { Measured (predicted) } \\
\text { lengths }\end{array}$ \\
\hline (a) & 125 & 0.4884 & 2.5909 & $23.250^{\star}$ & 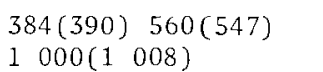 \\
\hline (b) & 135 & 0.5684 & 2.5276 & 11.696 & $\begin{array}{l}326(337) 526(500) \\
1000(1018)\end{array}$ \\
\hline (c) & 175 & 0.4936 & 2.5825 & $211.416^{\star *}$ & $\begin{array}{l}383(382) 537(538) \\
1000(999)\end{array}$ \\
\hline (d) & 185 & 0.5399 & 2.5496 & $16.182^{\star}$ & $\begin{array}{l}346(354) \quad 535(515) \\
1000(1013)\end{array}$ \\
\hline (e) & 209 & 0.5358 & 2.5526 & $17.160^{*}$ & $\begin{array}{l}349(357) 536(518) \\
1000(1013)\end{array}$ \\
\hline (f) & 223 & 0.5250 & 2.5578 & $17.557^{*}$ & $\begin{array}{ll}359(361) & 525(520) \\
1000(1024)\end{array}$ \\
\hline (g) & 225 & 0.5190 & 2.5636 & $64.730^{\star}$ & $\begin{array}{l}364(366) \quad 529(524) \\
1000(1003)\end{array}$ \\
\hline$(\mathrm{h})$ & 252 & 0.4961 & 2.5805 & 359.221 ** & $\begin{array}{l}381(381) 536(537) \\
1000(999)\end{array}$ \\
\hline G.M. & 187.2 & 0.5206 & 2.5631 & $28.826^{*}$ & $\begin{array}{l}361(366) 536(525) \\
1000(1007)\end{array}$ \\
\hline
\end{tabular}

\section{FAMILY TETRAODONTIDAE}

The members of this family appearing in the earlier local lists (Johnston 1883, 1891) under the broad category Gymnodontes are in the later catalogues (Lord 1923, 1927, Lord \& Scott 1924) referred to Tetraodontidae, a course followed by the majority of Australian authors though some, e.g., Whitley (1968), adopt Lagocephalidae, a taxon Greenwood et al. (1966) in their provisional classification of living teleosts recommend subsuming in Tetraodontidae. Part XI of this series (1963) provided a key to the four species then known from our waters - Tetraodon armizza McCulloch \& Waite, 1915 (referred by Whit1ey (1964) in his definitive Austra1ian name-1ist to his genus Omegaphora, 1934), Sphaeroides hamiztoni (Gray \& Richardson, 1843) (in Whitley's namelist placed Aphanacanthus Troshche1, (1856), Sphaeroides richei (Freminville) (now often referred to Contusus Whitley, 1947). Sphaeroides Ziosomus Regan, 1909 (now genera11y regarded as a junior synonym of Gastrophysus glaber Freminville, 1813).

Since the appearance of Part XI two species have been added to the local list, Boesemanichthys firmamentum (Temminck \& Schlegel, 1850), recorded in Part XIII (1965), being there referred to the genus Tetraodon, and Lagocephatus Zagocephalus (Linne, 1758). first Tasmanian (and Australian) record by Andrews (1970). The latter differs trenchantly from the species keyed in Part XI in having on each side two nostrils instead of one or a pair of flaps without an aperture (Lagocephalus accommodated by some writers in a separate family Lagocephalidae, the nares diagnostic). Boesemanichthys firmamentum is readily separable from the keyed species by its large number of dorsal and anal rays, 14 in each fin, a maximum of $9-11$ being found in the other species. 
E.0.G. Scott

TABLE 5

GNATHAGNUS INNOTABILIS WAITE, 1904

Head in plan: $W=A+B N-C N^{2}$ calculated for 8 individuals from 10 measurements $(N)$ of width taken at equal intervals between most advanced point and level of opercular border at visual ventral plane, widths expressed as percentages of relevant anteroposterior length.

\begin{tabular}{|c|c|c|c|c|c|c|c|}
\hline Specimen & $L s, \mathrm{~mm}$ & A & B & C & $R$ & Tangent & $\begin{array}{l}\text { Measured (predicted) } \\
\text { widths }\end{array}$ \\
\hline (a) & 125 & 50.19 & 16.530 & 1.1064 & 0.9993 & 2.2129 & 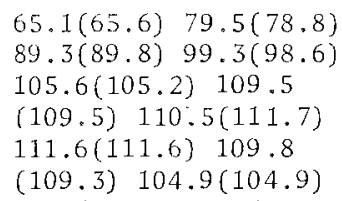 \\
\hline (b) & 135 & 42.31 & 13.917 & 0.9828 & 0.8646 & 1.9656 & $\begin{array}{ll}54.6(55.3) & 67.1(66.2) \\
75.0(74.2) & 81.5(82.2) \\
88.5(87.3) & 91.0(91.4) \\
90.4(91.6) & 89.8(90.7) \\
88.5(87.9) & 83.3(83.2)\end{array}$ \\
\hline (c) & 175 & 27.12 & 16.246 & 0.9814 & 0.9972 & 1.9629 & $\begin{array}{ll}40.8(42.4) & 58.1(55.9) \\
67.5(67.0) & 75.5(76.4) \\
83.1(83.8) & 89.4(89.3) \\
92.3(92.7) & 94.2(94.3) \\
95.1(93.8) & 90.8(91.4)\end{array}$ \\
\hline (d) & 185 & 31.65 & 14.334 & 0.8769 & 0.9955 & 1.7537 & $\begin{array}{ll}42.9(45.1) & 60.3(56.8) \\
66.7(69.8) & 74.1(75.0) \\
81.0(82.4) & 85.9(86.1) \\
88.9(88.7) & 90.5(90.2) \\
89.7(89.6) & 87.3(87.3)\end{array}$ \\
\hline (e) & 209 & 31.99 & 14.935 & 0.9379 & 0.9989 & 1.8758 & $\begin{array}{ll}46.7(46.0) & 58.0(58.1) \\
67.3(68.4) & 76.4(76.7) \\
82.7(83.2) & 89.5(87.8) \\
90.7(90.6) & 91.2(91.5) \\
90.5(90.4) & 87.3(87.6)\end{array}$ \\
\hline (f) & 223 & 32.98 & 12.915 & 0.7398 & 0.9983 & 1.4795 & $\begin{array}{ll}45.0(45.2) & 56.5(55.8) \\
64.5(65.1) & 72.6(72.8) \\
78.9(79.1) & 84.9(83.8) \\
86.3(87.1) & 88.8(89.0) \\
90.0(89.2) & 87.8(88.2)\end{array}$ \\
\hline (g) & 225 & 29.38 & 12.280 & 0.6265 & 0.9779 & 1.2530 & $\begin{array}{ll}40.0(41.0) & 53.3(51.4) \\
60.5(60.6) & 68.1(68.5) \\
75.0(75.1) & 79.8(80.7) \\
83.8(84.6) & 88.0(87.5)\end{array}$ \\
\hline$(h)$ & 252 & 19.86 & 17.167 & 1.0481 & 0.9883 & 2.0962 & $\begin{array}{ll}91.4(89.2) & 88.1(89.5) \\
34.7(36.0) & 51.3(50.0) \\
63.0(61.9) & 71.7(71.8) \\
78.4(79.5) & 84.6(85.1) \\
89.1(88.7) & 90.3(90.1) \\
89.1(90.0) & 87.0(85.7)\end{array}$ \\
\hline
\end{tabular}


TABLE 6

GNATHAGNUS INNOTABILIS WAITE, 1904

Disposition of fins along anteroposterior axis of fish: specifications for 8 specimens, standard I ength, $L s, 125-252 \mathrm{~mm}$, of the relation $L=b \mathrm{Nk}$ (rectified as $\log L=k$ $\log N+\log b$ ) where $L=\{$ length to pectoral origin, anal origin, dorsal origin, dorsa termination, anal termination, caudal origin $\}, N=\{1,3,4,7,8,10\}$.

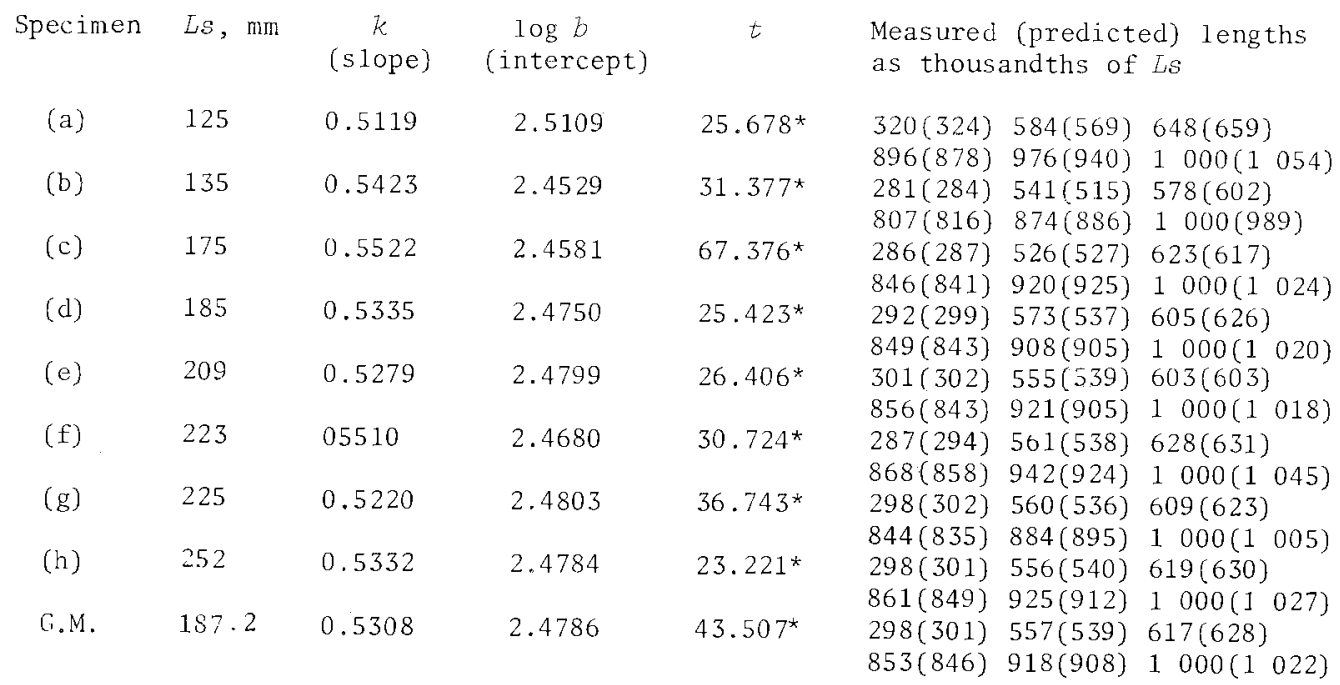

GenuS BOESEMANICHTHYS Abe, 1952

Boesemanichthys Abe, 1952, Jap. Joum. Iohth., 2(1), p.40. Type-species, Tetraodon fimamentrom Teminck \& Schlege1, 1850.

Boesemanichthys firmamentum (Temminck \& Schlege1, 1850)

Tetraodon firmamentum Temminck \& Schlege1, 1850, FAUN. JAP. POISS., p.280, p1.126, fig.2. Type-1ocality: Japan.

? Tetraodon gillsbanksii C1arke, 1897, Trans. N.Z. Inst., 29, pp.244, 245, p1.14. Type-1ocality: Moturoa, Taranaki.

Boesemanichthys firmomentum: Whitley, 1964, Proc. Linn. Soc. N.S.W., $89(1)$, p.59.

\section{Additional material}

This rather rare wide-ranging deepwater species, recorded in the Check-list (McCulloch 1929) from Japan (type-locality), New South Wales, Victoria New Zealand (the last-named presumably on the basis of Tetraodon gizlsbankii Clarke, 1897, treated in the Australian Check-List as a synonym, but accepted in the New Zealand Check-List (Whitley 1968) as a valid species) was first recorded for this state in Part XIII (1965) on the basis of an example, $L s 237 \mathrm{Lt} 302$, found washed up on the sand after a storm at Greens Beach, north coast, in July 1961. Two additional examples, Ls 240246 Lt 301 302, are here noted, both taken off Eddystone Point, east coast, in April 1979 by Mr Shane Down. 
E.O.G.Scott

\section{TABLE 7}

GNATHAGNUS INNOTABILIS WAITE, 1904

Ventral fin, 8 specimens, $L=b N^{* k}$ (rectified as $\log L=k \log N^{*}+\log b$ ) where $L=$ \{length of spine, 5th 4 th $3 \mathrm{rd}$ 2nd ray, as thousand ths of standard length $\{1$ st ray that farthest from spine $\}, N^{*}=\left\{\begin{array}{lllll}1 & 2 & 3 & 4 & 5\end{array}\right\}$.

\begin{tabular}{|c|c|c|c|c|c|}
\hline Specimen & $\begin{array}{c}\text { Standard } \\
\text { Length } \\
\text { mm }\end{array}$ & $\underset{k}{\text { Slope }}$ & $\begin{array}{l}\text { Intercept } \\
\quad \log b\end{array}$ & $t$ & Measured (predicted) lengths \\
\hline (a) & 125 & 0.6518 & 1.8636 & $30.885 * \star *$ & $\begin{array}{l}72(73) \quad 116(115) \quad 152(149) \\
184(180) \quad 202(208)\end{array}$ \\
\hline (b) & 135 & 0.8339 & 1.7691 & $14.004^{* * *}$ & $\begin{array}{l}56(59) 111(105) \quad 156(147) \\
190(187) \quad 207(225)\end{array}$ \\
\hline (c) & 1.75 & 0.7865 & 1.7911 & $18.418^{* * *}$ & $\begin{array}{l}61(62) \quad 108(107) \quad 149(147) \\
194(184) \quad 206(219)\end{array}$ \\
\hline (d) & 185 & 0.7970 & 1.7396 & $23.626 * * *$ & $\begin{array}{l}54(55) \quad 97(95) \quad 130(132) \\
175(166) \quad 189(198)\end{array}$ \\
\hline (e) & 209 & 0.7578 & 1.7580 & $35.737 * * *$ & $\begin{array}{l}57(57) \quad 96(97) \quad 132(132) \\
170(164) \quad 189(194)\end{array}$ \\
\hline (f) & 223 & 0.9102 & 1.6702 & $28.733^{* * *}$ & $\begin{array}{l}45(47) \quad 92(88) \quad 130(127) \\
166(165) \quad 195(202)\end{array}$ \\
\hline$(g)$ & 225 & 0.8536 & 1.6573 & $22.749^{* \star \star}$ & $\begin{array}{l}44(45) 85(82) 118(116) \\
153(148) 170(179)\end{array}$ \\
\hline$(h)$ & 252 & 0.7579 & 1.7233 & $22.492^{* \star *}$ & $\begin{array}{l}52(53) 93(89) 121(122) \\
157(151) 171(181)\end{array}$ \\
\hline G.M. & 186.2 & 0.7936 & 1.7465 & $25.219 * * *$ & $\begin{array}{l}54(56) 99(97) \quad 135(133) \\
173(168) 191(200)\end{array}$ \\
\hline
\end{tabular}

Dimensions as TLS

The principal dimensions as millesimals of standard length (smaller present individual first, earlier specimen last entry) follow. Length to origin termination of dorsal 742732779829833868 , of anal 788776826879870894 . Lengh to origin of pectoral 325346345 , length of fin 163.165 143. Length to vent (middle) 742732 740. Head to front of gill slit $296313 \quad 323$, to back of slit 317333333 . Snout 108 126 115. Eye 5469 51. Interorbital 146175187 . Length of longest of last ray of dorsal 19246,183 45, 194 46, of anal 200 46, 185 45, 19457 . Depth at front of eye 200203 203, at back of eye 217248262 , at gill slit 277362359 , at vent 242244257 ; maximum depth 313386 367; depth of cauda1 peduncle 100100105 .

Meristic characters

$$
\text { D.14. A.14. P.16 } 1517 \text {. C. main rays } 1+7+1 \text {. }
$$

Coloration, spinulation

As was the case with the 1965 specimen the general coloration is in good broad agreement with that of the original figure, reproduced by McCulloch (1922, pl.58, fig. 369f). Chief differences: in both individuals demarcation between upper dark and lower light regions much less definite; lighter area less extensive, extending in larger fish only about halfway from ventral profile to level of pectoral, in smaller reaching obscurely to somewhat below that fin; hinder part of caudal dusky in part blackish; in smaller fish light spots on caudal fewer smaller less well defined, in one subvertical row only. 
The nature of the spines and their pattern of distribution are similar to those described in Part XIII (1965).

Some aspects of form

(a) Head, length to vent, standard Zength. On a loglog grid these three lengths are sigrificantly linear for both individuals ( $23.309^{\star} 52.884^{\star}$ ) and for the earlier example ( $\left.t 41.635^{*}\right)$ - measurements of which were not given in Part XIIr but have now been made - on 1510 .

Dimensions below as TLs, 1965 specimen last.

$\log L=0.5041 \log N+2.5050$. Measured (predicted) lengths $317(320) 742(720)$ $1000(1021)$.

$\log L=0.4796 \log N+2.5242$. Lengths $333(334) 732(723) 1000(1008)$.

$\log L=0.4706 \log N+2.5340$. Lengths $340(342) 740(729) 1000(1011)$.

Among a large number of species representative of a wide range of families in which this head, pre-vent, precaudal relationship has been investigated abscissal values in the $\log \log$ formulation of 1510 are exceptional (modal set 123 , followed in frequency by 234 ). To arrive at some general provisional idea of the general situation in this family, regression equations have been calculated for some species noted in earlier contributions in this series, namely, in Part XI (1963), 8 specimens of Contusus richei, Ls 74-125 (table 5, species there referred to Sphaeroides), in same table 1 specimen of Sphaeroides homittoni, Ls 78, and in Part XVIII (1971) 1 specimen, Ls 78, of Tetraodon armizla (dimensions of beach example reported in Part XI not recorded).

For Contusus richei the abscissal set is, as in the present species, 1510 , the $t$ values ranging from $20.930^{*}$ to $211.568^{* *}$, mean $102.373^{* *}$, with 6 of the 8 significances being better than P 0.01 . For Sphaeroides hamiztoni the best straight line (t $\left.43.865^{*}\right)$ has the abscissal set 17 10, while the set for Tetraodon armizza is 1610 .

(b) Disposition of fin origins and terminations. On a $\log 10 g$ grid the lengths to pectoral origin dorsal origin anal origin dorsal termination anal termination caudal origin ( Ls) are highly significantly linear ( $t 38.360^{* * *} 28.058^{* *} 11.624^{* * *}$ ) on 156 7810 . Dimensions below as TLs, 1965 specimen last.

$\log L=0.4846 \log N+2.5156$. Measured (predicted) 1engths 325(328) 742(715) $788(781) 829(841) 879(898) \quad 1000(1010)$.

$\log L=0.4534 \log N+2.5396$. Lengths 346(346) 732(719) 778(781) 833(837) $870\{889\} 1000(984)$.

$\log L=0.4655 \log N+2.5477$. Lengths $345(353) 779(741) 826(807) 868(867) 894$ (923) $1000\left(\begin{array}{ll}1 & 024\end{array}\right)$.

It is of interest to note the same 1567810 formulation (covering in the absence of ventral in these fishes all the fins) is applicable to the 1971 example of Tetraodon amiliza noticed above ( $t$ 24.145***).

$\log L=0.4045 \log N+2.5852$. Lengths $383(384) 765(738) 790(794) 840(845)$ $354(892) 1000(998)$. 


\section{E.O.G. Scott}

\section{FEFERENCE:}

Allen, G.R., Hoese, D.F., Paxton, J.R., Randa11, J.E., Russell, B.C., Stark, W.A.II, Talbot, F.H. and Whitley, G.P. 1976: Annotated checklist of the fishes of Lord Howe Island. Rec. Aust. Mus., 30(15) (Ophichthyidae, D.H. Hoese: 378-379).

Andrews, A.P., 1970: A record of the oceanic puffer Lagocephalus Zagocephalus (L.), order Tetraodontoidea, from King Island, Tasmania, Pop. Proc. R. Soc. Tasm., 104: $111-112$, p1.1.

- 1971: A catalogue of the type material (Fishes) in the Tasmanian Museum. Pap. Proc. R. Soo. Tasm., 105: 1-3.

Anon., 1956: (Report of xanthic eel from Victoria). Angters' Digest and Shooters' Monthly, oct. 1956.

Bloch, M.E. and Schneider, J.G., 180I: SYSTEMA ICHTHYOLOGIAE. Sanderiano. Berlin. Castelnau, F.N., 1872: Contribution to the ichthyology of Australia. No. 1. The Melbourne fish market. Proc. zool. acolim. Soc. Viat., l: 29-242, one pl. , 1875: Researches on the fishes of Australia. Intercolonial Exhibition essays. No. 2: 1-52. PHILADELPHIA CENIENNIAL EXHIBITION, 1876 (MELBOURNE, 1875): OFFICTAL RECORD.

Dawson, C.E., 1977: Review of the Indo-Pacific pipefish genus Liscocampus (syngnathidae). Proc. biol. Soo. Wash., 89(53): 599-620, figs $1-7$.

Garman, S., 1913: The plagiostomia. Mem. Mus. comp. Zool. Harvard, 36: 1-528, pls $1-77$.

Gill, T., 1861: Synopsis of the Uranoscopoids. Proc. Acad. nat. Sci. PhiZad: 108-117.

Greenwood, P.H., Rosen, D.L., Weitzman, S.H. and Myers, G.S., 1966: Phyletic studies of teleostean fishes with a provisional classification of living forms. BuZl. U.S. Mus. nat. Hist., I3I(4).

Gúnther, A., 1859: CATALOGUE OF THE ACANTHOPTERYGIAN FISHES IN THE COLLECTION OF THE BRITISH MUSEUM, l. British Museum, London.

1860: CATALOGUE OF THE ACANTHOPTERYGIAN FISHES IN THE COLLECTION OF THE BR.ITISH MUSEUM, 2. British Museum, London.

Haast, J., 1873: On some undescribed fishes of New zealand. Trans. N.Z. Inst., 5: 272-278, pl. 16 .

Haysom, N.H., 1960: (Xanthic fish). QZd Eisher. inform. BuZZ., 17: 2.

Hutton, F.W., 1872: Catalogue with diagnoses of the species. FISHES OF NEW ZEALAND: $1-93$.

Johnston, R.M., 1883: General and critical observations on the fishes of Tasmania with a classified catalogue of all known species. Pap. Proc. R. Soc. Tasm. (1882): 54-144.

1885: Description of a new species of Odax. Pap. Proc. R. Soc. Tasm. (1884): $231-232$

1891: Further observations on the fishes and fishing industries of Tasmania, together with a revised list of indigenous species. Pap. Proc. R. Soc. Tasm. (I890): 22-46.

Jordan, D.S. and Snydex, J.O., 1902: A review of the trachinoid fishes and their supposed aliies found in the waters of Japan. Proc. U.S. nat. Mus., 24: 229-256. Kershaw, J.A., 1904: A colour variety of the common eel, Anguizza australia Rich. Viet. Nat., 20(10), 242: 129-1.40.

Ling Roth, H., 1899: THE ABORIGINES OF 'TASMANIA; 2nd ed.F. King and Sons, HaJifax, England. (Facsimile reissue, n.d. = 1969, Fullers Bookshop, Hobart).

Longley, W.H. and Hildebrand, S.F., 1940: New genera and species of fishes from Tortugas, Florida. Pap. Tortugas Lab. 5(32) (Carnegie Institute publication No.,517): $223-285$.

Lora, C.E., 1923: A list of the fishes of Tasmania. Pap. Proc. R. Soc. Tasm. (1922): $60-73$

$11-16$

1927: A list of the fishes of Tasmania. J. pan-Pac. res. Inst., 2(4): 
Lord, C.E. and Scott, H.H., 1924: A SYNOPSIS OF THE VERTEBRATE ANIMALS OF TASMANIA. olcham Beddome and Meredith, Hobart.

Lucas, A.H.S., 1890: A systematic census of indigenous fishes hitherto reported from Victoria. Proc. R. Soc. Vict. (n.s.), 2: 15-47.

McCulloch, A.R., 1911: Report on the fishes obtained by the F.I.S. 'Endeavour' on the coasts of New South Wales, Victoria, South Australia and Tasmania. Part 1. Zool. res. Endeavour, 1(1): 1-87, pls 1-16, figs 1-19. , 1914: Notes on some Australian pipe-fishes. Aust. Zool., 1(1): $29-31$, figs $1-4$ , 1916: Ichthyological itens. Mem. Q2d Mus., 5: 58-69, pls 7-9, figs $1-4$.

- 1921: Check-list of the fishes and fish-like animals of New South Part 2. Aust. Zool., 2(2): 14-58, pls 4-24.

wales. Part 2. Aust. Check-list of the fishes and fish-lik

wales. Part 3. Aust. Zool. 2(3): 86-130, pls 25-43.

1929: A check-list of the fishes recorded from Australia. Aust. Mus. Mem., 5(1-4) (part 4, index, 1930): i-ix + 1-534.

McKay, R.J., 1966: Studies on Western Australian sharks and rays of the families Scyliorhinidae, urolophidae and Torpedinidae, J. R. Soc. W. Aust., 49(3): 65-82, figs $1-6$.

Marshall T.C., 1964 : FISHES OF THE GREAT BARRIER RFEF AND THE COASTAL WATERS OF QUEENSLAND. Angus \& Robertson, Sydney.

Mees, G.F., 1960: The Uranoscopidae of Western Australia (Pisces, Perciformes). J. R. Soc. W. Aust., 43(2): 46-58, figs $1-9$.

Munro, I.S.R., 1956: Handbook of Australian fishes, 1: 1-8. In: Fisher. Newst. (now Aust. Fisher.), $15(7)$.

1957a: Handbook of Australian fishes, 11: 45-48. In: Fisher. News2. (now Aust. Fisher.), $16(5)$.

1957b: Handbook of Australian fishes, 17:69-72. In. Fisher. Newst. (now Aust. Fisher.), $16(11)$.

1958: Handbook of Australian fishes, 21: 85-88. In: Fisher. News2. (now Aust. Fisher.), $17(3)$.

, 1967: THE FISHES OF NEW GUINEA. Department of Agriculture, Stock and Fisheries, Port Moresby.

Myers, G.S., 1946: Occurrence of uranoscopid fishes of the Western Pacific genus Gnathagmus in the American Atlantic fauna. Copeia, 1946, 1: 42.

Neave, S.A., 1940(+): NOMENCLATOR ZOOLOGICUS. A LIST OF THE NAMES OF GENERA AND SUBGENERA IN ZOOLOGY FROM THE TENTH EDITION OF LINNAEUS 1758 TO THE END OF 1935. zoological Society, London.

Norman, J.R., 1934: A SYSTEMATIC MONOGRAFH OF THE FLATFISHES (HETEROSOMATA), VOL.1: PSETTODIDAE, BOTHIDAE, PLEURONECTIDAE. British Museum, London.

Ogilby, J.D., 1897a: Some Tasmanian fishes. Pap. Proc. R. Soc. Tasm. (1896): 69-85. , 1897b: On a larval teleost from New South wales. Proc. Linn. Soc. N.S.W., $22(1): 158-160$, fig. 1 .

, 1916: Check-list of the Cephalochordates, Selachians and Fishes of Queensland. Mem. Q2d Mus., 5: 70-98, fig.l.

Olsen, A.M., 1958: New fish records and notes on uncommon Tasmanian species. Pap. Proc. R. Soc. Tasm., 92: 155-159.

Plomley, N.J.B., 1976: A WORD-LIST OF THE TASMANIAN ABORIGINAI LANGUAGE. Launceston, author in association with Tasmanian Government.

phillipps, w.J., 1927: Bibliography of New Zealand fishes. N.Z. Mar. Dept. Fisher. Buz2. 1: 1-68.

Schmidt, E.J., 1928: The fresh-water eels of Australia. With some remarks on the short-finned species of Anguizla. Rec. Aust. Mus., 16(4): 179-210, figs 1-14.

Schultz, L.P., 1953: Family ophichthyiaae: 45-60, figs 10-12. In: Schultzet al., Fishes of the Marshall and Marianas Islands. Vol.1. (Asymetrontidae through Siganidae). U.S. Nat. Mus. Bull. 202. 
Scott, E.O.G., 1934-1979: Observations on some Tasmanian fishes. Parts I-XXV; in this journal (except part XVI, 1969, Aust. Zool., 15(2): 160-177, figs 1, 2). Contributions here cited. 1936, III: 113-129, figs 1-3. 1942b, V: 45-54, pl.7. 1953, VI: 14l-166, figs 1-4. 1957, VIII: 145-156. 1961, X: 49-65, figs 1-3. 1963, XI: 1-29, figs 1, 8. 1964, XII: 85-106, fig.1. 1965, XIII: 53-65, fig.1. 1966, XIV: 93-115, fig.1. 1971, XVIII: 119-143, fig.l. 1974a, XIX: 247-292, figs 1,2. 1974b, XX: 171-197, figs 1-4. 1975, XXI: 127-175, figs. 1,2. 1976, XXII: 157-217, pl.1. 1977, XXIII: 111-180, figs 1-3. 1978, XXIV: 289356, figs 1-3. 1979, XXV: 99-148.

1942a: Syngnathus tuckeri, sp. nov.: a new Tasmanian pipefish. Reo. Queen Vict. Mus., $1(1): 17-20$, pl. 5 . 1968: First Tasmanian record of the long-snouted pipefish. Tasm. Fisher. Res., 2(2): 4-7.

Scott, J.K., 1976: A review of the Eish genus Neoodax of Western Australia with description of a closely allied new genus and species. Rec. W. Aust. Mus., 4(4): 349-373, figs $1-6$.

Scott, T.D., 1962: THE MARINE AND FRESH WATER FISHES OF SOUTH AUSTRALIA. Government Printer, Adelaide.

Scott, I.D., Glover, C.J.M. and Southcott, R.V., 1974: THE MARINE AND FRESHWATER FISHES OF SOUTH AUSTRALIA. Government Printer, Adelaide.

Stead, D.G., 1963: RAYS AND SHARKS OF AUSTRALIAN SEAS. Angus \& Robertson, Sydney. Temminck, J.C. and Schlegel, H., 1842: Pisces. In: Siebold's FAUNA JAPONICA. Leyde. waite, E.R., 1899: Scientific results of the trawling expedition of H.M.C.S. 'Thetis'. Introduction and Fishes. Aust. Mus. Mem., 4(1): 1-132, frontispiece, pls 1-31. 1904: New records or recurrences of rare fishes from eastern Australia. No. 3. Rec. Aust. Mus., 5(4): 231-244, pls 25,26, figs 33, 34 .

, 1907: A basic list of the fishes of New Zealand. Ree. Canterb. Mis., $1(1): 3-39$.

, 19l1: Scientific results of the New Zealand Government trawling expedition 1907. Pisces, Part 2. Rec. Canterb. Mus., 1(3): 157-272, pls 24-57, figs 1-3. Waite, E.R. and McCulloch, A.R., 1915: The fishes of the South Australian Government trawling cruise, 1914. Trans. R. Soc. S. Aust., 39: 455-476, fig.l.

Weber, M. and De Beaufort, L.F., 1929: THE FISHES OF THE INDO-AUSTRALIAN ARCHIPELAGO, 5. J.S. Brill, Leiden.

Whitley, G.P., 1928: Studied in ichthyology. No. 2. Ree. Aust. Mus., 9(3): 211-239, pls 16-28, figs 1,2 .

- 1929a: R.M. Johnston's memoranda relating to the fishes of Tasmania. Pap. Proc. R. Soc. Tasm. (1928): 46-68, pls 2-4. , 1929b: Additions to the check-list of the fishes of New south wales. Aust. Zoot., 5(4): 353-357. , 1939: Taxonomic notes on sharks and rays. Aust. Zoot., 9(3): 227-262, pls 20-22, figs 1-18. , 1940: THE FISHES OF AUSTRALIA PART 1. THE SHARKS, RAYS, DEVIL-FISH, AND OTHER PRIMITIVE FISHES OF AUSTRALIA AND NEW ZEALAND. ROYal ZOOlOgical Society of New South Wales, Sydney. 1943a: Ichthyological notes and illustrations. (Part 2). Aust. Z002., 10(2): 167-187, figs 1-10.

- 1943b: Ichthyological descriptions and notes. Proc. Linn. Soc. N.S.W., 68: 114-144, figs 1-12.

1943c: A new Australian shark. Rec. S. Aust. Mus., 7 (4): 397-399. , 1944: New sharks and fishes from western Australia. Aust. Zool.,

$10(3): 252-273$, figs $1-6$.

, 1948: New sharks and fishes from western Australia. Part 4. Aust. Zool., lil $(4): 259-276$, pls 24,25 , figs $1-7$.

, 1950: Studies in Ichthyology. No. 14. Rec. Aust. Mus.22(3): 234-245. pl. 17, figs 1-5. 
Whitley, G.P., 1951: New fish names and records. Proc. R. sool. Soc. N.S.W. 1949/50: 51-68, figs 8-10.

1952: Some noteworthy fishes from eastern Australia. Proc. R. Zool. Soe.N.S.W., 1950/51: 27-32, figs ].-5.

1962: MARINE FISHES OF AUSTRALIA, 2 vols. Jacaranda Press, Brisbane. 1964: A survey of Australian Ichthyology. Presidential address. Proc. Linn. Soc. N.S.W., 89(1): 11-127. Appendix A: Subject index: 20-32. Appendix B: Name-list of the fishes recorded from Australia: 32-60.

1967: Sharks of the Australasian region. Aust. 200 . . 14(2): 173-187, pl. 4, figs 1,2 .

1968: A check-list of the fishes recorded from the New zealand region. Aust. Zoo2., 15(1): 1-102, figs 1,2.

Whitley, G.P. and Phillipps, W.J., 1939: Descriptive notes on some New Zealand fishes. Trans. R. Soc. N.Z., 69(2): 228-236, pls 21,22 . 